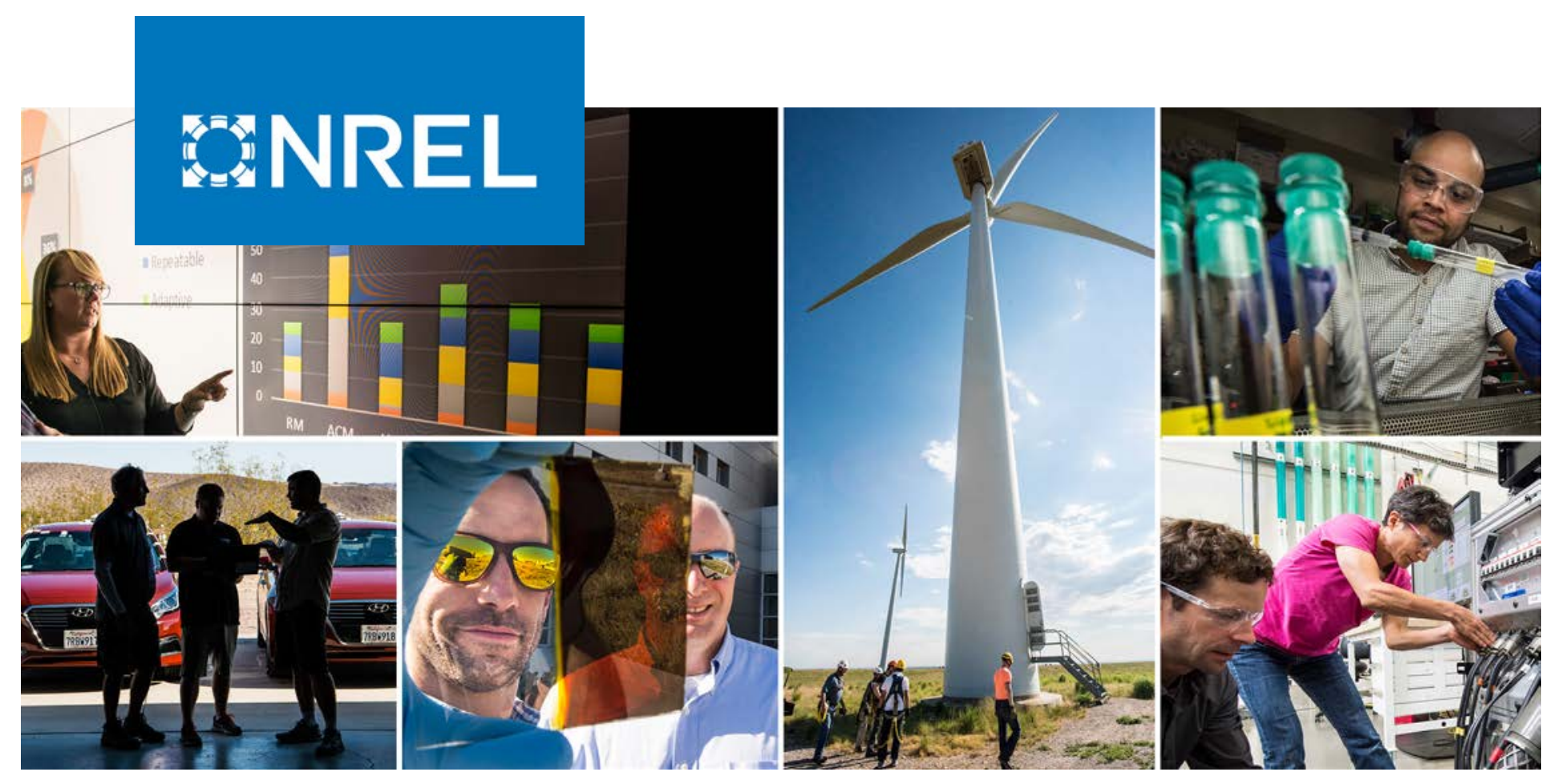

\title{
2019 Standard Scenarios Report: A U.S. Electricity Sector Outlook
}

Wesley Cole, Nathaniel Gates, Trieu Mai, Daniel Greer, and Paritosh Das

National Renewable Energy Laboratory

NREL is a national laboratory of the U.S. Department of Energy

Office of Energy Efficiency \& Renewable Energy

Operated by the Alliance for Sustainable Energy, LLC

This report is available at no cost from the National Renewable Energy Laboratory (NREL) at www.nrel.gov/publications.

\section{Technical Report}

NREL/TP-6A20-74110

December 2019 


\title{
GHREL
}

\section{Standard Scenarios Report: A U.S. Electricity Sector Outlook}

\author{
Wesley Cole, Nathaniel Gates, Trieu Mai, Daniel Greer, \\ and Paritosh Das
}

National Renewable Energy Laboratory

\section{Suggested Citation}

Cole, Wesley, Nathaniel Gates, Trieu Mai, Daniel Greer, and Paritosh Das. 2019.

2019 Standard Scenarios Report: A U.S. Electricity Sector Outlook. Golden, CO: National Renewable Energy Laboratory. NREL/TP-TP-6A20-74110.

https://www.nrel.gov/docs/fy20osti/74110.pdf.

NREL is a national laboratory of the U.S. Department of Energy Office of Energy Efficiency \& Renewable Energy Operated by the Alliance for Sustainable Energy, LLC

This report is available at no cost from the National Renewable Energy Laboratory (NREL) at www.nrel.gov/publications.

Contract No. DE-AC36-08G028308
Technical Report

NREL/TP-6A20-74110

December 2019

National Renewable Energy Laboratory 15013 Denver West Parkway Golden, CO 80401

303-275-3000 • www.nrel.gov 


\section{NOTICE}

This work was authored by the National Renewable Energy Laboratory, operated by Alliance for Sustainable Energy, LLC, for the U.S. Department of Energy (DOE) under Contract No. DE-AC36-08GO28308. Funding provided by the U.S. Department of Energy Office of Energy Efficiency and Renewable Energy Office of Strategic Programs. The views expressed herein do not necessarily represent the views of the DOE or the U.S. Government.

This report is available at no cost from the National Renewable Energy Laboratory (NREL) at www.nrel.gov/publications.

U.S. Department of Energy (DOE) reports produced after 1991 and a growing number of pre-1991 documents are available free via www.OSTI.gov.

Cover Photos by Dennis Schroeder: (clockwise, left to right) NREL 51934, NREL 45897, NREL 42160, NREL 45891, NREL 48097, NREL 46526.

NREL prints on paper that contains recycled content. 


\section{Preface}

This report is one of a suite of National Renewable Energy Laboratory (NREL) products aiming to provide a consistent and timely set of technology cost and performance data and define a scenario framework that can be used in forward-looking electricity analyses by NREL and others. The long-term objective of this effort is to identify a range of possible futures for the U.S. electricity sector that illuminate specific energy system issues by defining a set of prospective scenarios that bound ranges of technology, market, and macroeconomic assumptions and assessing these scenarios in NREL's market models to understand the range of resulting outcomes, including energy technology deployment and production, energy prices, and emissions.

This effort, supported by the U.S. Department of Energy's (DOE) Office of Energy Efficiency and Renewable Energy (EERE), focuses on the electric sector by creating a technology cost and performance database, defining scenarios, documenting associated assumptions, and generating results using NREL's Regional Energy Deployment System (ReEDS) model and the Distributed Generation Market Demand Model (dGen). The work leverages significant activity already funded by EERE to better understand individual technologies, their roles in the larger energy system, and market and policy issues that can impact the evolution of the electricity sector.

Specific products from this effort include:

- An Annual Technology Baseline (ATB) workbook documenting detailed cost and performance data (both current and projected) for both renewable and conventional technologies

- An ATB summary website describing each of the technologies and providing additional context for their treatment in the workbook

- This Standard Scenarios report describing U.S. power sector futures using the Standard Scenarios modeling results.

These products can be accessed at https:/www.nrel.gov/analysis/data-tech-baseline.html.

These products are built and applied to analyses to ensure (1) the analyses incorporate a transparent, realistic, and timely set of input assumptions, and (2) they consider a diverse set of potential futures. The application of standard scenarios, clear documentation of underlying assumptions, and model versioning is expected to result in:

- Improved transparency of modeling input assumptions and methodologies

- Improved comparability of results across studies

- Improved consideration of the potential economic and environmental impacts of various electric sector futures

- An enhanced framework for formulating and addressing new analysis questions.

Future analyses under this family of work are expected to build on the assumptions used here and provide increasingly sophisticated views of the future U.S. power system with the potential to expand to other sectors of the U.S. energy economy. 


\section{Acknowledgments}

We gratefully acknowledge the many people whose efforts contributed to this report. The ReEDS and dGen modeling and analysis teams, including Jonathan Becker, Max Brown, Stuart Cohen, Kelly Eurek, Will Frazier, Pieter Gagnon, Jonathan Ho, Kevin McCabe, Matthew Mowers, Caitlin Murphy, Ben Sigrin, Dan Steinberg, Yinong Sun, Nina Vincent, and Matt Zwerling, were active in participating in the model development and analysis leading to this work. We thank Billy Roberts for creating some of the maps used in this work and Philipp Beiter, Galen Barbose, and Paul Spitsen for providing data on state policies. Numerous NREL colleagues reviewed and improved this report, including Doug Arent, Philipp Beiter, Dan Bilello, Stuart Cohen, Will Frazier, Bethany Frew, Pieter Gagnon, Jenny Heeter, Eric Lantz, Jeff Logan, Matt Mowers, Dan Steinberg, and Gord Stephens. We are grateful to Peter Balash (NETL), Sam Baldwin (DOE), Galen Barbose (LBNL), Jose Benitez (Deloitte), Aaron Bloom (NextEra Analytics), Cynthia Bothwell (DOE), Paul Donohoo-Vallett (DOE), Sarah Garman (DOE), Cara Marcy (EPA), Chris Namovicz (EIA), Ivonne Peña-Cabra (KeyLogic), Cristian Rabiti (INL), Paul Spitsen (DOE), Joel Theis (NETL), Bob Wallace (KeyLogic), and Evelyn Wright (Sustainable Energy Economics) for providing feedback on this work. This report was funded by the EERE Office of Strategic Programs under contract number DE-AC36-08GO28308. All errors and omissions are the sole responsibility of the authors. 


\section{List of Acronyms}

AC

$\mathrm{ACP}$

AEO

ATB

BA

CAES

CAISO

$\mathrm{CC}$

CCS

CES

$\mathrm{CO}_{2}$

CONUS

CSP

CT

DC

dGen

DOE

EERE

EIA

ELCC

EIPC

ERCOT

GW

GWh

ISO

ITC

LCOE

LSE

MMBtu

MW

MWh

NERC

NG

NG-CC

NG-CT

NREL

O\&M

OGS

PPA

PSH

PTC

PV

RE

ReEDS

RGGI alternating current

alternative compliance payment

Annual Energy Outlook

Annual Technology Baseline

balancing area

compressed air energy storage

California Independent System Operator

combined cycle

carbon capture and storage

clean energy standard

carbon dioxide

contiguous United States

concentrating solar power

combustion turbine

direct current

Distributed Generation Market Demand Model

U.S. Department of Energy

DOE's Office of Energy Efficiency and Renewable Energy

U.S. Energy Information Administration

effective load carrying capacity

Eastern Interconnection Planning Collaborative

Electric Reliability Council of Texas

gigawatt

gigawatt-hour

independent system operator

investment tax credit

levelized cost of energy

load-serving entity

million British thermal units

megawatt

megawatt-hour

North American Electric Reliability Corporation

natural gas

natural gas combined cycle

natural gas combustion turbine

National Renewable Energy Laboratory

operations and maintenance

oil-gas-steam

power purchase agreement

pumped-storage hydropower

production tax credit

photovoltaic(s)

renewable energy

Regional Energy Deployment System

Regional Greenhouse Gas Initiative 
RPS

RTO

SPP

TW

TWh

VRE renewable portfolio standard

regional transmission organization

Southwest Power Pool

terawatt

terawatt-hour

variable renewable energy 


\section{Executive Summary}

This report summarizes the results of 36 forward-looking Standard Scenarios of the U.S. power sector simulated using the Regional Energy Deployment System (ReEDS) and Distributed Generation Market Demand Model (dGen). The annual Standard Scenarios, which are now in their fifth year, have been designed to capture a range of possible power system futures considering a variety of factors that impact power sector evolution. The ReEDS and dGen models project utility-scale power sector evolution and distributed photovoltaic (PV) adoption, respectively, for the contiguous United States using the Standard Scenarios definitions to specify model inputs. The ReEDS model takes a system-wide, least-cost approach when making decisions, while dGen uses a customer-centric adoption approach. The ReEDS model has been designed with special emphasis on capturing the unique traits of renewable energy, including variability and grid integration requirements. Scenario results at the state level have been included as part of this report at en.openei.org/apps/reeds. Additionally, for select scenarios, the 2050 system built by ReEDS and dGen was run using the PLEXOS production cost model to further evaluate system operation.

The scenarios include a reference scenario (Mid-case) that uses policies in place as of July 31 , 2019, and other default assumptions (e.g., natural gas prices) in the models. Figure ES-1 summarizes the generation and capacity results from this Mid-case scenario. The scenarios also include 41 side cases that incorporate sensitivities such as fuel prices, demand growth, retirements, technology and financing costs, transmission and resource restrictions, and policy considerations, resulting in a wide range of possible generation mixes (Figure ES-2).
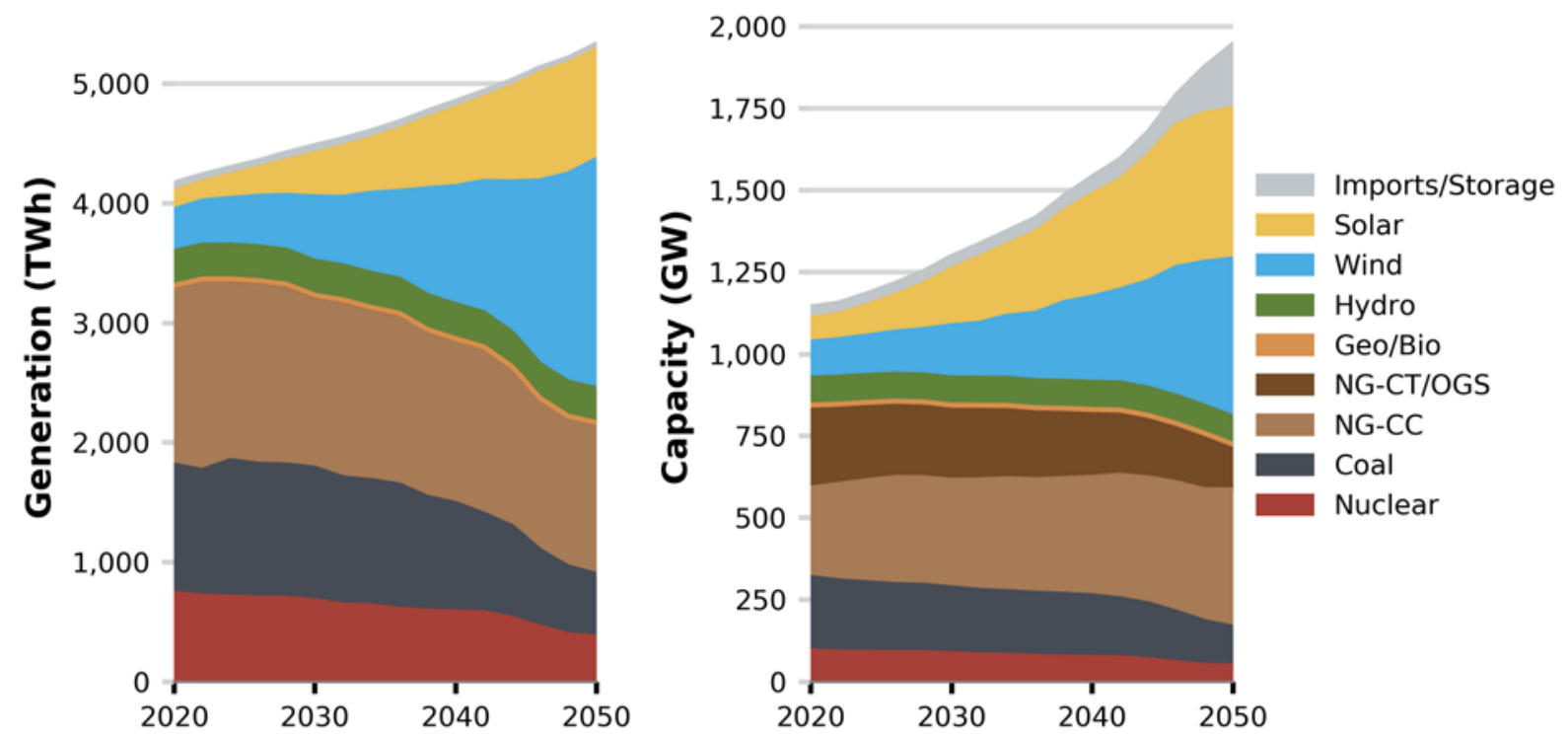

Figure ES-1. U.S. power sector evolution over time for the Mid-case scenario. The gray area represents imports from Canada in the left figure and storage capacity in the right figure. Storage generation is not shown because storage always has a negative net generation (due to losses). NG-CC is natural gas combined cycle, NG-CT is natural gas combustion turbine, OGS is oil-gas-steam, Geo/Bio is geothermal and biopower, TWh is terawatt-hours, and GW is gigawatts. 

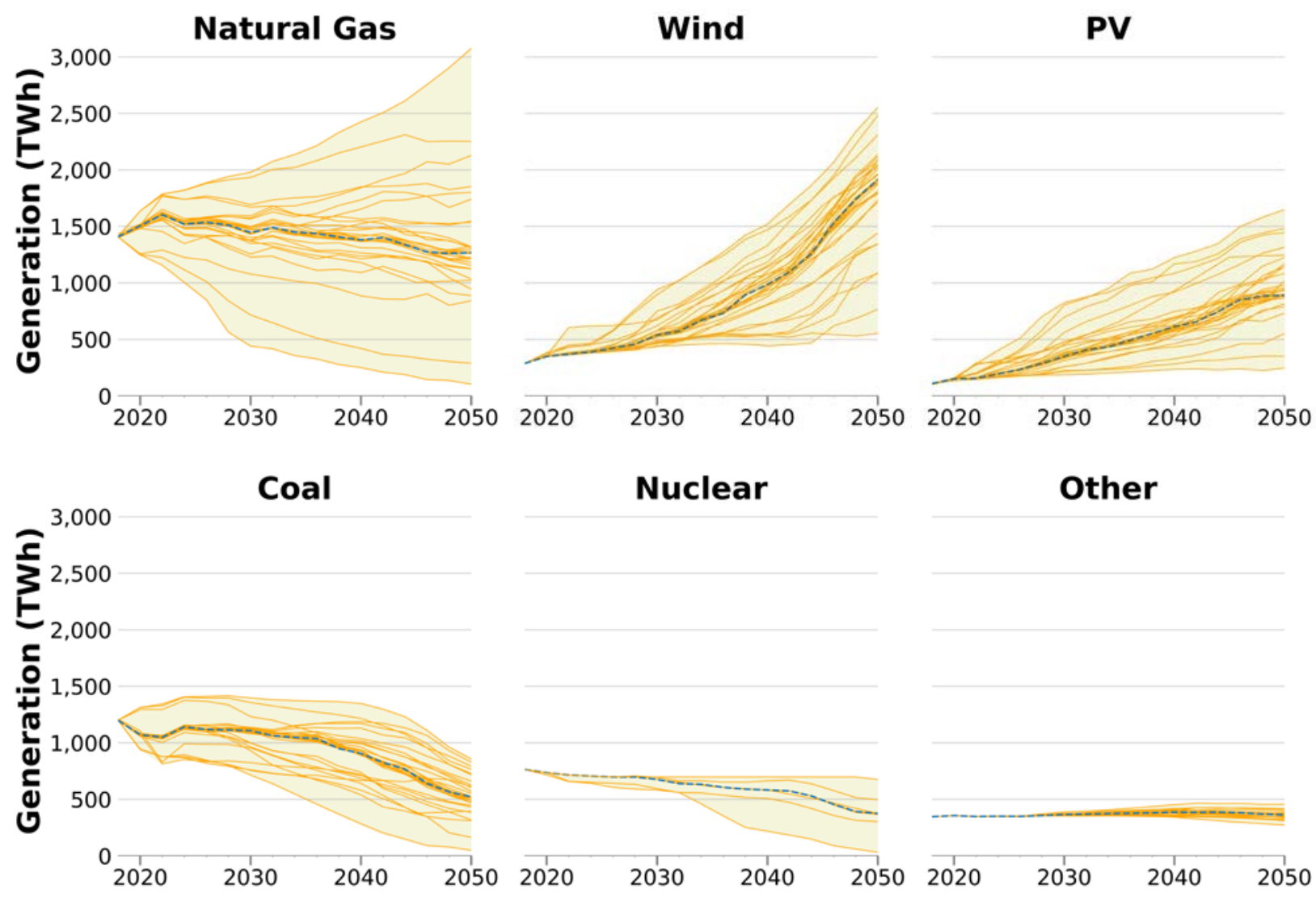

Figure ES-2. Generation across the suite of Standard Scenarios for the fuel types indicated. The Mid-case scenario is shown as the blue dashed line. Other includes biopower, concentrating solar power, geothermal, hydropower, and landfill gas.

Based on the Standard Scenarios results, we explore in this report three key themes of U.S. power sector evolution:

- How the revenue of technologies changes with the evolving generation mix

- How resource adequacy is maintained across scenarios as the generation mix evolves to include more variable generation

- How technology costs, policies, resource quality, and other factors are leading to potential changes in regional-level generation mixes.

We discuss each of these themes in the context of recent trends and projected changes based on the modeled scenario results. Summaries of each of these themes are provided below. 
The modeled revenue received by technologies through delivering grid services changes over time and across scenarios as the grid mix evolves. The four primary grid services modeledenergy, planning reserves, operating reserves, and state policy compliance - have varying prices over time and across the scenarios. In particular, natural gas prices, renewable energy costs, storage costs, and the level of variable renewable energy (VRE) deployment tend to have significant impacts on the prices of grid services. The modeled revenue of a technology is based on the prices of these services as well as how a technology can contribute to each service within the model. Figure ES-3 shows the fraction of revenue for each major technology type in the Midcase scenario in 2030 and 2050. In 2030, most technologies get most of their revenue from providing energy, with natural gas combustion turbines (NG-CTs) being the lone exception. Only batteries have a visible fraction of revenue from providing operating reserves, which mostly disappears by 2050 due to declining operating reserve prices and the spreading of that revenue across many gigawatts of battery storage. By 2050, the fraction of revenue from providing energy has declined for all technologies and has largely been displaced by revenue in providing planning reserves.

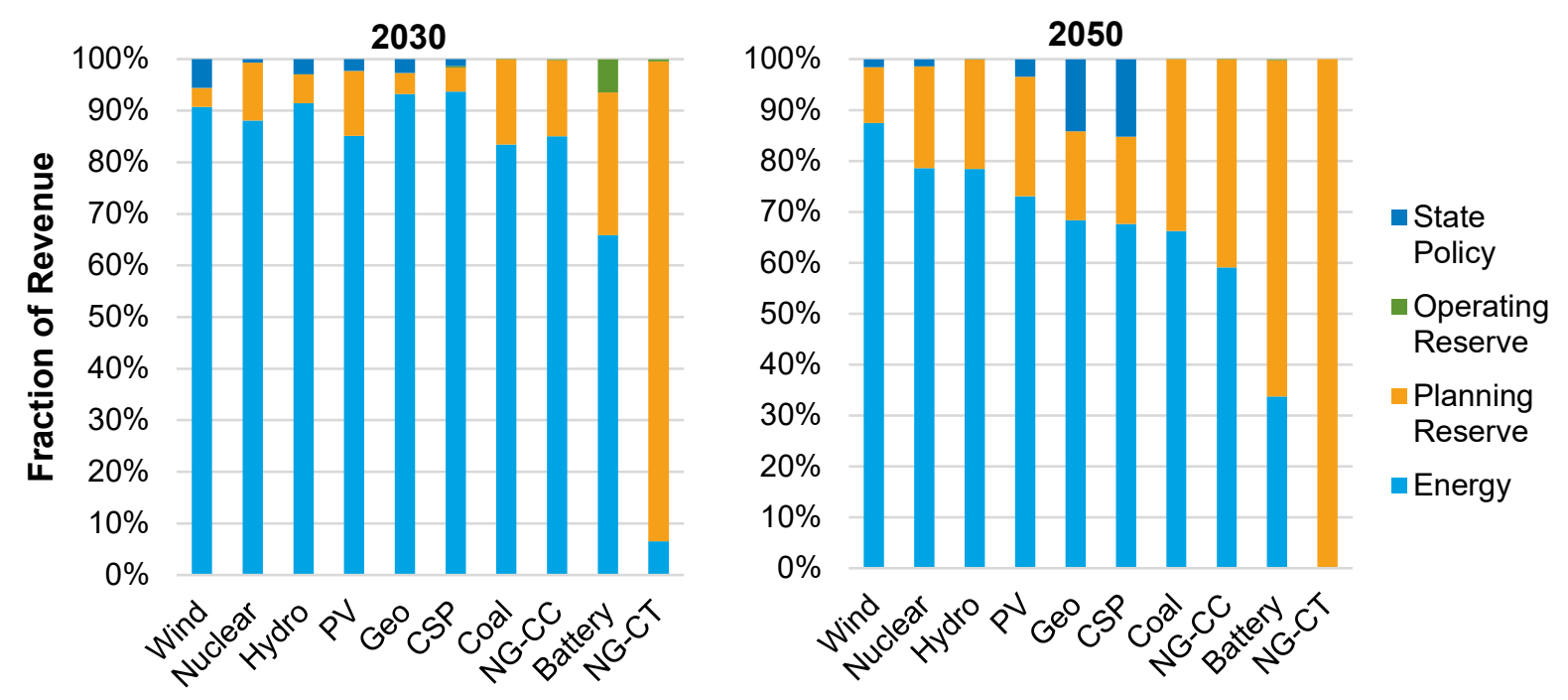

Figure ES-3. Fraction of revenue by technology type from the different sources in $\mathbf{2 0 3 0}$ (left) and 2050 (right) for the Mid-case scenario. State policy indicates that the technology is receiving revenue from helping to meet state renewable portfolio standard or clean energy standard requirements. 
Even at high VRE penetrations, resource adequacy requirements are largely supplied by nonvariable technologies. With the increase in natural gas, wind, and PV in most scenarios, the fraction of total installed capacity that is comprised of variable technologies grows over time. However, most planning reserve provisions (i.e., the capacity that contributes toward the planning reserve requirement) are still supplied by non-variable technologies, even in scenarios with very high renewable energy penetration (see Figure ES-4). Planning reserves help ensure system resource adequacy, which is one aspect of reliability. Though wind and PV technologies contribute to the planning reserve requirements, they never comprise more than $26 \%$ (combined) of the requirement in any scenario even though they provide $21 \%-62 \%$ of total installed capacity and $17 \%-72 \%$ of total generation across the full set of scenarios. Under reference conditions, the overnight capital cost of 4-hour battery storage is assumed to decline below that of NG-CTs, which results in 4-hour batteries becoming the most common type of peaking plant from approximately 2030 onward in most scenarios. PV capacity credit ${ }^{1}$ declines with increasing PV penetration, while wind capacity credit is mixed due to its increasing capacity factor over time and the shifting time of net peak demand.

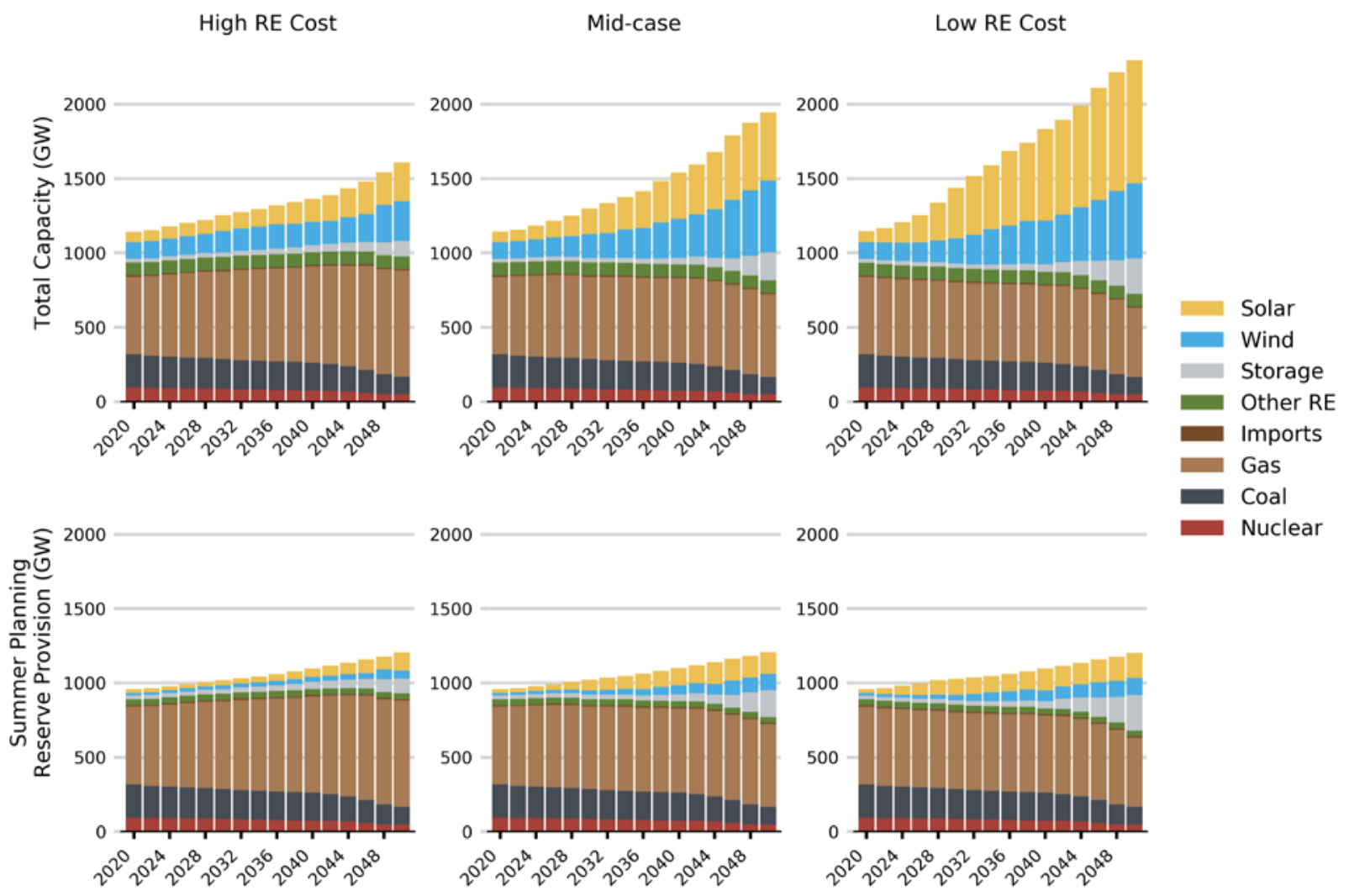

Figure ES-4. Total capacity (top) and planning reserve provision (bottom) by fuel type in the High RE Cost, Mid-case, and Low RE Cost scenarios. The planning reserve provision is the capacity that contributes toward the planning reserve margin.

\footnotetext{
${ }^{1}$ Capacity credit is the fraction of nameplate capacity that contributes the planning reserve requirement. For example, a 10-MW PV plant with a 0.5 capacity credit would count $5 \mathrm{MW}$ toward the planning reserve requirement.
} 
Regional generation mixes continue to change, driven predominantly by technology costs, state policies, and resource quality. The national grid mix has evolved considerably over the past decade, and nearly every state has also experienced considerable change. States have generally moved away from coal toward either natural gas, wind, or solar technologies - a trend that continues in these scenarios. Regional trends are generally similar to national trends, though differences in the current system, resource quality, and policies result in some meaningful regional variation. For example, in the Mid-case scenario, some states reach annual VRE penetration in excess of $90 \%$ (as a fraction of total in-state generation), while others have less than 10\% (see Figure ES-5). Curtailment of VRE resources varies across the country but is especially high in areas with high concentrations of both wind and solar. Transmission and storage additions help mitigate curtailment in some cases. Zero-price energy hours have a similar but broader distribution to curtailment, with the highest concentration of zero-price hours occurring in regions with higher quality wind resources and in regions with less transmission connectivity.
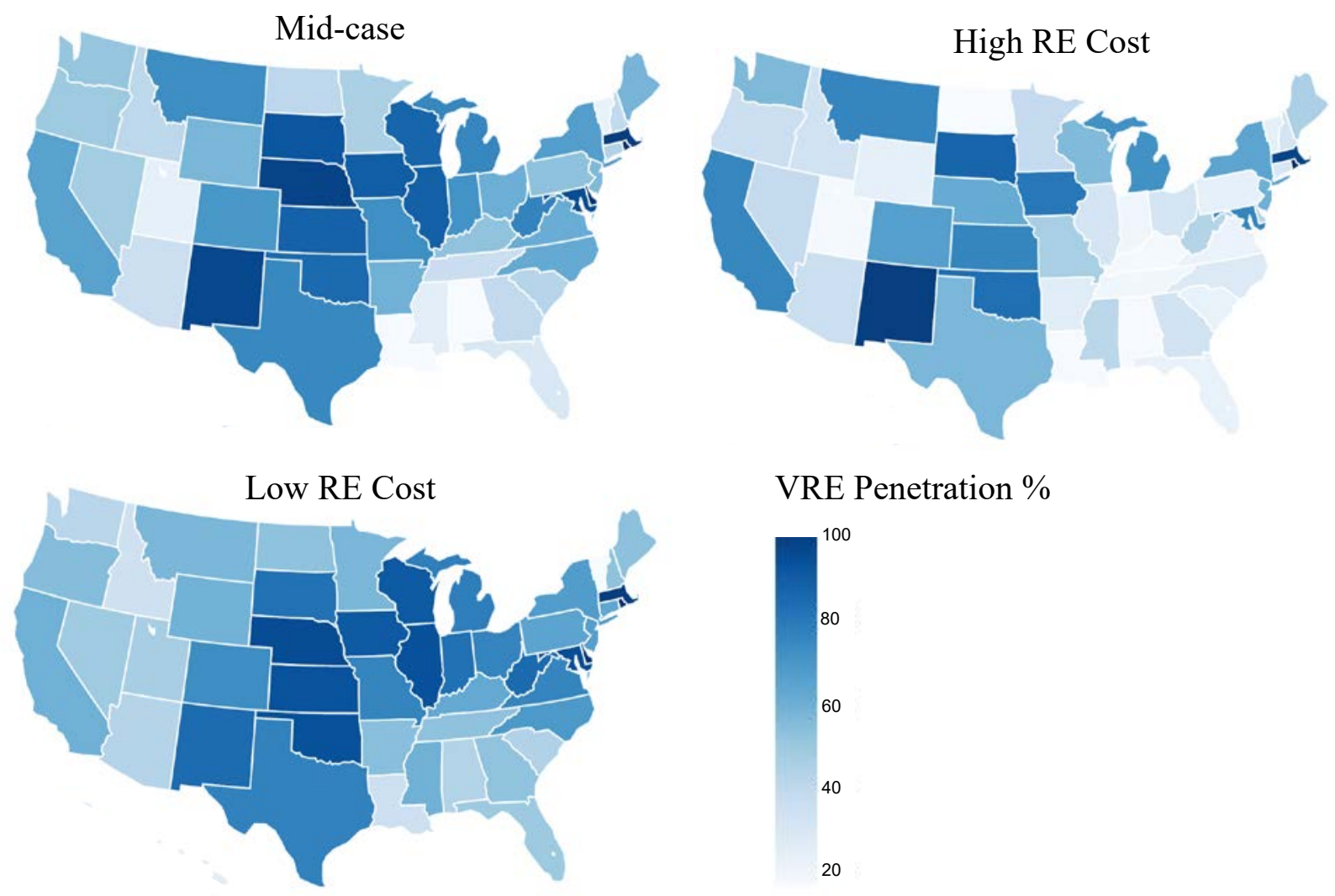

VRE Penetration \%

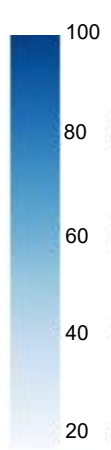

Figure ES-5. Map of VRE penetration by state in the Mid-case, High RE Cost, and Low RE Cost scenarios in 2050. Note that states with $100 \%$ clean energy standards can use non-VRE resources such as hydropower, geothermal, biopower, CSP, and nuclear to fulfill their clean energy requirement.

The themes highlighted above are only three areas that reflect potential changes in the U.S. power sector over the next three decades. The rapid advances in technologies, markets, and policies create a wide range of uncertainty in expected long-term power sector outcomes. For this reason, we anticipate that the Standard Scenarios will provide context, discussion, and data to inform stakeholder decision making regarding the future direction of the U.S. power sector. 


\section{Table of Contents}

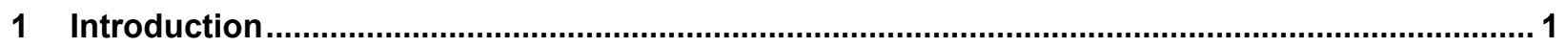

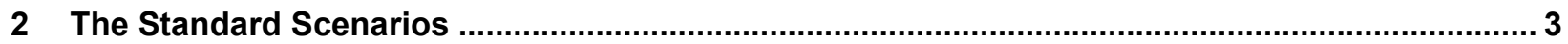

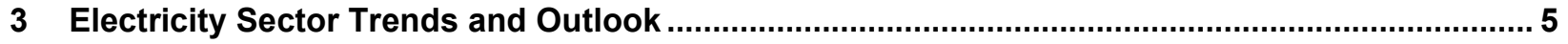

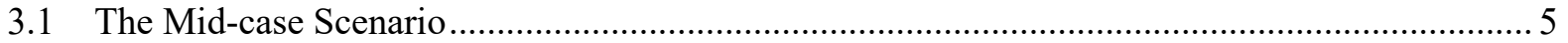

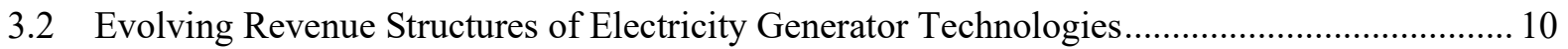

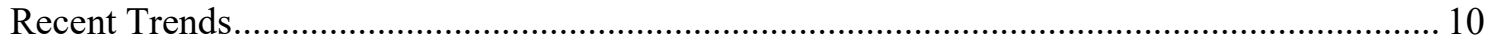

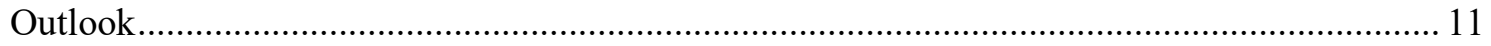

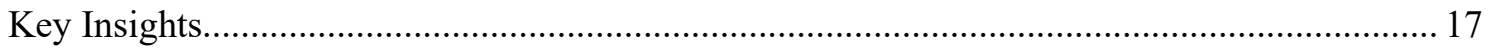

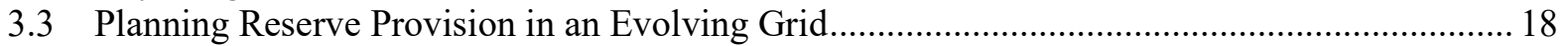

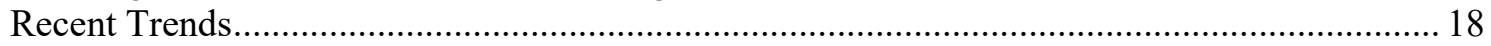

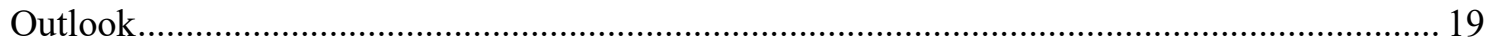

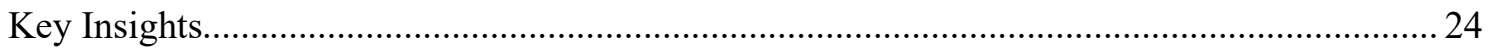

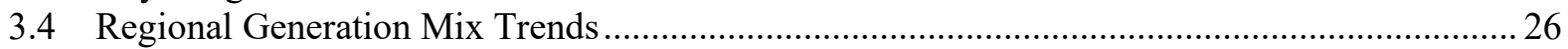

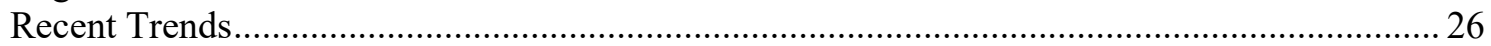

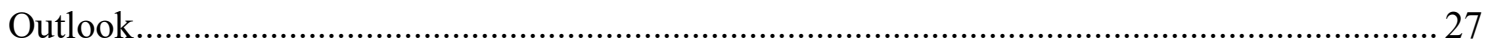

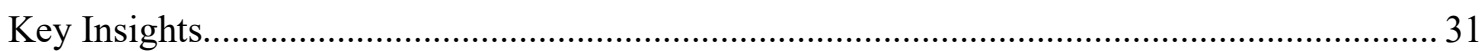

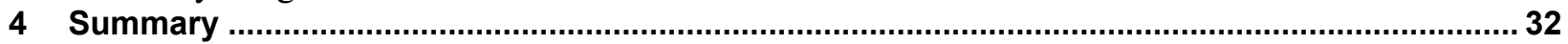

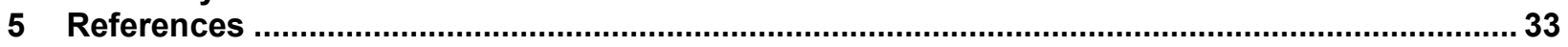

Appendix

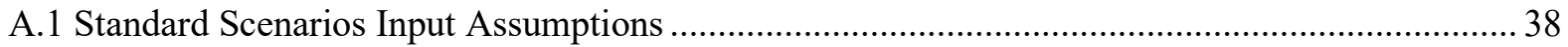

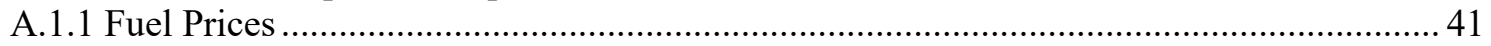

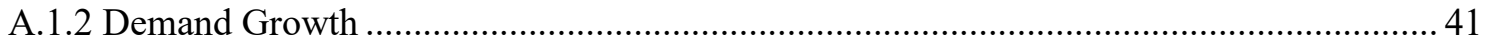

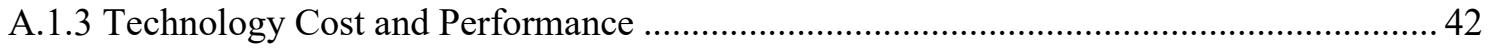

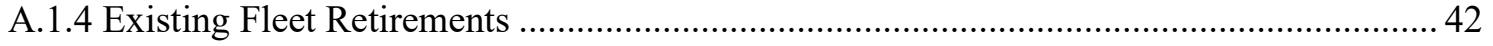

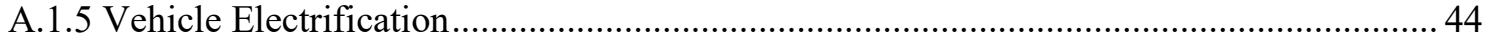

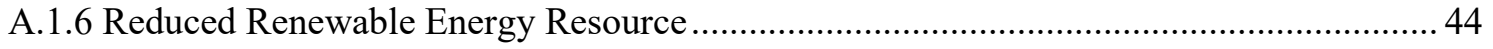

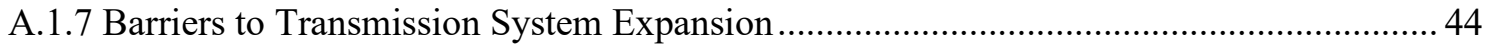

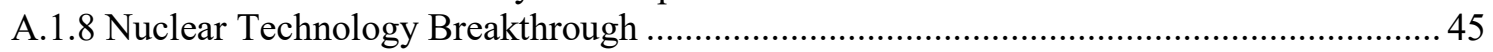

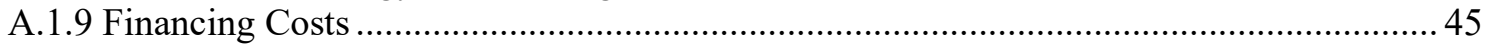

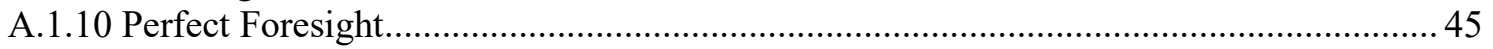

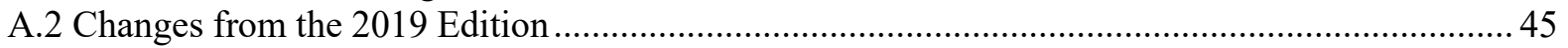

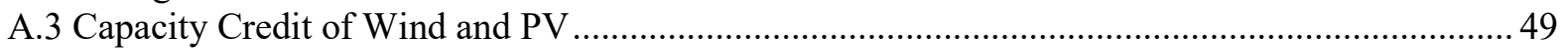

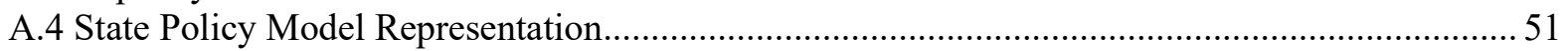




\section{List of Figures}

Figure ES-1. U.S. power sector evolution over time for the Mid-case scenario.......................................vii

Figure ES-2. Generation across the suite of Standard Scenarios for the fuel types indicated. ..................viii

Figure ES-3. Fraction of revenue by technology type from the different sources in 2030 (left) and 2050 (right) for the Mid-case scenario.

Figure ES-4. Total capacity (top) and planning reserve provision (bottom) by fuel type in the High RE Cost, Mid-case, and Low RE Cost scenarios.

Figure ES-5. Map of VRE penetration by state in the Mid-case, High RE Cost, and Low RE Cost

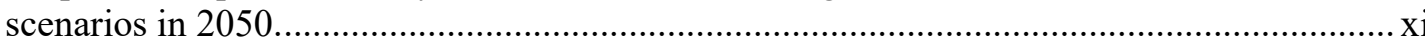

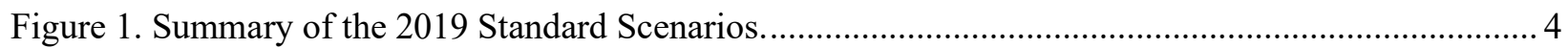

Figure 2. U.S. power sector evolution over time for the Mid-case scenario............................................ 5

Figure 3. Evolution of the U.S. power system from the current system (top) to one powered primarily by wind, solar, and natural gas capacity (bottom) in all regions in the Mid-case scenario........... 7

Figure TB-1. Renewable energy, nuclear, natural gas, and coal generation fraction from the organizations

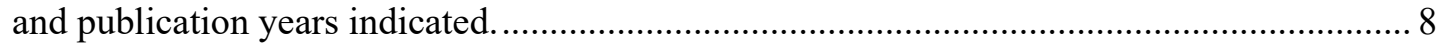

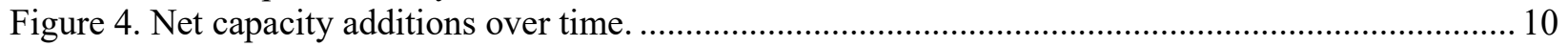

Figure 5. PV deployment in California (left) and energy prices in CAISO (right)................................. 11

Figure 6. Natural gas, wind, and PV generation (top) and capacity (bottom) across the full suite of

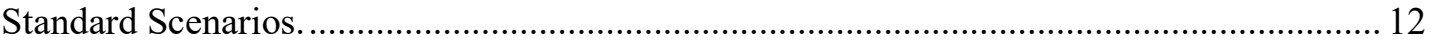

Figure 7. National average LCOE over time for the technologies indicated for $2020-2050 \ldots \ldots \ldots \ldots \ldots \ldots \ldots . . . . . .13$

Figure 8. National average annualized cost of capacity for the technologies indicated for $2020-2050 \ldots . .13$

Figure 9. National annual average prices for the services indicated across all scenarios....................... 14

Figure 10. Fraction of revenue by technology type from the different sources in 2030 (left) and 2050

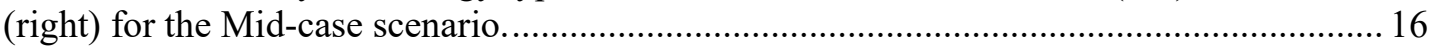

Figure 11. Average curtailment rate as a function of VRE penetration (by generation) across scenarios.. 17

Figure 12. VRE penetration over time across the suite of scenarios..................................................... 19

Figure 13. Non-variable capacity (including storage) over time across the suite of scenarios .................. 20

Figure 14. Planning reserve capacity contributions by fuel type in the High RE Cost, Mid-case, and Low

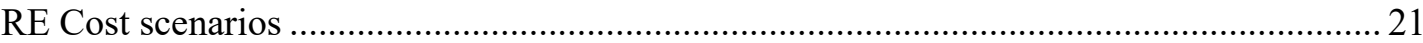

Figure 15. Fraction of planning reserve contribution and total capacity from the specified technology

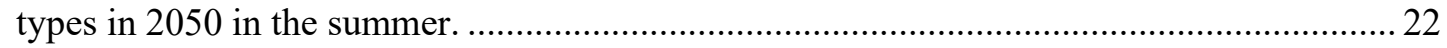

Figure 16. Average capacity credit of utility PV, land-based wind, offshore wind, and 4-hour duration battery storage by season and interconnection in the Mid-case scenario.............................. 23

Figure 17. Hourly dispatch from PLEXOS for the Mid-case in 2050 …............................................... 24

Figure 18. Overnight capital cost of NG-CT and 4-hour batteries over time in the Mid-case scenario. .... 24

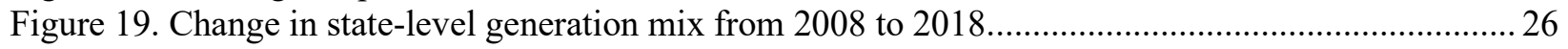

Figure 20. Map of VRE penetration by model region in the Mid-case, Low RE Cost, and High RE Cost

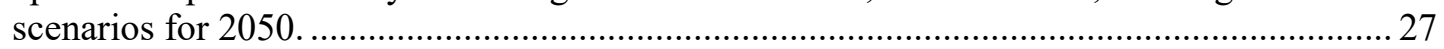

Figure 21. Marginal curtailment rate for wind (left) and utility-scale PV (right) in 2050 for the Mid-case

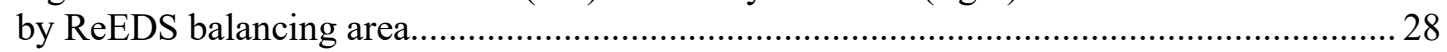

Figure 22. National cumulative long-distance transmission capacity for the scenarios indicated............. 29

Figure 23. Percent of hours with $\$ 0 / \mathrm{MWh}$ electricity prices in 2050 for the scenarios indicated .............. 30

Figure 24. Wind and PV capacity factor versus penetration for the Mid-case scenario........................... 31

Figure A-1. Fuel price trajectories used in the Standard Scenarios .................................................... 41

Figure A-2. Demand growth trajectories used in the Standard Scenarios ........................................... 42

Figure A-3. Mid-case projections from the 2015, 2016, 2017, 2018, and 2019 editions of the Standard

Scenarios. 


\section{List of Tables}

Table 1. Capacity Credit Assigned to Wind and PV for the Various Regional Transmission Organizations

(RTOs.... 18

Table A-1. Summary of the 2019 Standard Scenarios.................................................................... 38

Table A-2. Lifetimes of Renewable Energy Generators and Batteries (Cohen et al. 2019) ...................... 43

Table A-3. Lifetimes of Conventional Energy Generators (Cohen et al. 2019) ....................................... 43

Table A-4. Amount of Nuclear Power Plant Capacity (in GW) in Each Bin ..............................................4

Table A-5. Nuclear Power Plant Lifetime (in Years) for Each Scenario by Bin ..................................... 44

Table A-6. Key Differences in Model Inputs and Treatments for ReEDS Model Versions....................... 46

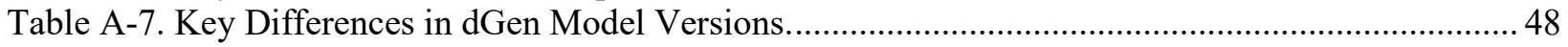

Table A-8. Capacity Credit Approaches and Values for Wind and PV by RTO....................................50

Table A-9. Effective State RPS Requirements in ReEDS ..................................................................5 52

Table A-10. Cumulative offshore wind capacity (MW) that is mandated in ReEDS............................. 54

Table A-11. Clean energy requirement as a percentage of in-state sales.................................................5 54

Table A-12. Power sector $\mathrm{CO}_{2}$ caps enforced in the model in RGGI states and in California (metric tons) 


\section{Introduction}

The U.S. electricity sector continues to undergo rapid change. To help us and others understand the implications, drivers, and key uncertainties of this change, we are introducing this fifth ${ }^{2}$ installment of the Standard Scenarios. This year's Standard Scenarios consist of 36 power sector scenarios for the contiguous United States (CONUS) that consider the present day through 2050 and have been studied using two models from the National Renewable Energy Laboratory (NREL) and a commercial production cost model:

- Regional Energy Deployment System (ReEDS) long-term capacity expansion model (Cohen et al. 2019)

- Distributed Generation Market Demand Model (dGen) rooftop photovoltaic (PV) diffusion model (Sigrin et al. 2016)

- Energy Exemplar's PLEXOS production cost model. ${ }^{4}$

The Standard Scenarios enable a quantitative examination of how various assumptions impact the development of the power sector. The full suite of scenarios considers a wide range of assumptions. In this report, we use the Standard Scenarios to focus on three key themes for U.S. power sector evolution, including:

- How the revenue of technologies changes with the evolving generation mix

- How resource adequacy is maintained across scenarios as the generation mix evolves to include more variable generation

- How technology costs, policies, resource quality, and other factors are leading to potential changes in regional-level generation mixes.

The objective of this analysis is not to predict the specific deployment trajectories for the various generator technologies but to consider a range of possible grid evolution pathways in an attempt to better understand and articulate key drivers, important implications, and necessary decision points that can contribute to better informed investment and policy decisions. The Standard Scenarios are not "forecasts," and we make no claims that our scenarios have been or will be more indicative of actual future power sector evolution than projections made by others. Instead, we note that a collective set of projections from diverse analytical frameworks and perspectives could offer a more robust platform for decision making (Mai et al. 2013).

In addition, our modeling tools and analyses have been designed with a particular emphasis on capturing the unique traits of renewable energy (RE) generation technologies and the resulting implications for the rest of the power system. The modeling tools used in this work have been designed with a specific emphasis on issues related to RE integration, including ensuring capacity adequacy and capturing curtailment and forecast error impacts in investment decisions. Other modeling and analysis frameworks will have different emphases, strengths, and

\footnotetext{
${ }^{2}$ See atb.nrel.gov/electricity/archives.html for the previous Standard Scenarios reports and data.

${ }^{3}$ For more information about ReEDS and dGen, see www.nrel.gov/analysis/reeds and www.nrel.gov/analysis/dgen, respectively. For lists of published work using ReEDS and dGen, see www.nrel.gov/analysis/reeds/publications.html and www.nrel.gov/analysis/dgen/publications.html, respectively.

${ }^{4}$ Only a subset of the 36 scenarios were modeled in PLEXOS, and only for the 2050 system.
} 
weaknesses. This work provides a perspective on the electricity sector that complements those provided by others. It also demonstrates how the model operates under a variety of input conditions and configurations.

Although the models used to develop the Standard Scenarios are sophisticated, they do not capture every aspect that will impact the evolution of each scenario. For example, the models do not consider the buildout of natural gas pipelines, and they take a system-wide planning approach when making capacity build decisions rather than representing current market actors or rules. Therefore, results should be interpreted within the context of model limitations. A morecomplete list of model-specific caveats is available in the models' documentation (Cohen et al. 2019, Section 1.4; Sigrin et al. 2016, Section 2.2).

The ultimate purpose of the Standard Scenarios and this associated report is to provide context, discussion, and data to inform stakeholder decision making regarding the future direction of the U.S. power sector. As a key feature of this report, the state-level Standard Scenarios outputs are presented in a downloadable format online using the Standard Scenarios' Results Viewer at en.openei.org/apps/reeds. This report reflects high-level observations, trends, and analyses, whereas the Standard Scenarios' Results Viewer includes the detailed scenario results needed for more in-depth analysis. ${ }^{5}$

\footnotetext{
${ }^{5}$ The data viewer provides additional state-specific data from the scenarios; however, we note that as a nationalscale model, ReEDS is not specifically designed to assess in detail the full circumstances of any individual state.
} 


\section{The Standard Scenarios}

The 2019 Standard Scenarios comprise 36 power sector scenarios that are run using the ReEDS model (Cohen et al. 2019) and the dGen model (Sigrin et al. 2016). Six of the scenarios are new to this year's edition, and scenario assumptions have been updated since last year to reflect the many policy, technology, and market changes occurring in the power sector (see Appendix A.2 for a complete list of changes). The scenarios are summarized in Figure 1. Details about specific scenario definitions and inputs are provided in Appendix A.1.

The 36 scenarios were selected to capture a breadth of trajectories of costs, performance, and other drivers. ${ }^{6}$ The diversity of scenarios covers a range of potential futures rather than focusing on a single-scenario outlook. For example, in addition to considering traditional sensitivities such as demand growth and fuel prices, we also assess a considerable number of other factors that impact the development of the power system such as transmission buildout, and technology progress. We do not assign probabilities to these scenarios nor identify which scenarios are more or less likely to occur.

This Standard Scenarios analysis also takes advantage of a tool that converts ReEDS scenario outputs into PLEXOS input data. PLEXOS is a commercially available production cost model that we use to model the hourly operation of the ReEDS Mid-case scenario, High RE Cost scenario, and Low RE Cost scenario. These scenarios were chosen in order to consider futures with lower and higher RE penetration levels than the Mid-case. The ReEDS model uses a reduced-form dispatch that captures annual generation using 17 time-slices (four time blocks per day times one day for each of the four seasons, plus a summer peak time-slice), so by using an production cost model at hourly resolution, we can examine results with greater temporal resolution and more fully capture the range of operational conditions and constraints that exists across the year.

To enhance transparency in model results, we also note that the ReEDS model used to generate these scenarios is now publicly available (see https://www.nrel.gov/analysis/reeds/).

\footnotetext{
${ }^{6}$ Although the scenarios cover a wide range of futures, they are not exhaustive. For example, carbon capture and sequestration, marine hydrokinetic wave, and various non-traditional battery storage technologies are currently active areas of research and could become significant contributors to the electricity system, but our scenario selections do not explore these or other potential futures.
} 


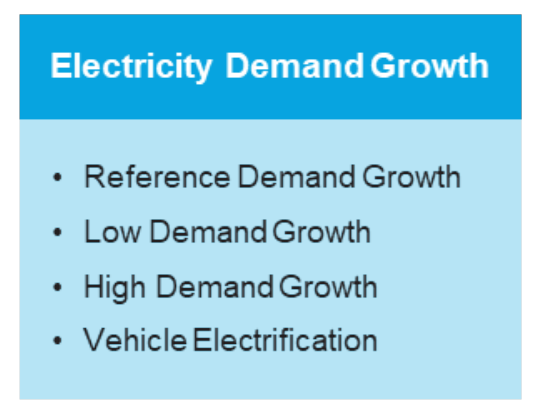

\section{Fuel Prices}

- Reference Natural Gas Prices

- Low Natural Gas Prices

- High Natural Gas Prices

\section{Financing Assumptions}

- Mid Finance Projections

- Shortened Cost Recovery

- Extended Cost Recovery

\section{Model Foresight}

- No Foresight

- Perfect Foresight
Electricity Generation

Technology Costs

- Mid Technology Cost

- Low RE Cost

- High RE Cost

- Low Wind Cost

- High Wind Cost

- Low PVCost

- High PVCost

- Low Geothermal Cost

- High Geothermal Cost

- Low CSP Cost

- High CSPCost

- Low Hydro Cost

- High Hydro Cost

- Low Offshore Wind Cost

- High Offshore Wind Cost

- Low Battery Cost

- High Battery Cost

- Nuclear Technology Breakthrough

- 2018 ATB Mid Technology Cost

\section{Combination Scenarios}

- Low Natural Gas Prices \& Low RE Cost

- High Natural Gas Prices \& Low RE Cost

- Low Natural Gas Prices \& High RE Cost

- High Natural Gas Prices \& High RE Cost

\section{Resource and System} Constraints

- Default Resource Constraints

- ReducedRE Resource

- Barriers to Transmission System Expansion

\section{Existing Fleet Retirements}

- Reference Retirement

- Accelerated Retirements

- Extended Lifetimes

- Endogenous Retirements

Figure 1. Summary of the 2019 Standard Scenarios. The Mid-case scenario uses the first item in each category (except for the combinations category). Additional scenario details are in Table A-1 of the appendix. All scenarios use current law as of July 31, 2019. 


\section{Electricity Sector Trends and Outlook}

In this section, we present the electricity sector trends and outlook from the 2019 Standard Scenarios by first examining the Mid-case scenario (Section 3.1). We then highlight three trends from the full suite of the 2019 Standard Scenarios (Sections 3.2-3.5).

\subsection{The Mid-case Scenario}

The Mid-case scenario uses the reference, mid-level, or default assumptions for scenario inputs (see Figure 1 for a summary of those assumptions and Table A-1 and Appendix A.1 for details about the assumptions). In this way, the Mid-case scenario represents a reference case and provides a useful baseline for comparing scenarios and evaluating the trends described in the following sections. Importantly, the Mid-case scenario does not necessarily reflect a most-likely scenario. Text Box 1, at the end of this section, provides some additional context for how the NREL Mid-case scenario relates to projections from other organizations.

Figure 2 shows the generation and capacity mix through 2050 for the Mid-case scenario. Total generation grows steadily over time, and that increased generation is provided primarily by a mix of new natural gas combined cycle (NG-CC), PV, and wind generation. Due to assumed lifetime retirements, the amount of coal and nuclear capacity declines over time, resulting in correspondingly less generation. In the late 2040s, wind and PV generation increase more rapidly in part to compensate for the more rapid retirements that occur during this period. The generation fractions for RE, fossil, and nuclear are $28 \%, 57 \%$, and $15 \%$, respectively, in 2030 and $60 \%$, $33 \%$, and $7 \%$ in 2050 .
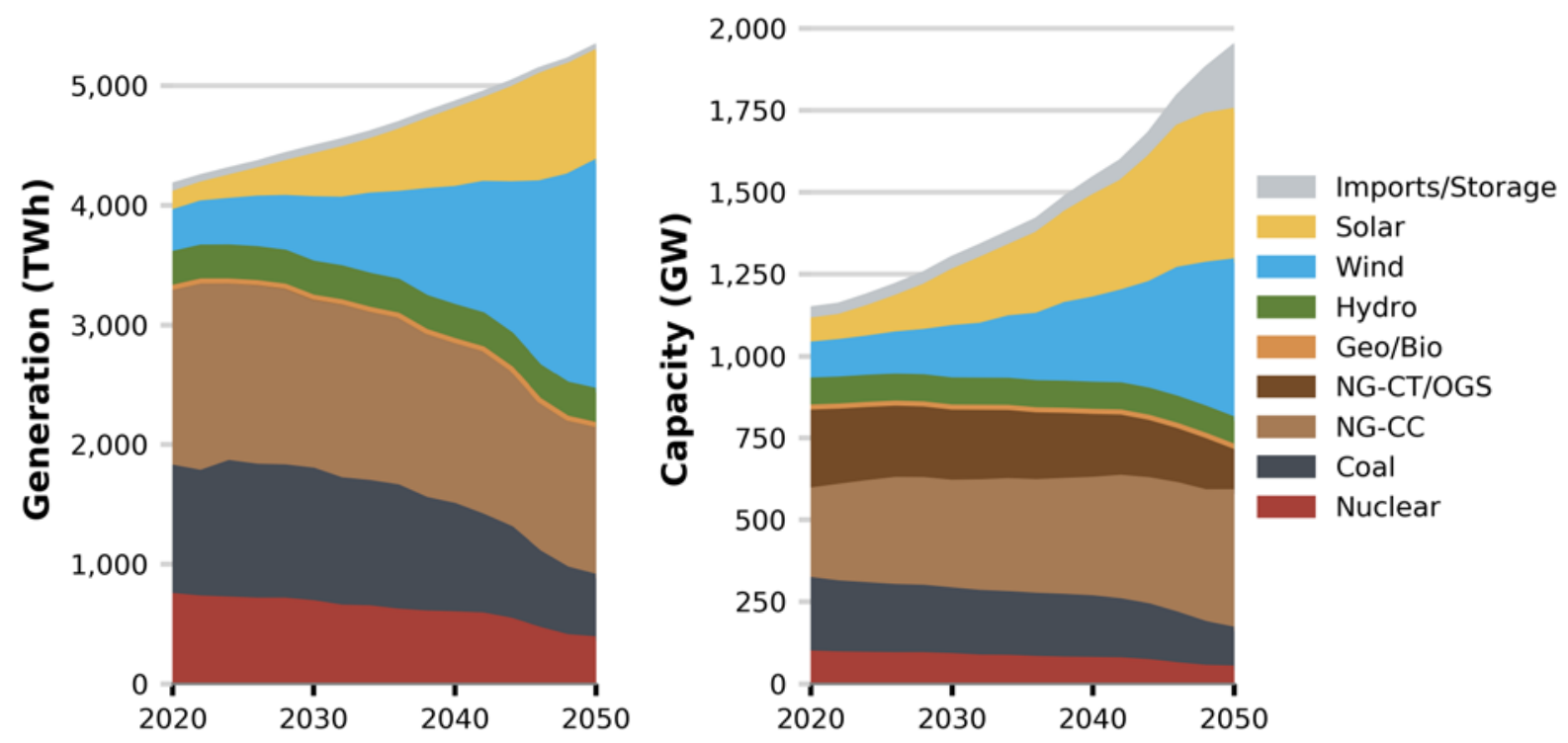

Figure 2. U.S. power sector evolution over time for the Mid-case scenario. The gray area represents imports from Canada in the left figure and storage capacity in the right figure. Storage generation is not shown because storage always has a negative net generation (due to losses). NG-CC is natural gas combined cycle, NG-CT is natural gas combustion turbine, OGS is oil-gassteam, Geo/Bio is geothermal and biopower, and TWh is terawatt-hours. 
Total natural gas capacity exceeds the capacity of any other technology type through 2050 , though in this scenario wind becomes the largest source of generation by 2050. Nuclear generation is the largest relative to its capacity, with capacity factors remaining constant over time at $90 \%$. The fleet-wide coal capacity factor is $50 \%$ by 2050 , which is similar to today's level of 54\% in 2018. Fleet-wide NG-CC capacity factors slowly decline over time as the NG$\mathrm{CC}$ units provide increasing amounts of flexibility to respond to the variability of the RE generators, reaching a fleet-wide capacity factor of $34 \%$ in 2050 , as compared to $58 \%$ in 2018 .

Under the Mid-case scenario, the U.S. electricity system evolves toward one with higher shares of natural gas and RE in all states (Figure 3 ). ${ }^{7}$ The regional distribution of power plants is projected to be similar in 2050 to what it was in 2018, with the largest generation levels occurring in states with the greatest electricity consumption (e.g., California, Florida, and Texas). However, proportionally larger future renewable deployment is found in some states (e.g., Nebraska and New Mexico) with particularly high-quality wind and solar resources or policies supporting high levels of renewables. ${ }^{8}$

For a summary of how the Mid-case scenario has changed over the various editions of the Standard Scenarios, see Appendix A.2.

\footnotetext{
${ }^{7}$ States with $100 \%$ clean energy standards do not necessarily have $100 \%$ of their generation from clean energy resources. As discussed in Section 3.4 and in Appendix A.4, we only require that the states satisfy their end-use sales with clean energy resources. Transmission and storage losses or exported energy can come from other resource types.

${ }^{8}$ Specific state-level scenario results can be downloaded using the Standard Scenario Results Viewer for all scenarios at en.openei.org/apps/reeds.
} 

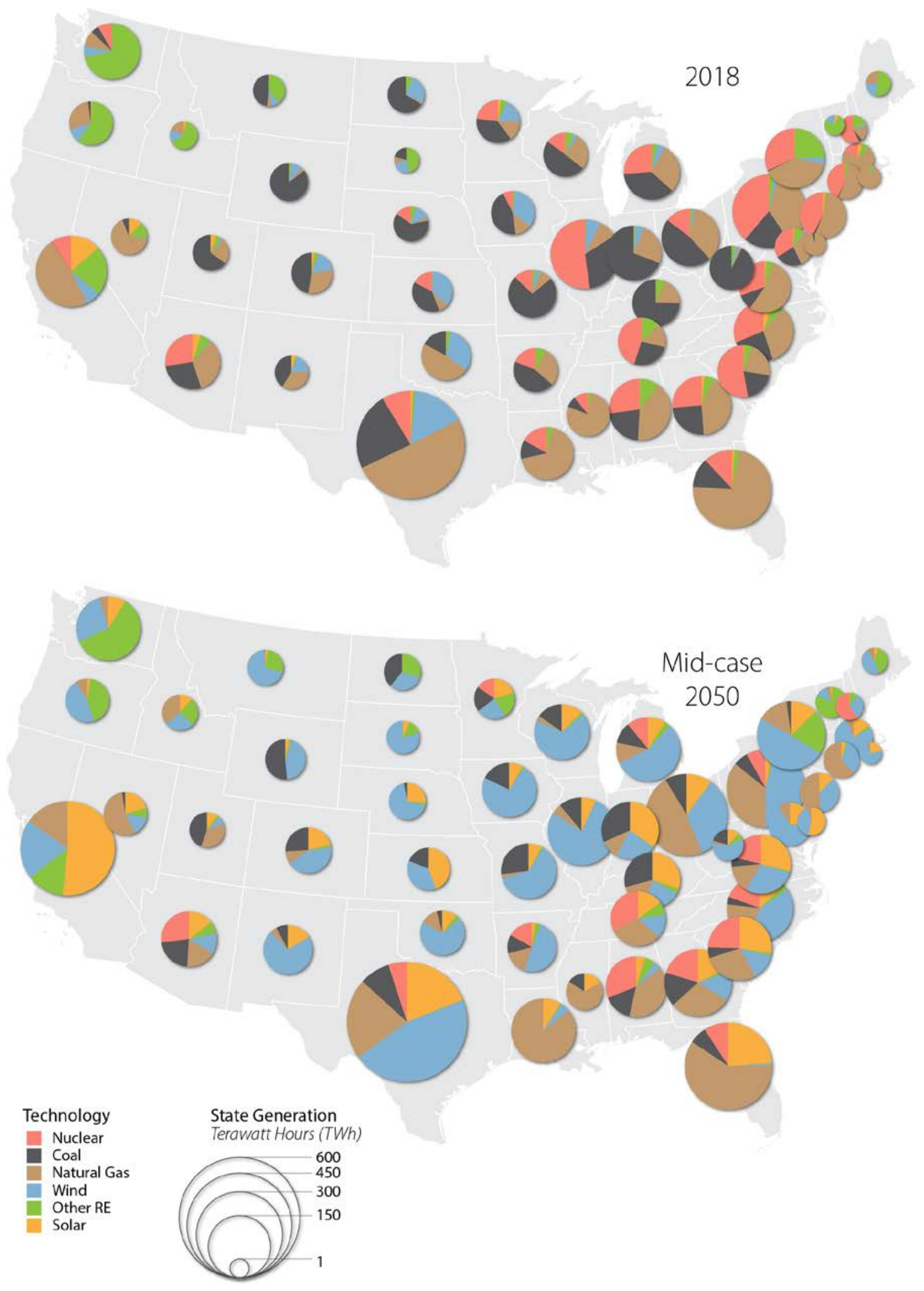

Figure 3. Evolution of the U.S. power system from the current system (top) to one powered primarily by wind, solar, and natural gas capacity (bottom) in all regions in the Mid-case scenario 


\section{Text Box 1. How 'Standard' are the Standard Scenarios Mid-cases over time?}

The current edition of the Standard Scenarios is NREL's fifth such set of annual projections. Here, we compare these projections with those from three well-known organizations - the U.S. Energy Information Administration (EIA), the International Energy Agency (IEA), and Bloomberg New Energy Finance (BNEF) - that have a much longer record of producing annual U.S. electricity sector outlooks. Although the Standard Scenarios and most of these organizations publish multiple scenarios that span a wide range of assumptions, this comparison focuses on the 'reference' scenarios only. Specifically, the Figure TB-1 shows results from the NREL Standard Scenarios Mid-Case, the EIA Annual Energy Outlook (AEO) Reference, the IEA World Energy Outlook (WEO) New Policies Scenario, and the BNEF New Energy Outlook (NEO) published since 2015 (IEA WEO 2019 was not available at the time of this writing). Note that the input assumptions, including the policies represented, can differ between the different reference scenarios.
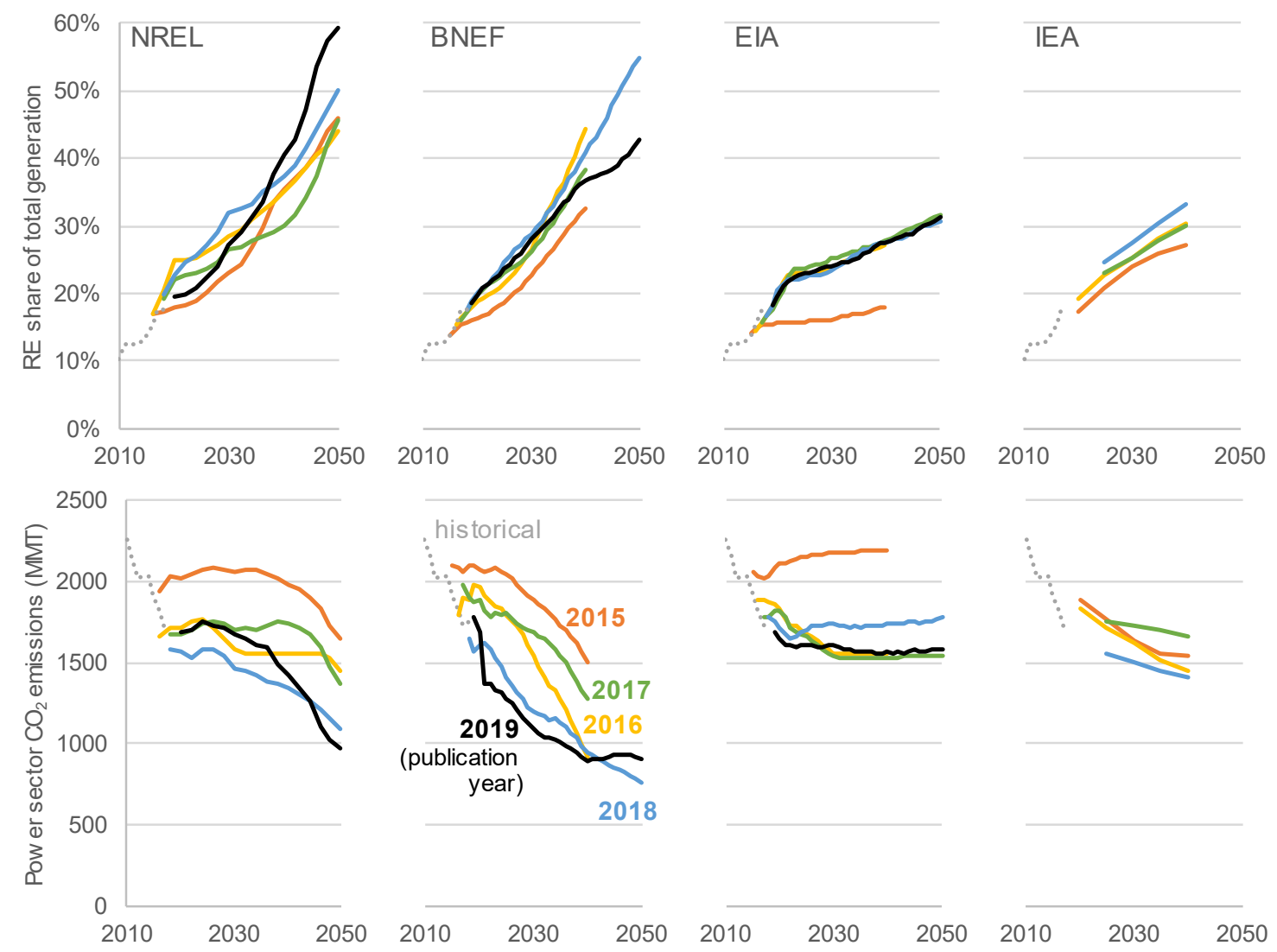

Figure TB-1. Renewable energy, nuclear, natural gas, and coal generation fraction from the organizations and publication years indicated. 


\section{Text Box 1 Continued}

Although we have not conducted an exhaustive comparison of the scenarios, several trends emerge from an examination of the projections. First, all scenarios (from all organizations and for all publication years shown) find increasing annual shares of renewable energy (RE) over time, where RE generation is from technologies that use biomass, geothermal, hydropower, solar, and wind resources. For example, the range of RE shares estimated from the most-recent set of projections from the four organizations is $24 \%-28 \%$ in 2030 , a narrow range of values that are higher than the $18 \% \mathrm{RE}$ observed for 2018 . These ranges widen over time $(27 \%-40 \%$ in 2040 and $31 \%-59 \%$ in 2050$)$ highlighting growing divergence between the projections into the future. For the model years after 2030, the NREL and BNEF projections typically include greater RE penetration than those from EIA and IEA. For NREL and BNEF, there are also substantial variations in estimated RE penetration across publication years in contrast to the more-similar projections from EIA and IEA across outlook editions.

Power sector $\mathrm{CO}_{2}$ emissions results from this collection of scenarios reveals similarly wide variations between organizations and publication years. In each organizations' most recent projection shown, the 2019 Standard Scenarios emissions trends are more closely aligned with those from EIA and IEA through 2040, drop at a much faster rate after 2040 compared with EIA and IEA, and approach BNEF's projections by 2050 . The emissions trends are, of course, related to the RE share, but also are closely tied to the amount and mix of fossil fuel-fired generation in the projections. For example, the latest BNEF projection shows a steadily increasing share of natural gas-fired generation that primarily offsets coal-fired generation, leading to the most-rapid and largest emissions reductions shown. In contrast, the EIA's 2019 Reference case projects slow growth for natural gasfired generation and a modest decline in coal-fired generation after 2030. The 2019

Standard Scenarios Mid-case results in slight near-term rise in fossil fuel-based generation followed by a steady decline through 2050. Furthermore, for all organizations, more recent projections generally include lower power sector emissions than earlier versions for most years. This trend of lower projected emissions follows trends in actual U.S. power sector emissions, which have fallen sharply over the past decade. 


\subsection{Evolving Revenue Structures of Electricity Generator Technologies}

\section{Recent Trends}

Natural gas, wind, and PV have been the primary resources added to the grid over the past decade (see Figure 4). The reason for these investments is driven by many cost-related factors including technology improvements and tax credits. However, costs alone do not reflect a technology's competitiveness or an investor's profitability. In practice, energy revenues and expected revenues from providing grid services or from credits to fulfill state policy requirements may affect investment decisions. In this section, we present estimated changes over time of the total avoided cost (i.e., system revenue) from providing both energy and grid services. The economic determination to build a new plant includes both on the cost of that plant and the total revenue the plant can obtain by delivering energy and services to the grid. In this section revenue is defined as revenue within the ReEDS model for providing a given service and should not be confused with revenue from actual markets. ${ }^{9}$

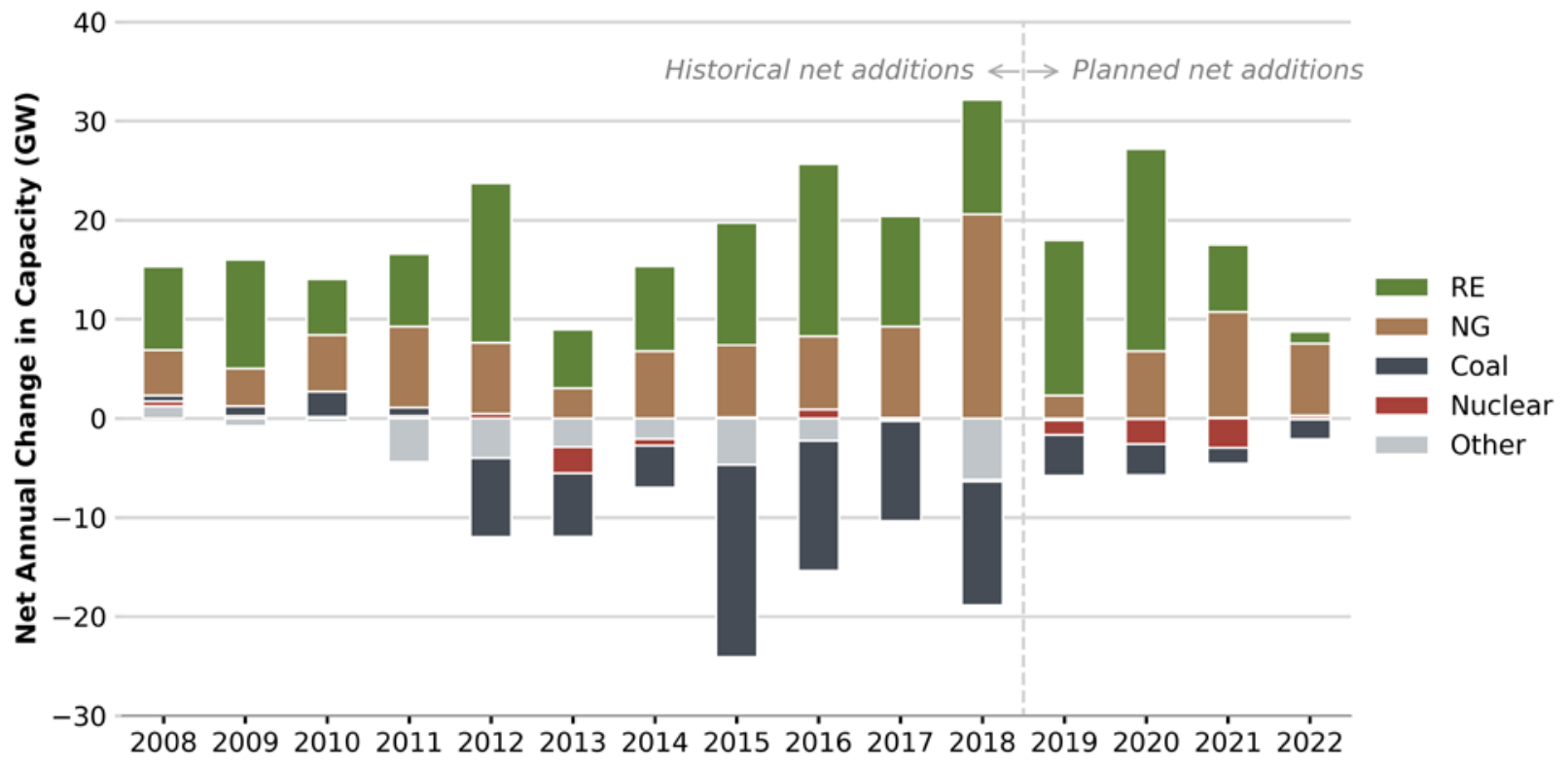

Figure 4. Net capacity additions over time. Historical net additions are defined as the differences in installed net summer capacity at the end of the year shown from the end of the prior year. Planned net additions are defined as planned capacity minus planned retirements. Planned additions differ from model-derived additions and can understate the amount of renewable capacity under consideration, as renewable technologies have relatively short siting and construction periods. $\mathrm{RE}=$ renewable energy.

The RE category is not broken up by RE technology type because the U.S. Energy Information Administration (EIA) did not collect that data in the earlier parts of this period.

Data sources: EIA Electric Power Annual and Electric Power Monthly (EIA 2019c)

Over the past decade, the cost and value of natural gas, wind, and PV plants have evolved considerably. Natural gas plants have seen lower natural gas prices and heat rate improvements,

\footnotetext{
${ }^{9}$ Specifically, the "revenue" is the shadow price from a given constraint times the level provided by a technology toward that constraint. For example, if the shadow price on the energy constraint for a given time period is $\$ 30 / \mathrm{MWh}$, and a technology provides $10 \mathrm{MWh}$ of energy in that time period, then the revenue for that technology in that time period would be $\$ 300$.
} 
which both serve to lower their generation costs. Wholesale energy prices have also declined (Wiser et al. 2017), which reduces the revenue potential from selling energy. Wind and PV cost reductions and performance improvements are well documented (Kavlak, McNerney, and Trancik 2018; Wiser and Bolinger 2018; NREL 2019; IRENA 2019). The value of wind and PV have long been shown to decline with increasing penetration (Denholm and Margolis 2007; Mills and Wiser 2012), and penetration levels have increased to levels where that value decline can be observed in market data (Wiser et al. 2017). For example, Figure 5 shows how energy prices at noon (when there is a lot of sun) in the California Independent System Operator (CAISO) system have declined relative to average prices at midnight (when there is no sun) as the deployment of PV capacity has increased. To better understand this trend of shifting value or revenue potential as the generation mix evolves, this section summarizes some changes in the grid mix, presents the cost of the various technologies, and then focuses on the revenues received by those technologies.
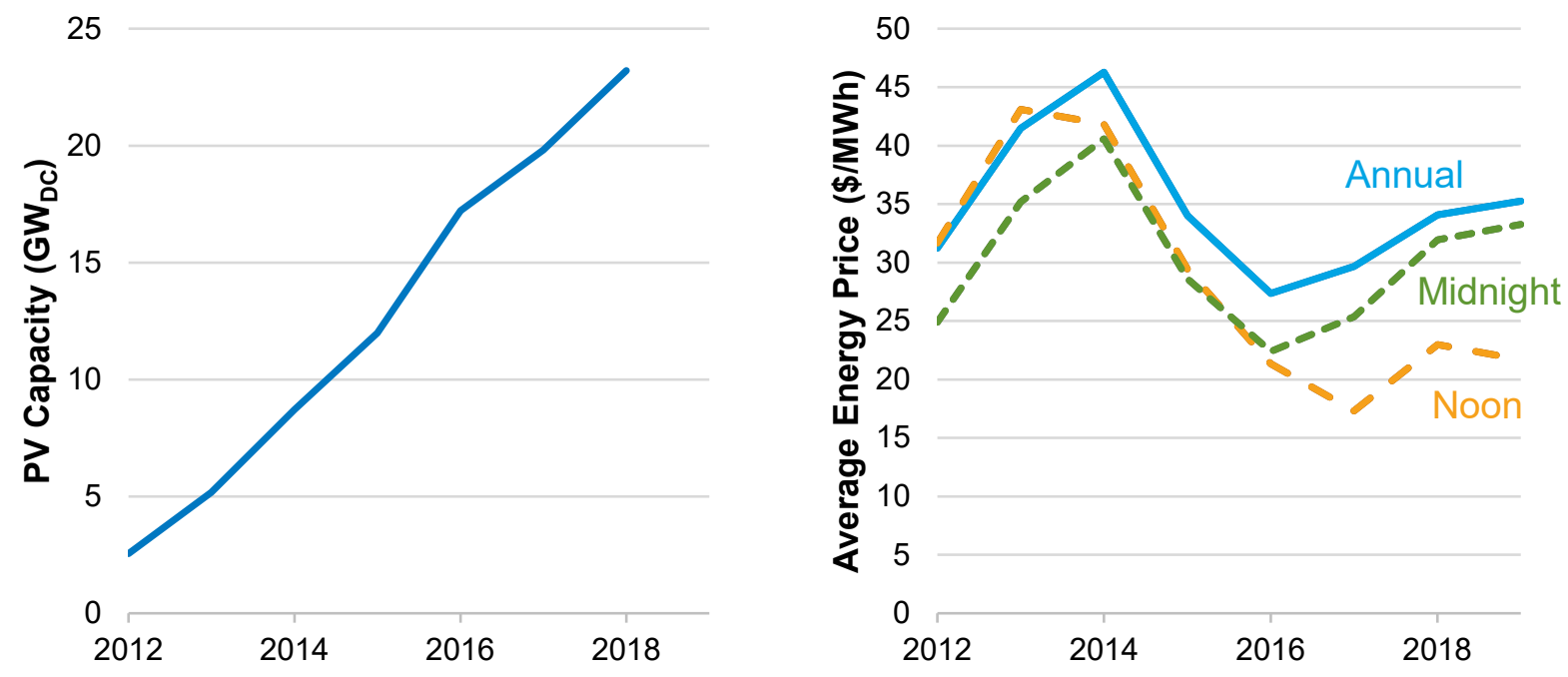

Figure 5. PV deployment in California (left) and energy prices in CAISO (right). Annual average prices are shown as the solid blue line. Average prices at midnight are shown in the smaller dashed green line, and average prices at noon are shown in the orange larger dashed line. Prices are from the ABB Velocity Suite (ABB 2019) and are weighted by load. Prices for 2019 include prices through August 12. PV capacity includes both utility-scale and distributed PV.

\section{Outlook}

Just as natural gas, wind, and PV have constituted the bulk of new capacity additions over the past decade, the suite of Standard Scenarios show that in most scenarios these three technologies continue to be the leading technologies for new capacity additions. Figure 6 shows that wind and $\mathrm{PV}$ increase in all scenarios, though the range of increase is broad. Natural gas generation is mixed with many scenarios showing flat or declining generation over time. Natural gas capacity, however, increases in all scenarios except those with high natural gas prices. 

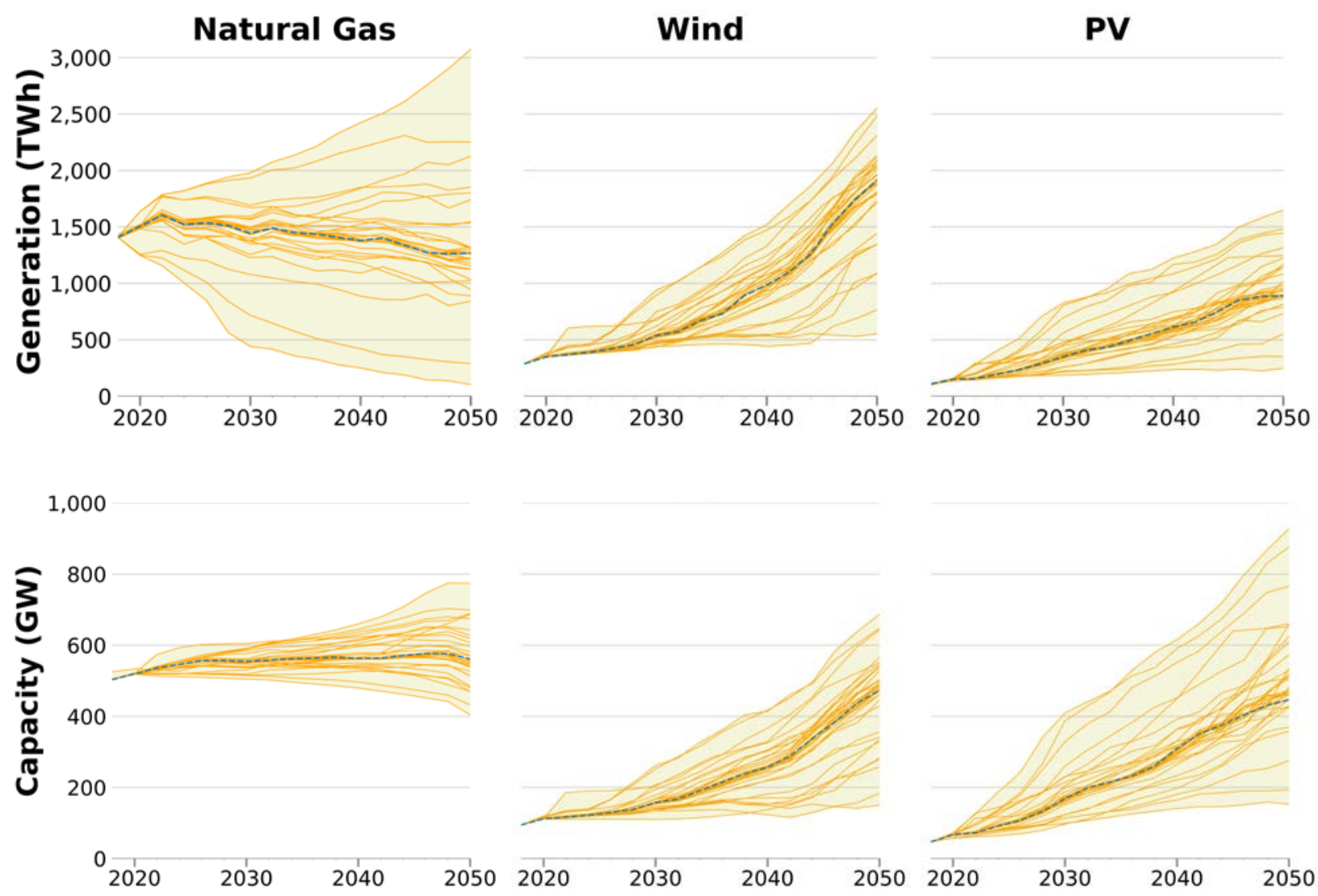

Figure 6. Natural gas, wind, and PV generation (top) and capacity (bottom) across the full suite of Standard Scenarios. The dashed line is the Mid-case scenario.

Figure 7 and Figure 8 show the national average levelized cost of energy (LCOE) and annualized cost of capacity ${ }^{10}$ respectively, for many technology categories in the ReEDS model in the Midcase. ${ }^{11}$ As shown by the figures, annualized cost of capacity declines for all technologies, reflecting the assumed technology improvements (NREL 2019). These improvements, coupled with improvements to heat rate and other performance factors, also lead to a reduction in LCOE for all technologies except for natural gas. For natural gas technologies, LCOEs increase due to the projected increase in natural gas prices over time (see Appendix A.1 for details on input assumptions such as fuel prices). By 2050, the technologies with the lowest LCOE are NG-CC, offshore and onshore wind, and PV, while the technologies with the lowest annualized cost of capacity in 2050 are PV, NG-CC, natural gas combustion turbine (NG-CT), and 4-hour battery storage.

\footnotetext{
${ }^{10}$ This annualized capital cost is analogous to the cost of new entry and is important when considering peaking capacity resources that will have a low capacity factor. It considers the annualized capital cost plus any fixed operations and maintenance cost.

${ }^{11}$ These costs are based on the 2019 Annual Technology Baseline (NREL 2019) and assume a 20-year cost recovery period. They also incorporate the transmission spur line costs for wind, PV, and CSP technologies.
} 


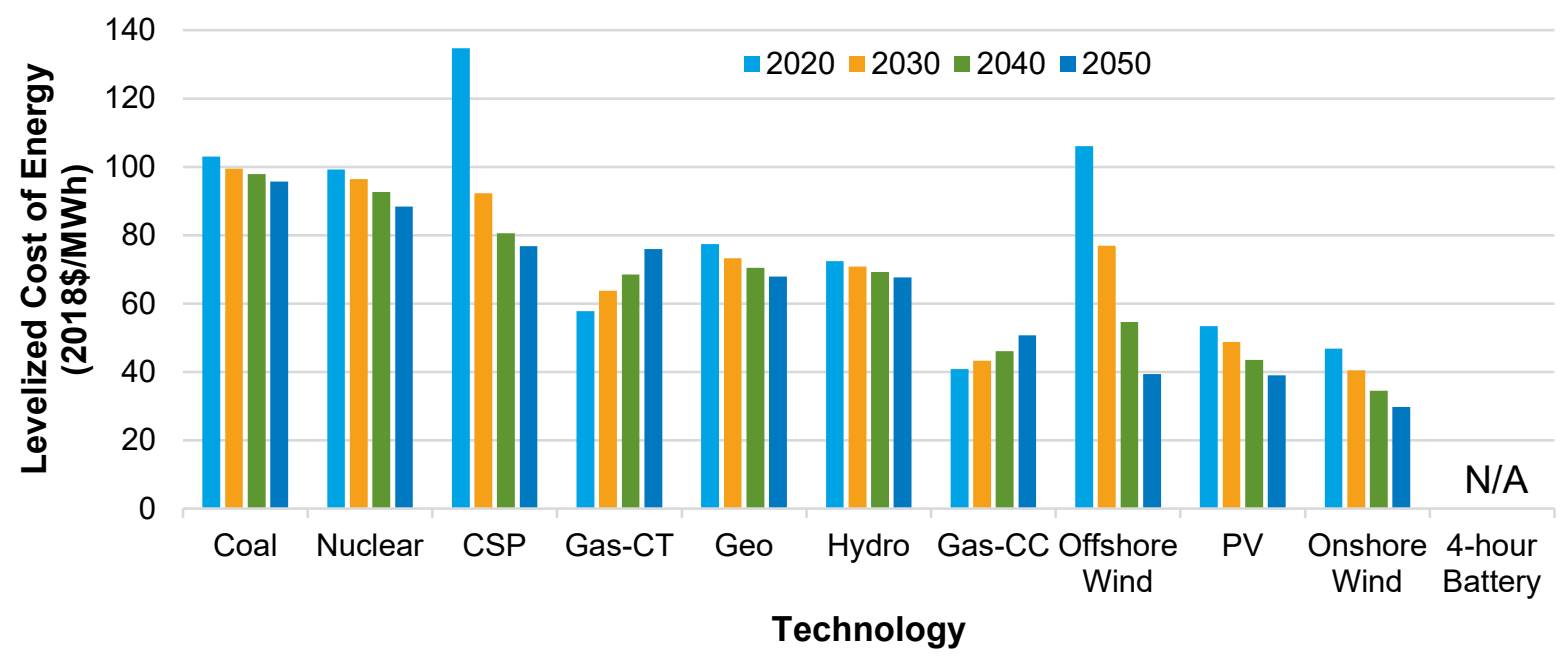

Figure 7. National average LCOE over time for the technologies indicated for 2020-2050.

Technologies are arranged from highest to lowest LCOE in 2050. This cost assumes that the technologies are producing energy at their maximum available capacity throughout the year (i.e., there is

no curtailment but there are still outages). Coal is ultra-supercritical pulverized coal without carbon capture. CSP includes 10 hours of thermal storage. PV is one-axis tracking utility-scale PV. Additional details are in the Annual Technology Baseline (NREL 2019). The 4-hour battery is not shown because it has a negative net generation.

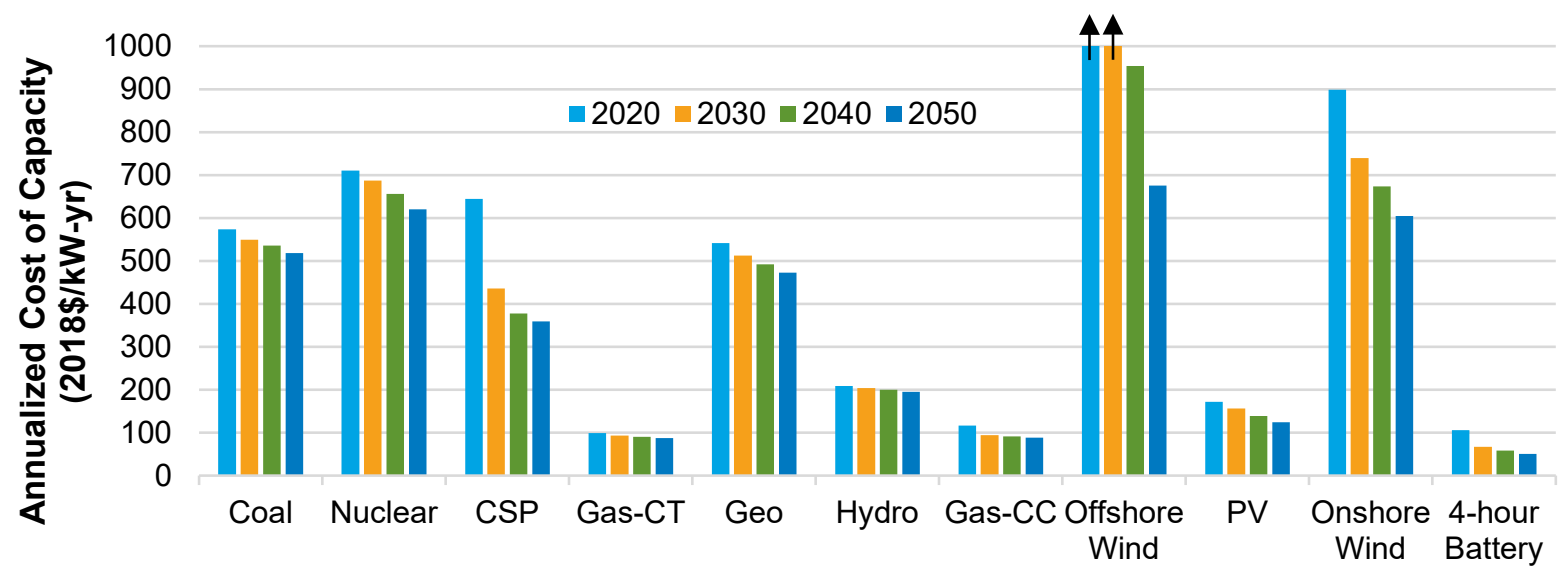

Technology

Figure 8. National average annualized cost of capacity for the technologies indicated for 2020 2050. For simplicity, this cost assumes a fixed 0.5 capacity credit for $P V$, a fixed 0.2 capacity credit for wind, and full capacity credit for all other technologies. ${ }^{12}$ Coal is ultra-supercritical pulverized coal without carbon capture. CSP includes 10 hours of thermal storage. PV is one-axis tracking utility-scale PV. Additional details are in the Annual Technology Baseline (NREL 2019). Values for offshore wind are $\$ 1,838 / \mathrm{kW}-\mathrm{yr}$ in 2020 and $\$ 1,350 / \mathrm{kW}-\mathrm{yr}$ in 2030.

Neither LCOE nor annualized cost of capacity is a sufficient metric to determine investment decisions because they do not consider all the revenue components that the technologies provide to the system. If LCOE were the only driver of new deployment, only onshore wind would be

\footnotetext{
${ }^{12}$ We use a fixed capacity credit in this figure for wind and PV for simplicity of showing the data. The ReEDS model uses hourly load and resource data for each model region to compute capacity credits.
} 
deployed (as long as there was sufficient wind resource). If the annualized cost of capacity was the driver, only 4-hour batteries and NG-CT would be deployed. However, multiple revenue streams for these technologies have been included to determine the optimal generation mix. In the ReEDS model, the primary revenue streams are energy, planning reserve provision, operating reserve provision, and state policy compliance [e.g., by contributing toward renewable portfolio standard (RPS) or clean energy standard (CES) requirements]. Figure 9 shows the national annual average prices for those services across the suite of scenarios. Although Figure 9 only shows the national annual averages, these prices vary by region and time period. For example, in the Mid-case in 2030, the national average annual energy price is $\$ 38 / \mathrm{MWh}$, but regional prices range from $\$ 25-\$ 89 / \mathrm{MWh}$ throughout the year, with the highest prices during summer peak periods and the lowest prices in the spring overnight periods.
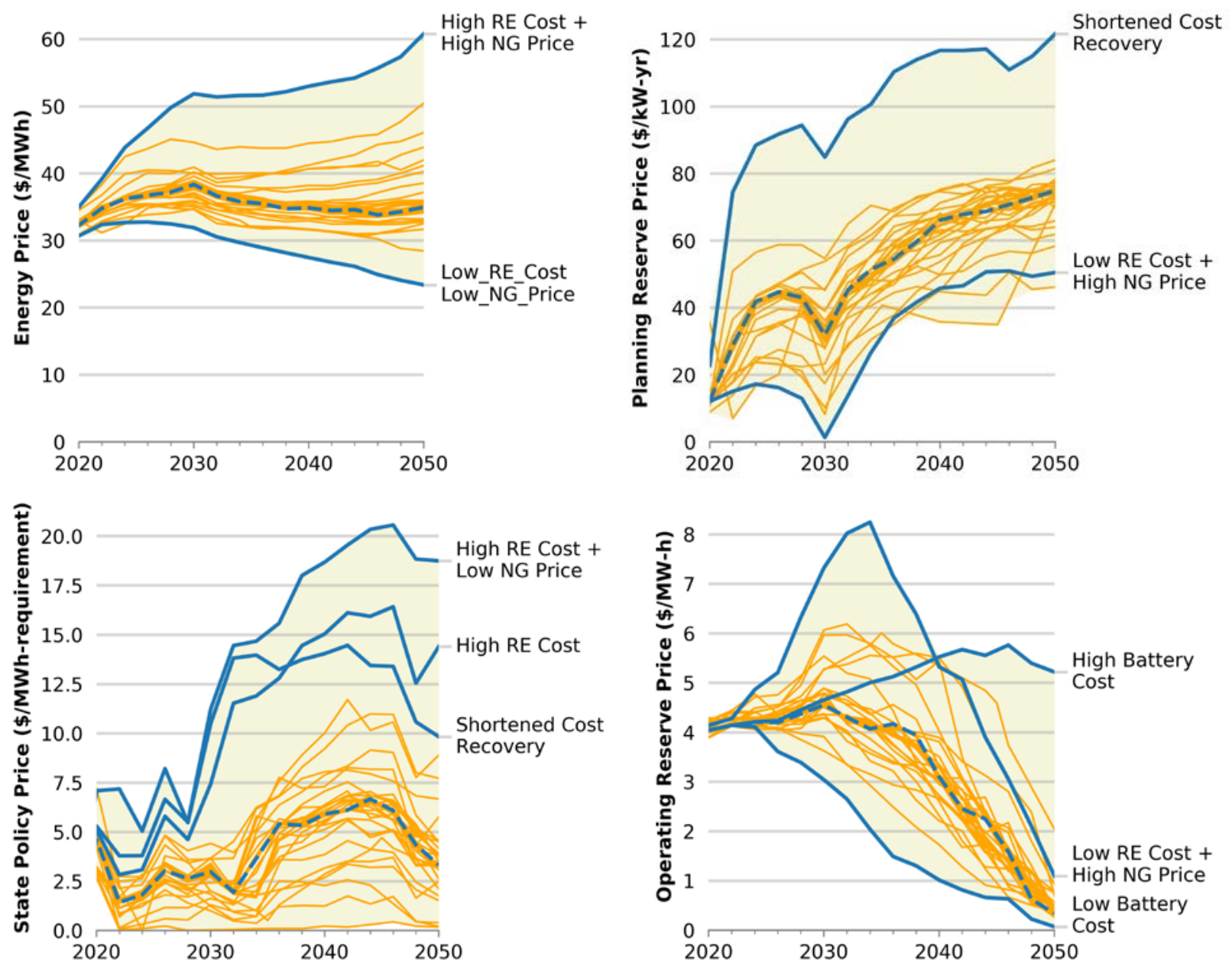

Figure 9. National annual average prices for the services indicated across all scenarios. The dashed line shows the Mid-case. Select high and low scenarios are also noted. The operating reserve price is the sum of the three operating reserve products: regulation, spinning, and flexibility.

The natural gas price assumptions are the largest driver of the energy prices in the Standard Scenarios due to natural gas generators typically being on the margin. Low and high RE costs also have a significant effect on long-term energy prices. 
The planning reserve price is the price of providing capacity that can meet the planning reserve margin requirement and is analogous to capacity prices in today's markets. The current system is long on capacity in most regions (NERC 2018), which tends to result in lower near-term planning reserve prices within the model. The planning reserve provision equilibrates at the NERC-recommended levels over time due to retirements and load growth, which increases planning reserve prices and therefore increases the revenue that plants receive from contributing toward the planning reserve margin. In many scenarios the planning reserve price dips in 2030 due to increasing policy stringency for many policies with 2030 targets.

For planning reserve prices, the Shortened Cost Recovery scenario leads to the highest prices. Because peaking resources are capital intensive, the planning reserve price is typically set by the annualized cost of the least-cost peaking unit. A shorter cost recovery period leads to a higher annualized cost because capital costs are recovered over a fewer number of years. The lowest planning reserve prices are from the scenario with Low RE Cost + High NG price scenario. This scenario leads to an abundance of new variable renewable energy (VRE) capacity, which provides additional planning reserve contribution and incentivizes more storage, both of which push down planning reserve prices. Additional details relating to planning reserve prices are discussed in Section 3.3.

The policy requirement prices are driven by the RPS and CES requirements (Section 3.4 explores those requirements in detail). As expected, the prices are higher in scenarios where renewables are less competitive and lower in scenarios where renewables are more competitive.

The operating reserves are the sum of the three operating reserve types included in the model: flexibility reserves, spinning reserves, and regulation reserves [see Denholm, Sun, and Mai (2019) and Cole et al. (2018) for details on these grid services]. These prices are generally much lower than the other prices, and there is less spread in absolute terms across the scenarios. Battery storage cost plays a key role in these prices, with overall reserve prices increasing through 2050 in the High Battery Cost scenario. In 2030, operating reserve prices are highest in the Low RE Cost + High NG Price scenario, which has especially high VRE penetration. That high VRE penetration increases the amount of reserves required, which in turn increases prices. Once enough storage has been deployed to meet these requirements, those prices return to the levels seen in other scenarios.

The technologies provide the services above at different levels in different points in time. For example, Figure 10 shows the fraction of revenue that each technology receives from the four categories of services shown in 2030 and 2050. These values are the average of all plants of that type in the Mid-case scenario. In 2030, most technologies get most of their revenue from providing energy. Of the RE technologies, $\mathrm{PV}$ has the highest fraction from providing planning reserve capacity. Batteries receive a sizable fraction from planning reserves, and NG-CTs receive over $90 \%$ of their revenue from this service. Only batteries have a visible fraction of revenue that comes from providing operating reserves. 


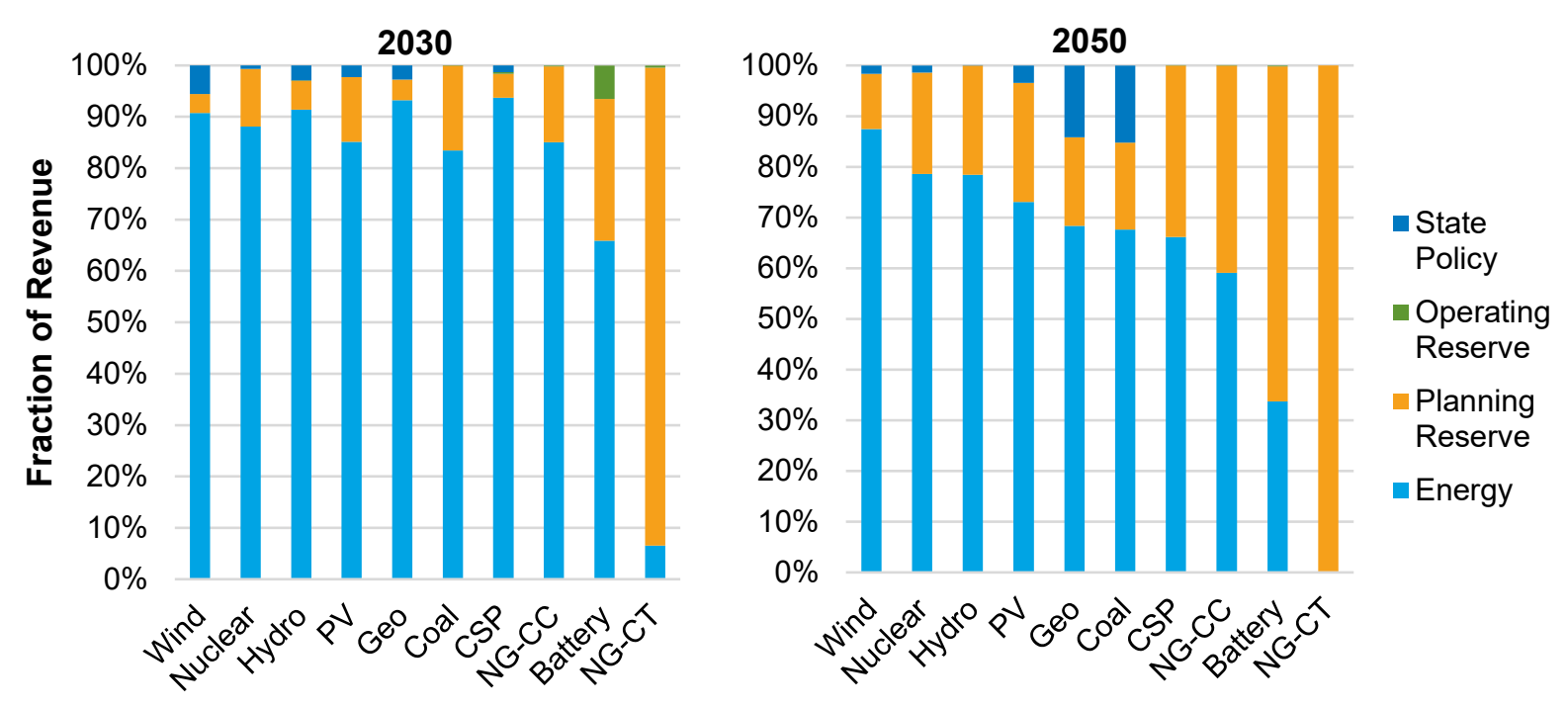

Figure 10. Fraction of revenue by technology type from the different sources in 2030 (left) and 2050 (right) for the Mid-case scenario. State policy indicates that the technology is receiving revenue from helping to meet state RPS or CES requirements.

By 2050 , the fraction of revenue from providing energy has declined for all technologies and has largely been displaced by revenue from providing reserve margin capacity. In 2050, batteries receive most of their revenue from capacity, and NG-CT plants receive their revenue almost exclusively from capacity. Operating reserve revenues for storage have mostly disappeared due to declining operating reserves prices that occur as storage deployment grows over time and due to spreading this revenue over an increasing amount of battery storage installed capacity (164 GW by 2050). Geothermal and CSP have outsized fractions of their revenue coming from state policy requirements because nearly all geothermal and CSP capacity in the Mid-case is located in California, which has a $100 \%$ CES in effect by 2050 (see Section 3.4).

Another factor driving the shift in average energy revenue for VRE technologies in Figure 10 is that the amount of curtailment increases as the penetration of wind and PV increases (see Figure 11). This curtailment drives down the value of energy for VRE technologies. The curtailment rates in Figure 11 are lower than they would be otherwise because of storage that has been deployed. The High Battery Cost scenario results in a steeper curtailment rate due to lower amounts of storage being deployed. 


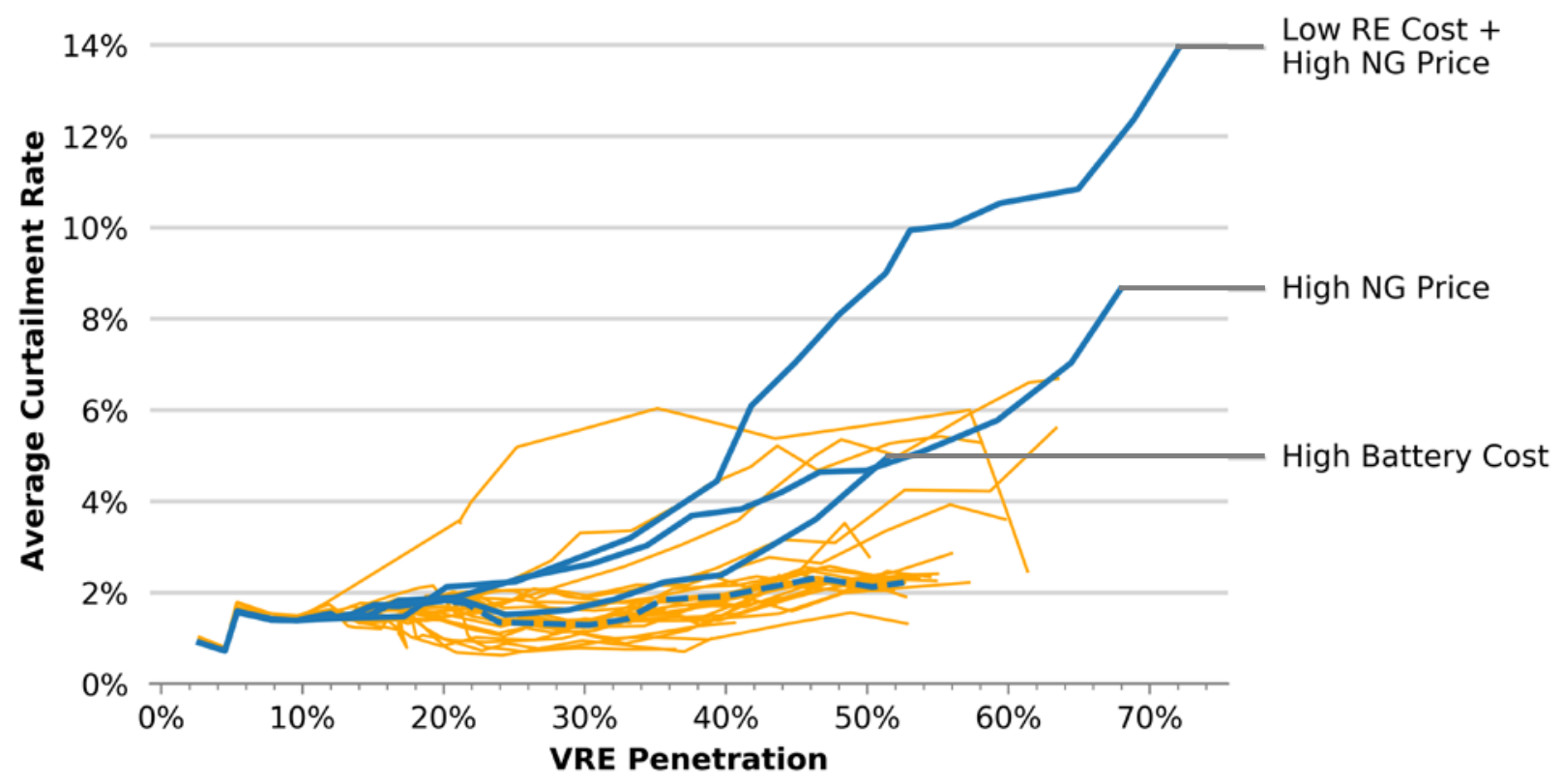

Figure 11. Average curtailment rate as a function of VRE penetration (by generation) across scenarios. The dashed line shows the Mid-case scenario.

\section{Key Insights}

- New capacity additions continue to be led by natural gas, wind, and PV. Natural gas, wind, and PV technologies have been the primary technologies deployed over the last decade. They continue to grow across nearly all the Standard Scenarios.

- Prices for providing grid services vary considerably over time and by scenario. Energy and planning reserve prices tend to increase over time, while operating reserve prices tend to decrease. However, these trends are heavily influenced by natural gas prices and RE and storage costs.

- The sources of revenue for the various technologies change as the generation mix evolves. Initially, when planning reserve prices are lower, plants tend to receive more revenue from providing energy. That shifts as planning reserve prices increase and as curtailment rates and RPS requirements increase. Revenue from providing operating reserves remains a small piece of overall power plant revenue. 


\subsection{Planning Reserve Provision in an Evolving Grid}

\section{Recent Trends}

Each of the grid entities across the country ensure they have access to sufficient amounts of capacity that can contribute to meeting a resource adequacy target, which is often approximated as the expected peak demand plus an additional planning reserve margin. ${ }^{13}$ The total capacity procured should be greater than this level in order to account for forecast errors in load, renewable generation, plant outages and/or other uncertainties in expected generation. The reference planning reserve margin levels vary by region and range from $12 \%$ to $20 \%$ for the U.S. regions (NERC 2018). Although not all regions or organizations apply the same methodology when assessing resource adequacy (Pfeifenberger et al. 2013; Zhou, Cole, and Frew 2018), we use the planning reserve methodology here because that it is the framework used by NERC that has been implemented in the ReEDS model (Cohen et al. 2019).

Historically when VRE capacity was much more limited than it is today, this planning reserve contribution primarily came from non-variable generators ranging from coal to large hydropower. However, that has changed over the past decade, as VRE has accounted for a growing fraction of total generation additions since 2008 (see Figure 4) and begun to provide modest contributions to the planning reserve.

Table 1. Capacity Credit Assigned to Wind and PV for the Various Regional Transmission Organizations (RTOs)

\begin{tabular}{|c|c|c|}
\hline RTO & Wind & PV \\
\hline PJM & $12.3 \%$ & $45.1 \%$ \\
\hline ERCOT & $\begin{array}{l}\text { Summer: } 15 \% \text { Non-Coastal / 58\% Coastal } \\
\text { Winter: } 20 \% \text { Non-Coastal / } 43 \% \text { Coastal }\end{array}$ & $\begin{array}{r}\text { Summer: } 74 \% \\
\text { Winter: } 12 \%\end{array}$ \\
\hline CAISO & $\begin{array}{r}\text { Summer: } 35 \% \\
\text { Winter: } 15 \%\end{array}$ & $\begin{array}{l}\text { Summer: } 43 \% \\
\text { Winter: } 0.8 \%\end{array}$ \\
\hline ISO-NE & $\begin{array}{r}\text { Summer: } 13.2 \% \\
\text { Winter: } 39 \%\end{array}$ & $29 \%$ \\
\hline NYISO & $\begin{array}{l}\text { Summer: } 10 \% \\
\text { Winter: } 30 \%\end{array}$ & $\begin{array}{l}\text { Summer: } 39 \% \\
\text { Winter: } 1 \%\end{array}$ \\
\hline MISO & $15.2 \%$ & $50 \%$ \\
\hline SPP & $\begin{array}{l}\text { Summer: } 24 \% \\
\text { Winter: } 16 \%\end{array}$ & $70 \%$ \\
\hline
\end{tabular}

Details on how these values are derived and associated citation information are included in Appendix A.3. These are current values used by ISOs and RTOs but are not the values used within the model. The model determines the wind and PV contribution by evaluating the contribution of wind and PV during the top 10 net load hours in each season (Cohen et al. 2019).

In actual systems, the methods for determining the VRE contribution toward the planning reserve requirement vary (Milligan et al. 2017), but the methods generally yield a fractional amount of the VRE nameplate capacity that is counted toward the planning reserve margin, sometimes differentiated by season (see Table 1). We define this fractional amount as the capacity credit, or the fraction of nameplate capacity that can contribute toward the planning reserve margin. The

\footnotetext{
${ }^{13}$ The planning reserve margin is the fraction of planning reserve capacity beyond the expected peak demand. For example, if a region had a peak demand of $100 \mathrm{MW}$ and $120 \mathrm{MW}$ of planning reserve capacity, the reserve margin would be $20 \%$.
} 
fractional capacity credit of wind and solar reflects the average capacity contribution the resource is expected to be able to make during times with the highest loss of load probability, which often but not always corresponds to high demand periods. For example, from Table 1, PV has a higher capacity credit than wind in the summer because PV generation is more correlated with summer peak loads than wind. PV has a low or negligible capacity credit in the winter because solar output is typically poorly correlated with winter peak periods. Like these real systems, the ReEDS model also adjusts the nameplate capacity of wind, PV, and storage when assessing their contribution toward the planning reserve requirement. It does so by evaluating the contribution of each resource during the top 10 net peak load ${ }^{14}$ hours in each season. Because the top 10 net load hours change as penetration levels change, the capacity credit within the model also changes as penetration levels change (Frew et al. 2017).

\section{Outlook}

Just as VRE capacity additions have been a major source of new capacity in recent years, projections from the suite of Standard Scenarios show significant and sustained VRE growth across most scenarios (see Figure 12). This growth means that understanding VRE's contribution to the planning reserve margin will increase in importance.

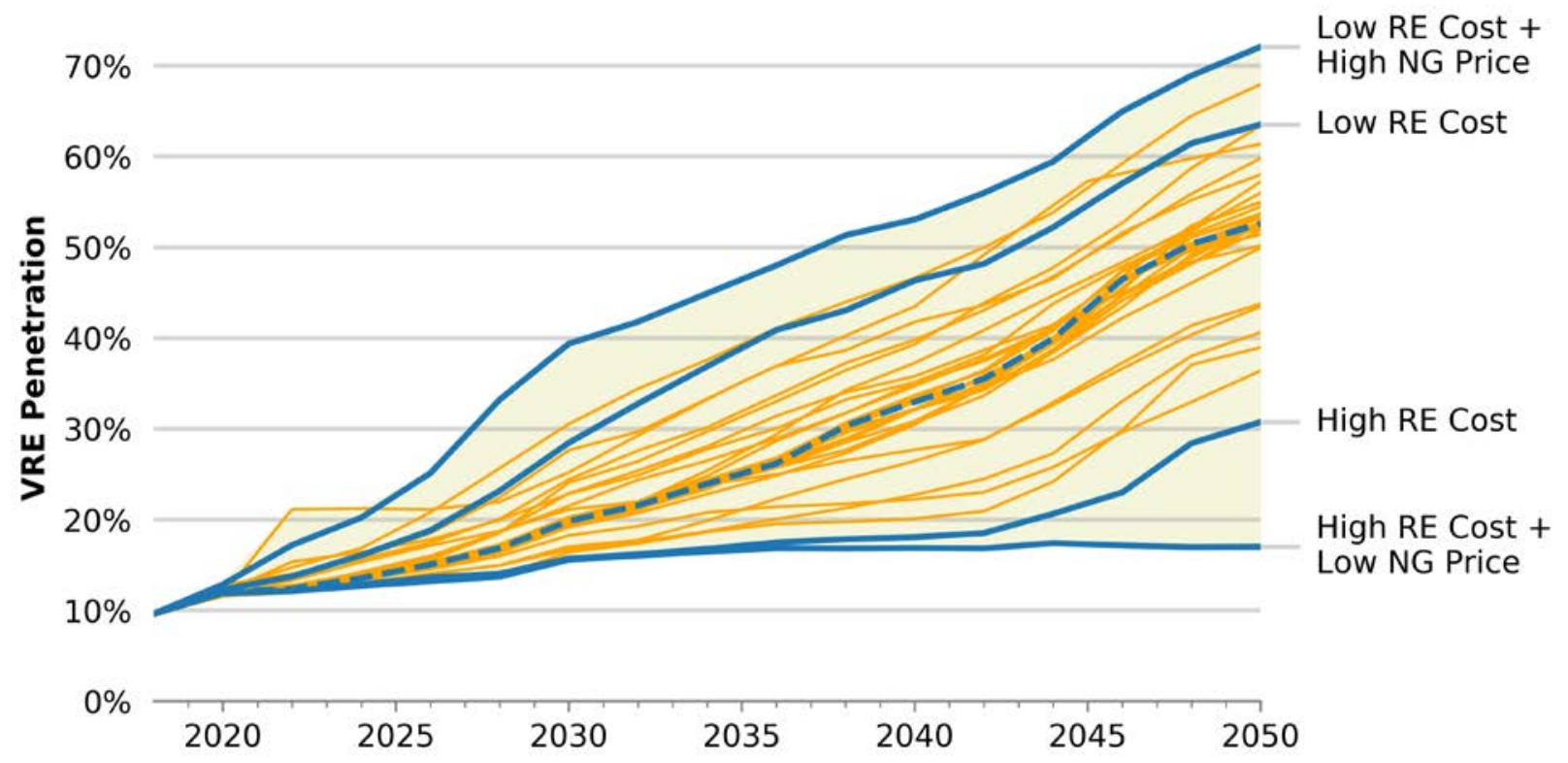

Figure 12. VRE penetration over time across the suite of scenarios. The highest and lowest VRE penetration scenarios in 2050 are labeled, along with the Low and High RE Cost scenarios. VRE penetration is defined as VRE generation divided by total generation.

Although VRE penetration grows across the suite of Standard Scenarios, not all capacity additions, even in the highest VRE penetration scenarios, are from VRE technologies. In all but three scenarios, total non-variable capacity increases from 2018 to 2050 (see Figure 13), where non-variable capacity is defined as all capacity except wind, PV, and CSP without storage. This non-variable capacity plays a key role in maintaining the resource adequacy requirements.

\footnotetext{
${ }^{14}$ Net load is load minus generation from VRE technologies.
} 


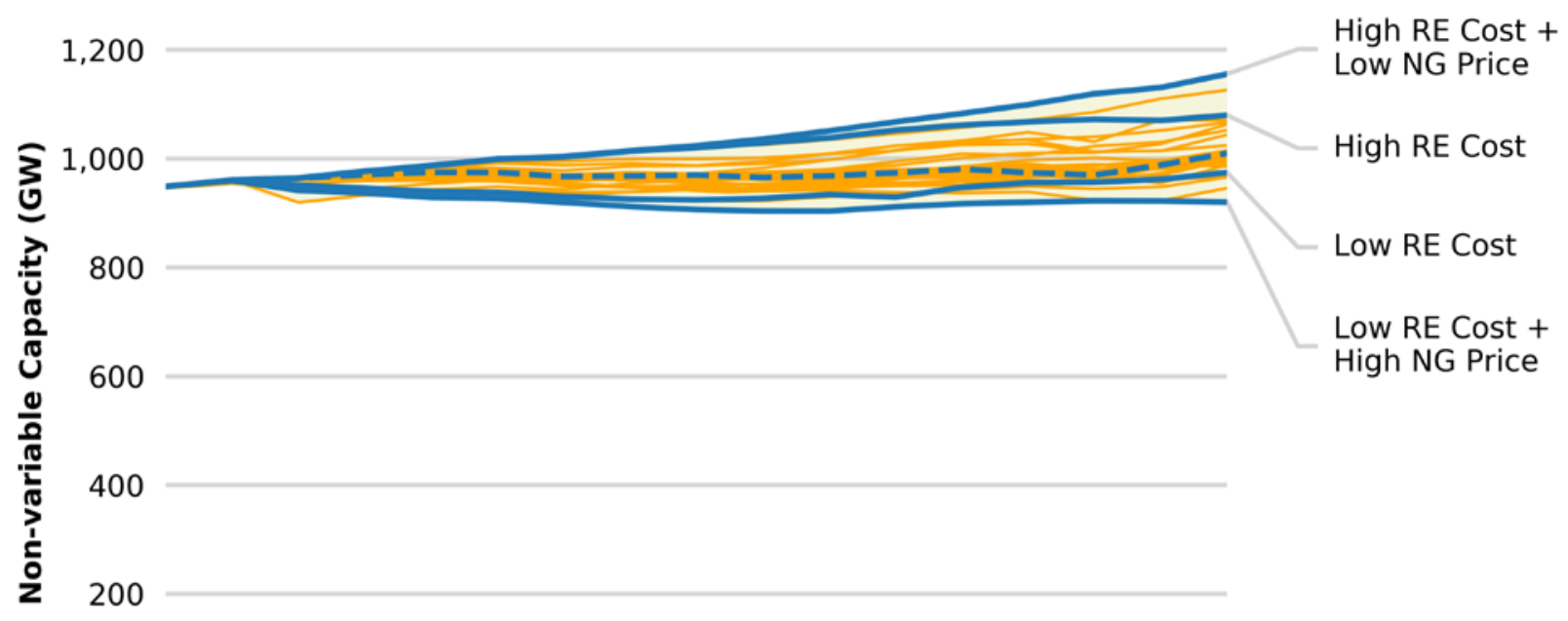

0 \begin{tabular}{llllll}
\hline 2020 & 2025 & 2030 & 2035 & 2040 & 2045
\end{tabular}

Figure 13. Non-variable capacity (including storage) over time across the suite of scenarios

Figure 14 shows the sources of planning reserve provision for the Mid-case and the High and Low RE Cost scenarios, which have a higher and lower fraction of non-variable capacity (respectively) relative to the Mid-case scenario. In each scenario, the total amount of nonvariable capacity remains near 1,000 GW for the entire model period. Across all the Standard Scenarios, the scenario with the least amount of non-variable capacity has nearly $300 \mathrm{GW}$ of planning reserve contributions from wind and solar (combined) in the summer, despite having a total combined wind and solar nameplate capacity of 1,500 GW. In the winter, PV provides virtually no capacity toward the planning reserve requirement because the top peak net load hours occur when there is little or no sunlight. Non-VRE generators, such as geothermal, some hydropower, biopower, and CSP with thermal storage all contribute in both seasons, but their absolute capacities are small relative to the conventional non-variable generators. 

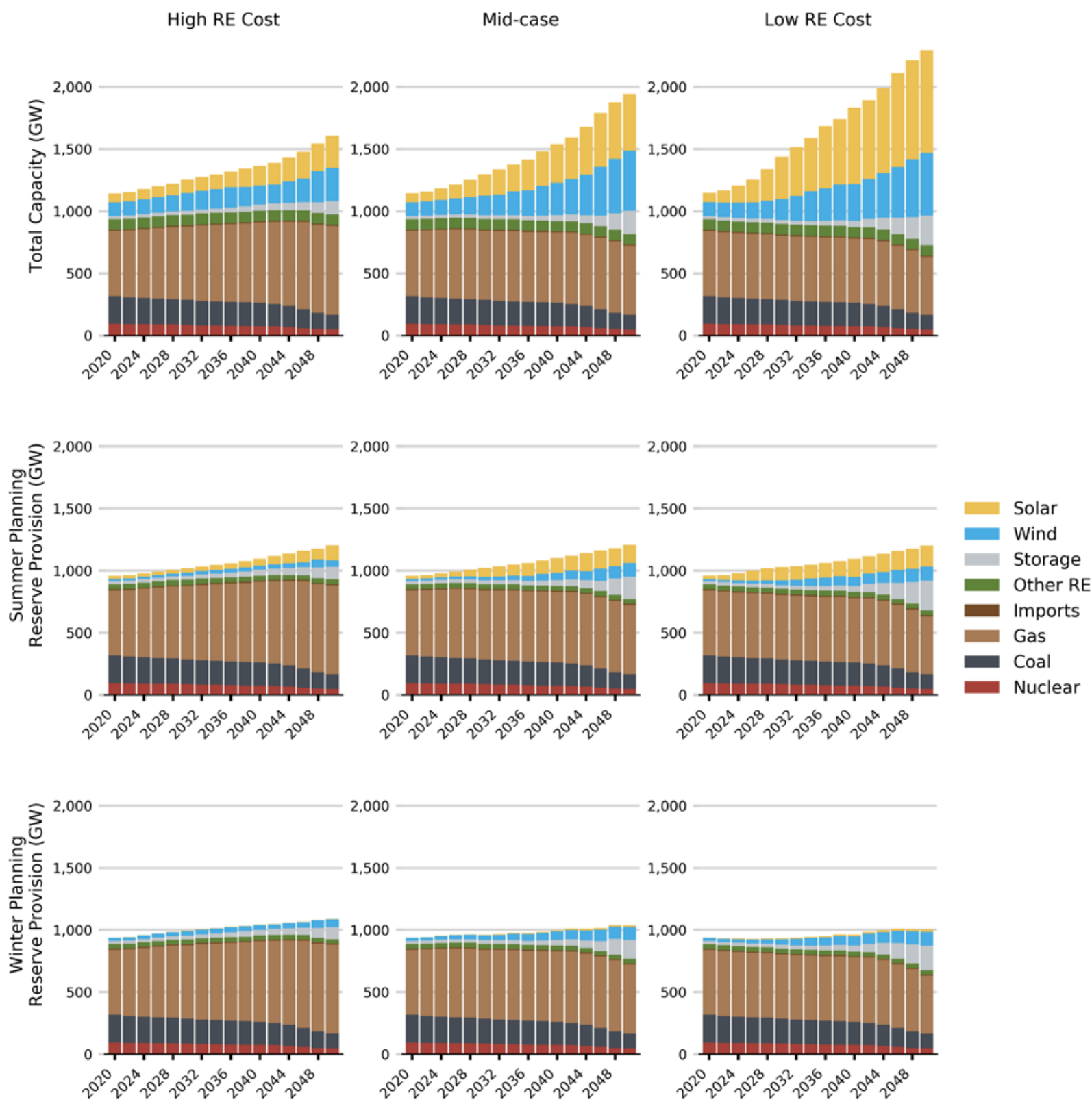

Figure 14. Planning reserve capacity contributions by fuel type in the High RE Cost, Mid-case, and Low RE Cost scenarios

The summary across all scenarios for summer ${ }^{15}$ planning reserve provision and overall total capacity is shown in Figure 15. Across all scenarios in 2050, non-variable technologies (including storage) make up $54 \%-82 \%$ of the planning reserve capacity. Wind contributes 3\%$11 \%$ of 2050 planning reserve capacity and PV 5\%-14\%. Even though wind and PV can make up a large fraction of overall capacity (see Figure 15), their contribution to the planning reserve requirement is modest.

Although non-variable technologies make up most of the planning reserve capacity, these projections are still different from today, where nearly all planning reserve capacity is provided

\footnotetext{
${ }^{15}$ Only summer is shown because the summer peak drives the planning reserve price in most years and scenarios.
} 
by non-variable technologies. These scenario results indicate that investments in non-variable technologies (including storage) will likely remain the more economically efficient means of satisfying resource adequacy requirements. Additionally, in scenarios with significant VRE growth, the operational characteristics of non-variable fleet are likely to shift to operate with lower capacity factors and more cycling (Lew et al. 2013).

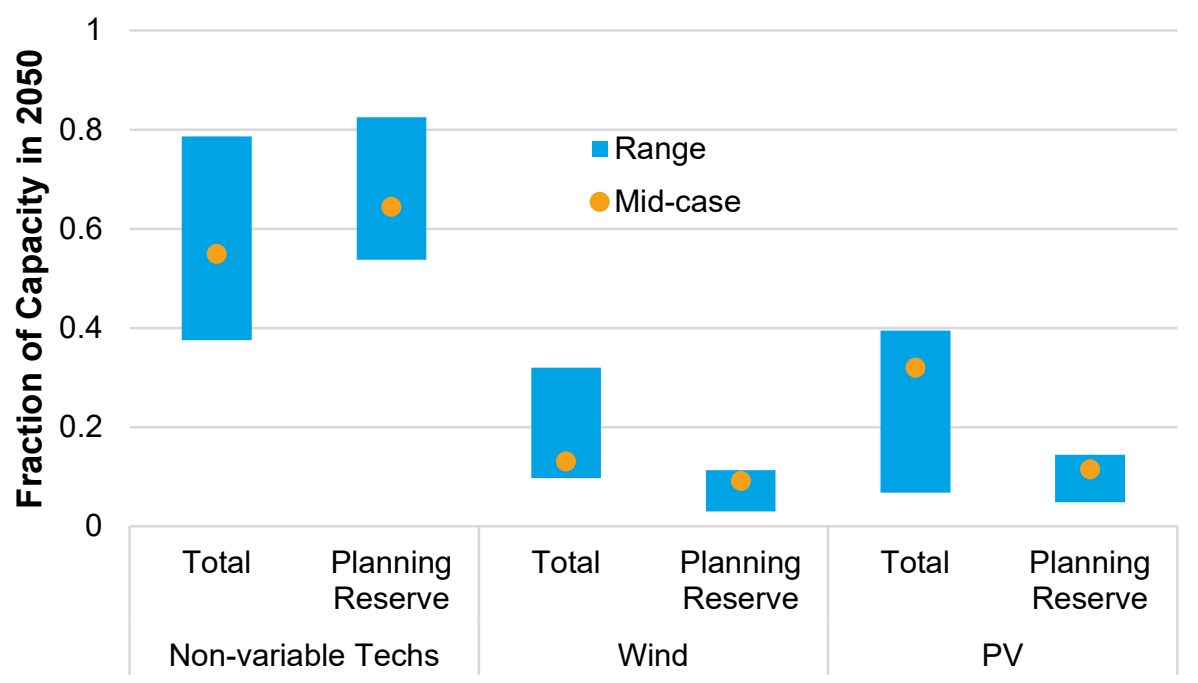

Figure 15. Fraction of planning reserve contribution and total capacity from the specified technology types in $\mathbf{2 0 5 0}$ in the summer. The orange dots show the values from the Mid-case scenario, and the bars show the range across all the scenarios.

Figure 16 shows the average capacity credit of wind, PV, and 4-hour batteries in the Mid-case scenario by interconnection that results from the ReEDS model. PV capacity credit in the winter is small or zero. In the summer, however, the capacity credit can be significant. PV capacity credit declines with penetration as net peak load hours are shifted into the evening. That is seen in the Figure 16 in that the capacity credit declines over time as new PV is added. In the Western Interconnection, $\mathrm{PV}$ penetration is higher than the other interconnections, which is one reason the capacity credit starts much lower. Wind capacity credit tends to be fairly constant over time. In some periods it does increase slightly due to (1) assumptions that capacity factors will continue to improve over time, (2) the shifting of the net peak demand into hours with higher probability of wind generation, and (3) the siting of new wind in locations that have profiles better aligned with peak demand periods. 

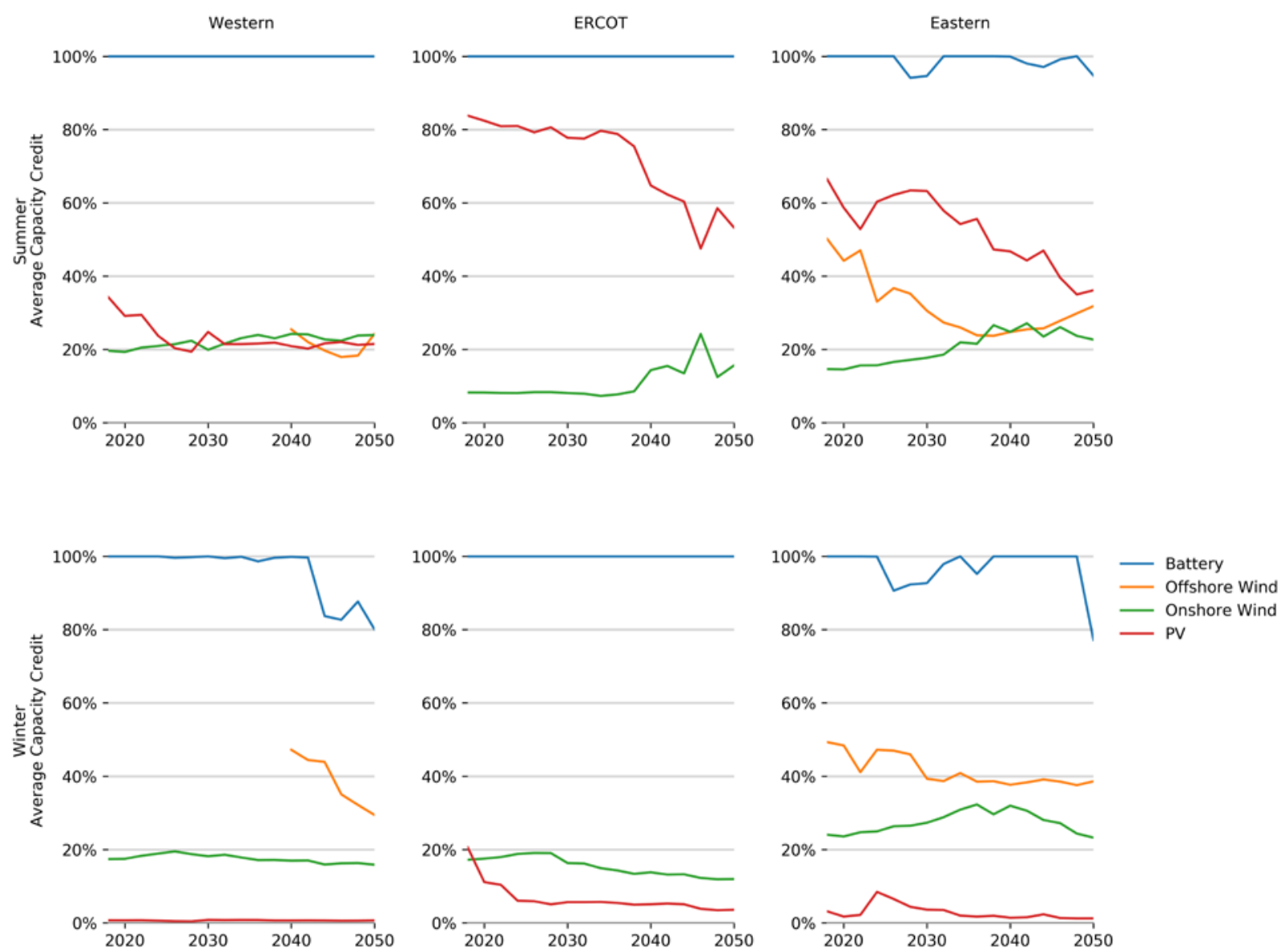

Figure 16. Average capacity credit of utility PV, land-based wind, offshore wind, and 4-hour duration battery storage by season and interconnection in the Mid-case scenario

Figure 16 also shows the storage capacity credit, which is at or near $100 \%$ for most years and regions in the Mid-case scenario. For this analysis, a capacity credit of $100 \%$ for storage means that it can discharge at its rated capacity for the full duration of the peak net load event. If the peak period is 6 hours long, a 4-hour storage device would have a capacity credit of 4/6=67\%. That capacity credit is influenced by how PV and wind impact the net load shape (Denholm et al. 2019).

The decline in storage capacity credit in the Eastern Interconnection is largely driven by the concentration of storage deployment in New York, driven primarily by its storage mandate. New York has a wide load shape, so 4 hours is often not sufficient to meet peak demand. The decline in winter capacity credit in the Western Interconnection is from a similar saturation, but it happens much later and with much higher levels of storage deployment.

The hourly dispatch of the Mid-case system for 2050 is shown in Figure 17 for the peak load day (left) and the net peak load day (right). The net peak demand in both days occurs at or near sunset. In both days, wind output tends to increase as solar output decreases. Storage and dispatchable generators play a key role in providing energy during both days, but especially in the net peak day. 


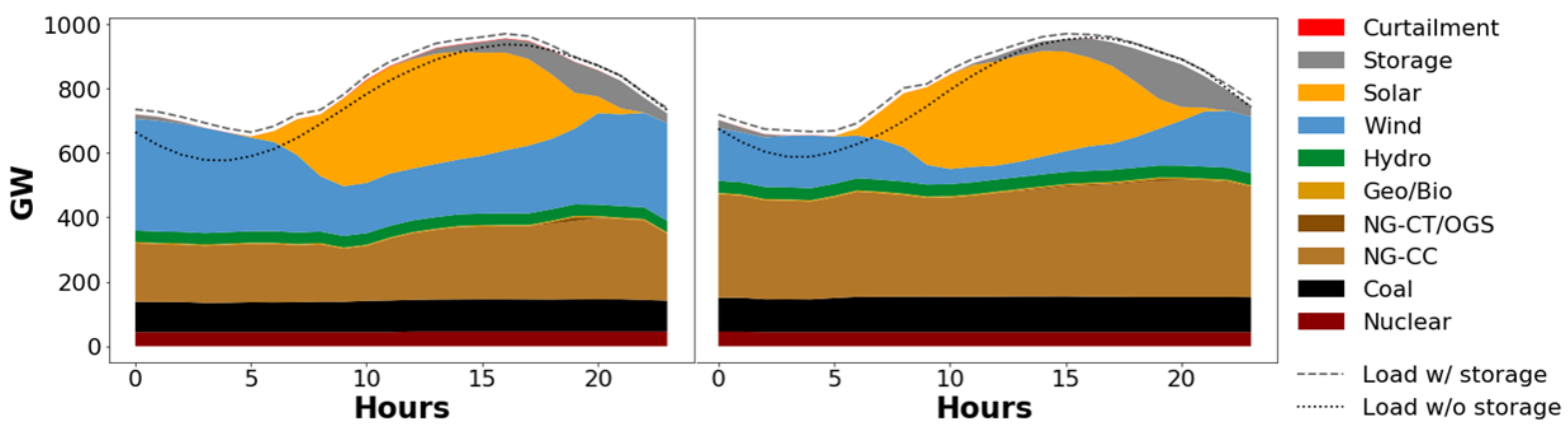

Figure 17. Hourly dispatch from PLEXOS for the Mid-case in 2050. The left figure shows the peak load day (July 26) and the right figure shows the peak net load day (August 8). Hour 0 is midnight.

One notable change in the scenarios relative to today's system is that storage tends to make up an increasingly large fraction of the planning reserve requirement (see Figure 14). Near-term growth in storage is driven by storage mandates, while mid- and long-term growth is driven by economics. As shown in Figure 18, 4-hour battery storage overnight capital costs are assumed to drop below those of NG-CT units by 2030. The lower capital costs mean that batteries are most often the preferred choice for meeting planning reserve margin requirements during peak net load hours, though other factors such as operations and maintenance (O\&M) costs, duration of peak demand periods, and technology lifetimes come into play as this tradeoff is evaluated within the model.

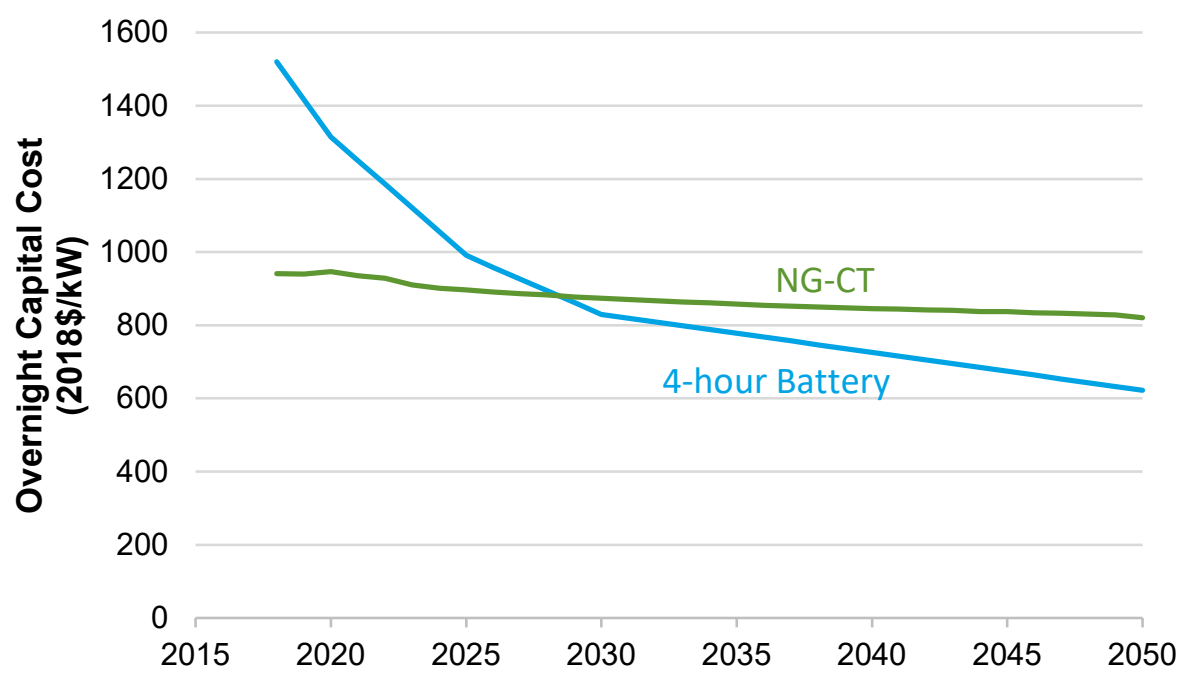

Figure 18. Overnight capital cost of NG-CT and 4-hour batteries over time in the Mid-case scenario. These battery capital costs are used for all scenarios except the Low and High Battery Cost scenarios. These NG-CT costs are used in all scenarios.

\section{Key Insights}

- Wind and PV can be large fractions of total capacity but make up relatively small fractions of the planning reserve requirement. This means that non-variable technologies are still the primary technology used for meeting planning reserve requirements. 
- Wind and PV capacity credit vary by region, season, and penetration level. PV has little capacity credit during the winter but can have a relatively high capacity credit in the summer, especially at lower penetration levels. Wind capacity credit varies less than PV but is influenced by the correlation of wind resources with net load shapes.

- Battery storage could displace a significant amount of NG-CT. Under reference assumptions, battery costs continue to decline. This decline results in batteries becoming the most common type of "peaker plant" deployed in most scenarios. 


\subsection{Regional Generation Mix Trends}

\section{Recent Trends}

Over the last decade, the generation mix has changed in every state in the contiguous United States (see Figure 19). The general trend has been away from coal toward natural gas, wind, and $\mathrm{PV}$, though one state (Arkansas) has increased coal generation over the decade. The generation mix in the southern states has shifted away from coal and toward natural gas, though PV and nuclear generation has increased in some states. Of the northeastern states, Pennsylvania experienced the largest change with a significant shift from coal to natural gas generation. Ohio experienced a similar shift. Several New England states had declines in generation with no corresponding increase, indicating either an increase of imports or reduction in consumption. Central states, from North Dakota down to Texas, have increased wind generation while decreasing in coal or nuclear. The mountain states saw increases in PV, wind, and natural gas, again accompanied by decreases in coal generation. California is unique in that its shift to wind and PV was not at the expense of coal but of natural gas and nuclear.

While the other sections of this report focus largely on national-scale trends, this section looks at regional elements of those trends to highlight that diverse futures impact the various regions in different ways.

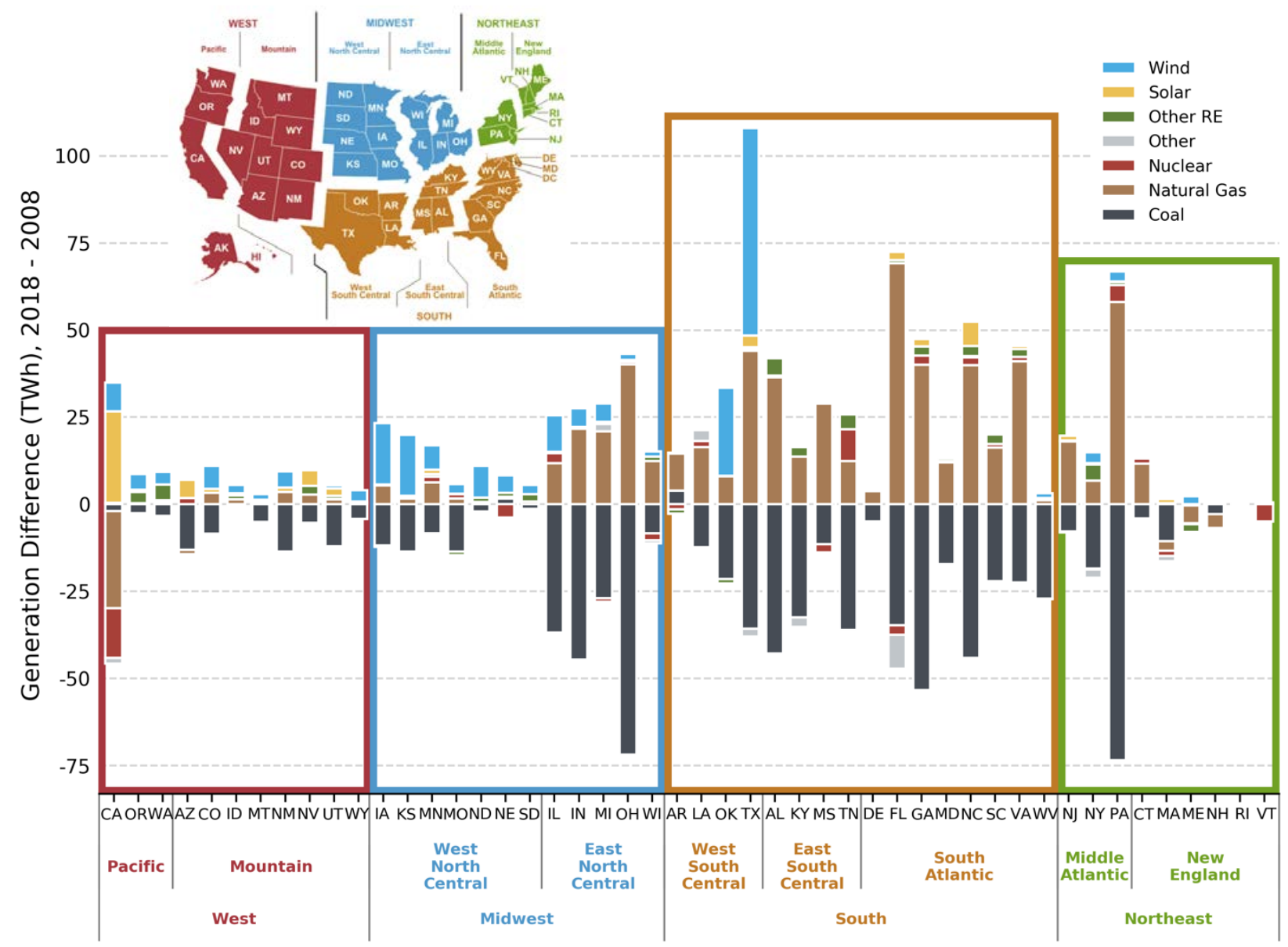

Figure 19. Change in state-level generation mix from 2008 to 2018. Positive values are increases in generation, and negative values are decreases. Census region map is from EIA (2019b). 


\section{Outlook}

The state-level generation mix in 2018 and 2050 in the Mid-case scenario is shown in Figure 3 in Section 3.1. Those changes in generation are specific to the assumptions in the Mid-case scenario, and alternative assumptions will lead to alternative buildouts. The full suite of buildouts can be viewed in the Standard Scenarios' Results Viewer at en.openei.org/apps/reeds. This section primarily focuses on the High RE Cost, Mid-case, and Low RE Cost scenarios to show a range of impacts with higher and lower RE deployment.

Figure 20 shows the penetration of VRE technologies in 2050 for these three scenarios. These are fractions of total instate generation and therefore do not account for imports and exports. The VRE penetration in any given state ranges from 9\% (Louisiana) to $98 \%$ (Rhode Island) in the Mid-case scenario.
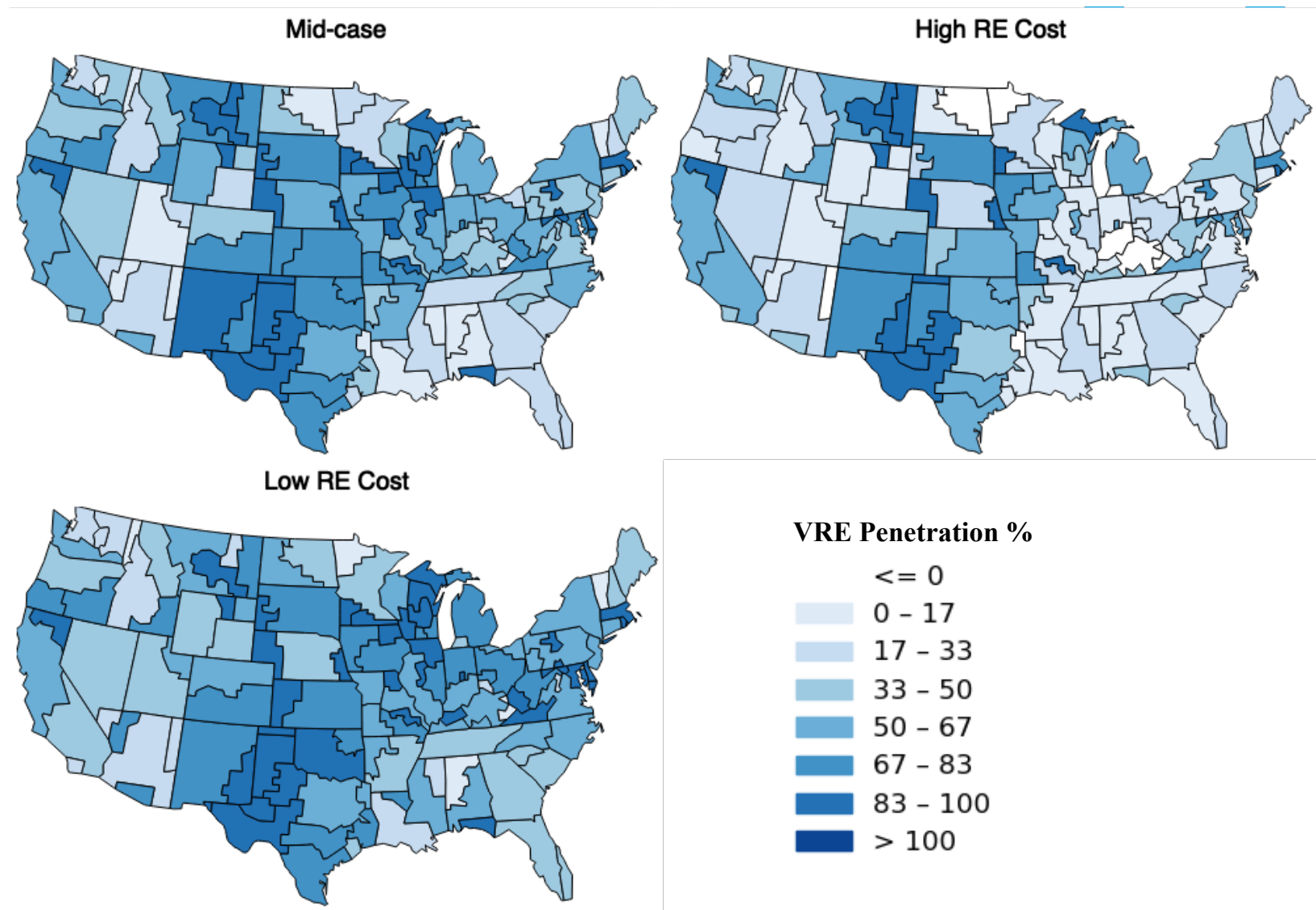

VRE Penetration \%

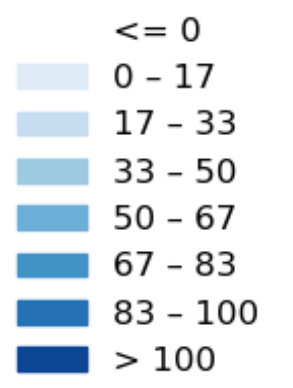

Figure 20. Map of VRE penetration by model region in the Mid-case, Low RE Cost, and High RE Cost scenarios for 2050. States with $100 \%$ CESs can use non-VRE resources such as hydropower, geothermal, biopower, and nuclear to fulfill their clean energy requirement.

Figure 20 demonstrates that the VRE penetrations vary substantially with assumed RE costsacross most states, moving from high-cost to low-cost VRE projections increases the penetration. However, the VRE penetration is relatively constant across these scenarios in some states. This demonstrates the impact of state policies. For example, New Mexico has a 100\% CES and has high VRE penetration independent of the RE costs assumed in the scenarios. Similar trends are 
observed in the northeastern states and California, with policy-driven RE deployment occurring independent of costs.

The increase in VRE deployment leads to increased curtailment rates, meaning that some of the wind or PV generation cannot be absorbed by the grid without taking another action (e.g., building more transmission, adding storage, reducing the minimum generation level in the region). Figure 21 shows the average marginal curtailment rate in each state. For both wind and solar PV, the highest marginal curtailment rates occur in the central United States, where much of the instate generation comes from a combination of wind and solar. This region corresponds with high-quality wind resource, good quality solar resource, and abundant land but relatively low load. Transmission can be a bottleneck for exporting the energy from these states to load centers in other parts of the country. Solar PV also has high marginal curtailment rates in California and the desert Southwest.
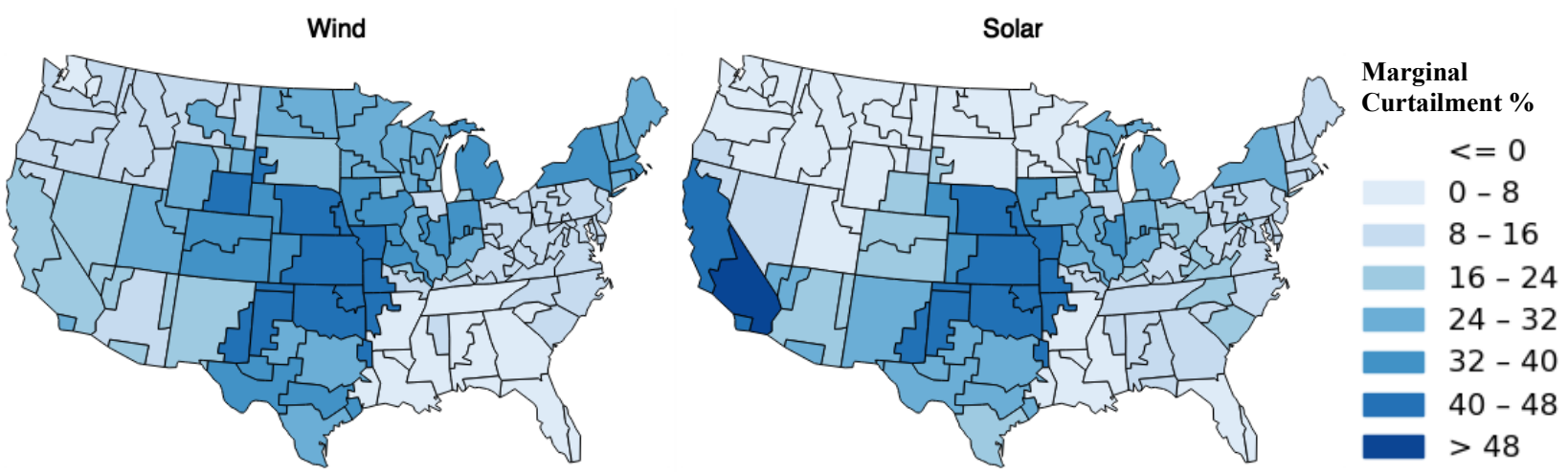

Figure 21. Marginal curtailment rate for wind (left) and utility-scale PV (right) in 2050 for the Midcase by ReEDS balancing area

The Southeast tends to have lower marginal curtailment rates primarily due to lower VRE penetration but also from having a flexible system (primarily with NG-CC units). The Northwest similarly has lower VRE penetration, and their flexibility largely comes from hydropower.

Both PV and wind curtailment are partially mitigated by the deployment of storage, which can absorb some of the wind and PV generation that would otherwise be curtailed. Additionally, long-distance transmission is added across the three scenarios, which helps reduce overall curtailment levels by moving power out of high production areas to load centers. Figure 22 shows the total amount of long-distance transmission capacity in the Mid-case and Low and High RE Cost scenarios. It also shows the Barriers to Transmission scenario for reference. The High RE Cost scenario adds the most transmission through 2050 because with higher RE costs it is more cost effective to share power between regions and to tap into the highest quality RE resources. In the Mid-case and Low RE Cost scenarios, it is often more cost-effective to develop local resources than to access the more distant but higher quality resource. 


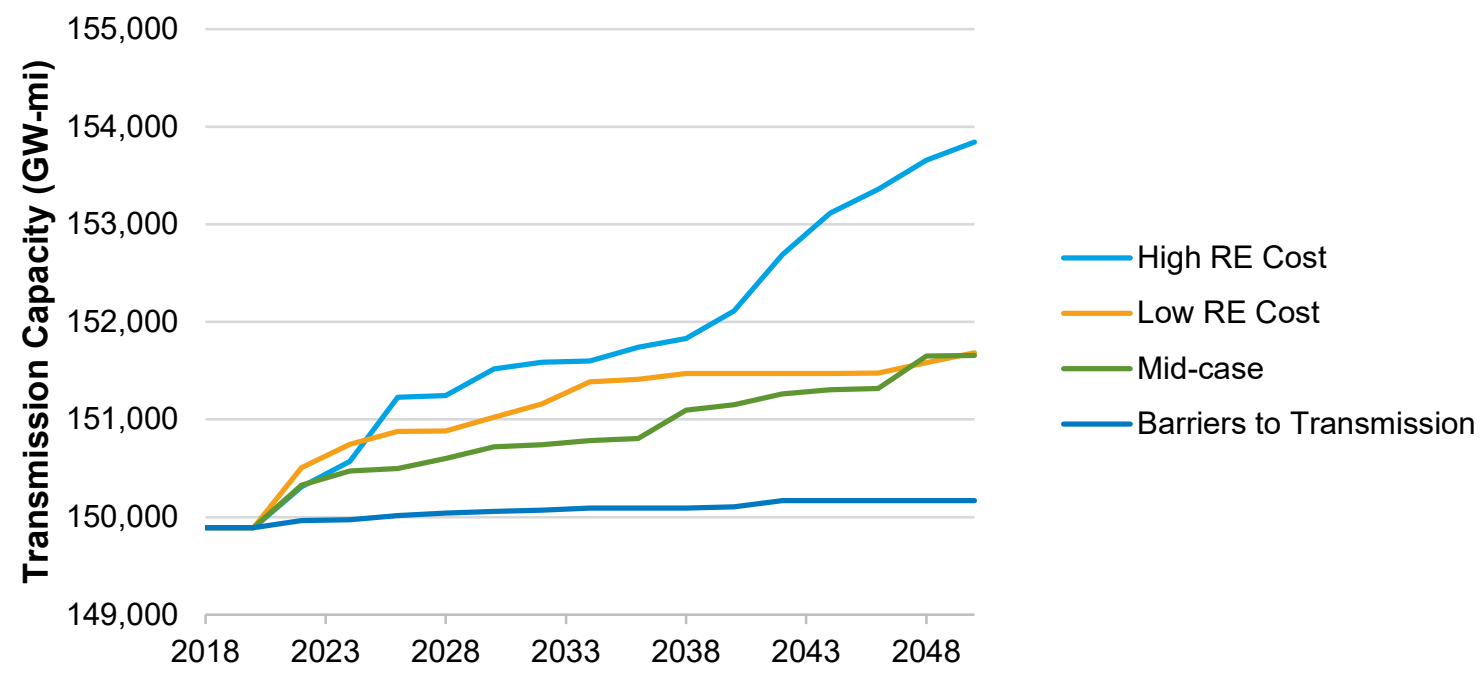

Figure 22. National cumulative long-distance transmission capacity for the scenarios indicated. This does not include the spur line transmission capacity used to connect RE resources into the bulk power system.

The increase in VRE generation sometimes leads to a decrease in electricity prices for certain hours in the year, where hourly electricity prices can be at or near zero during periods of high VRE generation. Using the hourly outputs from the PLEXOS model, Figure 23 shows the spatial distribution of the zero or negative price hours that occur in 2050 in these three scenarios. The regions with the highest fraction of zero price hours occur in the middle of the country at the edges of interconnects where there is high-quality wind resource (and therefore high wind deployment) and/or limited transmission capacity to move power to other regions. The amount of zero price hours is much lower with lower VRE penetration (the High RE Cost scenario) and much higher with higher VRE penetration (the Low RE Cost scenario). The distribution also varies. In the Low RE Cost scenario in 2050, all regions experience $\$ 0 / \mathrm{MWh}$ prices for at least $5 \%$ of hours within the year, while in the High RE Cost scenario, some regions have no hours at $\$ 0 / \mathrm{MWh}$. 

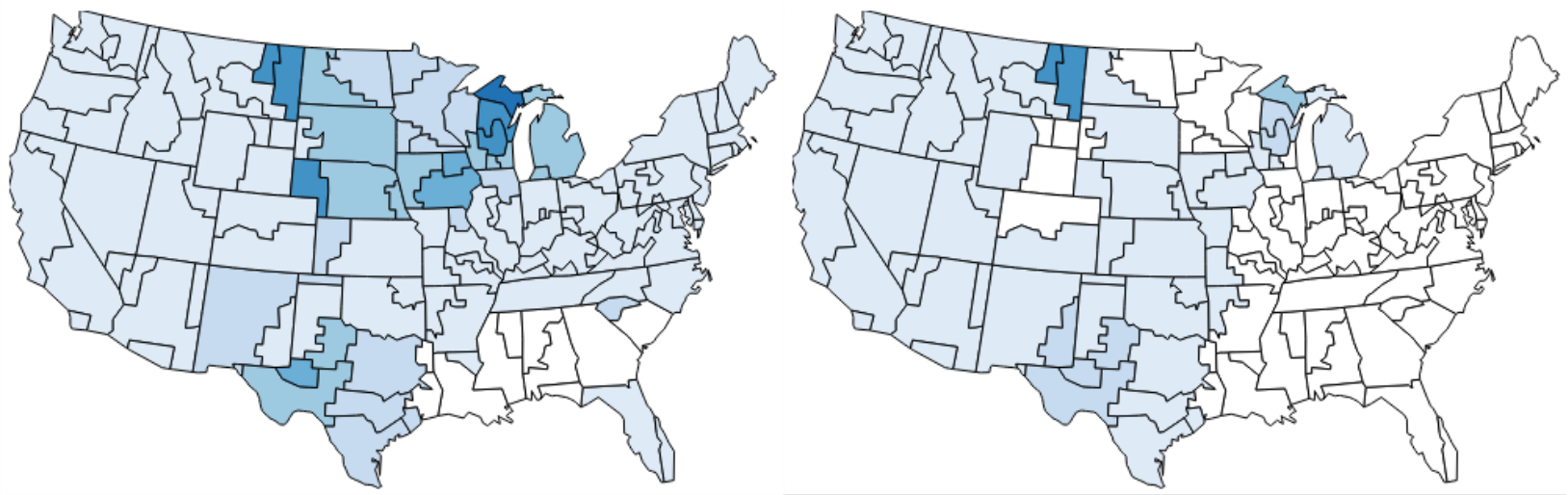

Low RE Cost

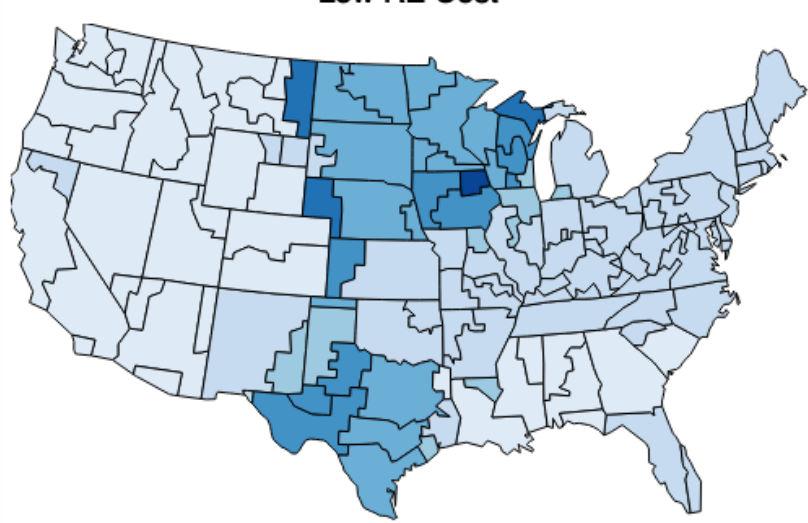

Percent of Hours at or Below \$0/MWh Price

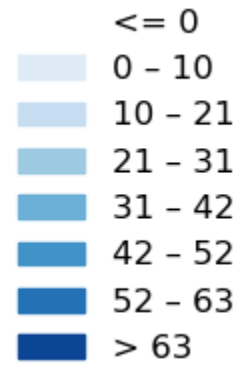

Figure 23. Percent of hours with \$0/MWh electricity prices in $\mathbf{2 0 5 0}$ for the scenarios indicated

Figure 24 shows how the wind and PV capacity factors change as a function of national penetration (where penetration is the fraction of total generation) in the Mid-case scenario. The declining PV capacity factor over time shows that initially PV deploys in regions with higher resource quality but then moves to lower resource quality regions with lower capacity factors. Wind capacity factors are assumed to improve over time due to technology improvements and larger and/or higher configurations. That improvement, coupled with copious wind deployment in high-quality wind regions, leads to the increase in capacity factor over time. So, regions with good resource tend to continue to rely on wind to provide energy, but PV tends to move into all regions irrespective of the quality of the resource. 


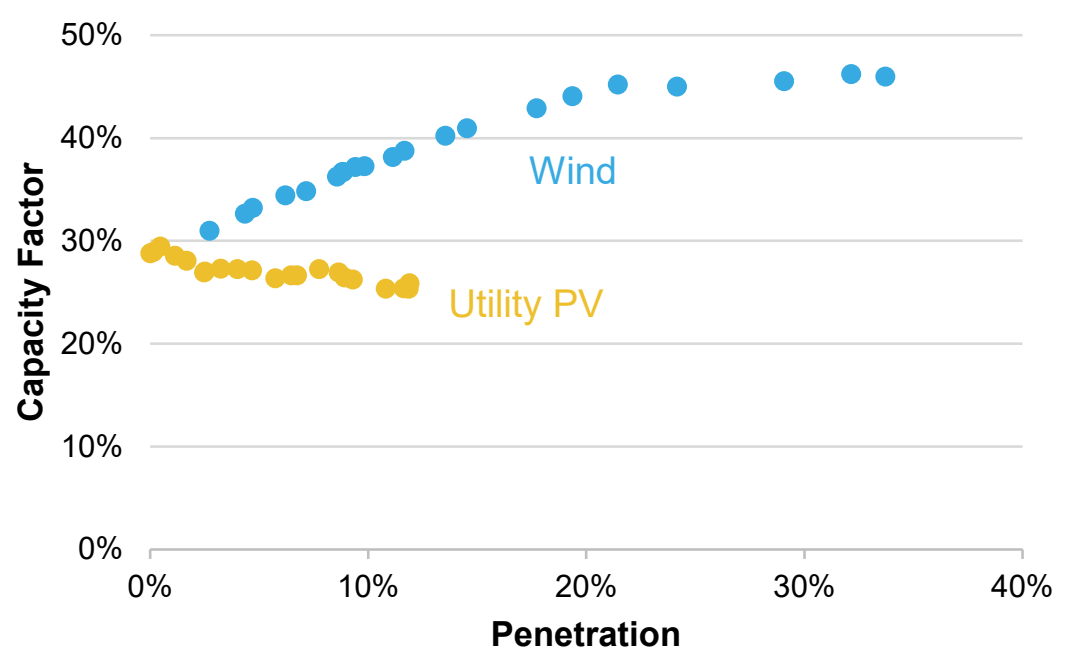

Figure 24. Wind and PV capacity factor versus penetration for the Mid-case scenario. Each point shows a separate year through 2050.

Key Insights

- Regional VRE deployment is driven by resource quality (especially for wind), state policies, and RE costs. VRE deployment varies considerably in most states as VRE costs change. Some states have high VRE deployment independent of cost because of state policy drivers. States with higher resource quality tend to have higher VRE penetration.

- Marginal VRE curtailment rates can be very high and vary by region. VRE curtailment tends to be highest in the central United States, which has good quality wind and solar resources.

- Zero-price hours increase with higher VRE penetration. Zero-price hours occur throughout the country but tend to be more frequent in regions with high VRE penetration and in areas near the edge of an interconnect. 


\section{Summary}

The Standard Scenarios provide a wide range of scenarios for the electricity power sector using complex electricity-sector models. The scenarios provide a benchmark for assessing trends and a data set to help advance thinking of how the power sector might evolve over time. We have highlighted several interesting story lines that we have observed from this suite of scenarios. Obviously, many others could also be considered. The purpose of this work is not to provide exhaustive analysis but to provide a set of data and observations that can help advance critical thinking and decision making in the power sector. Within NREL, we have found significant value in using the Standard Scenario to accelerate analysis and provide a baseline for related work. We share them with the hope that they can be of similar value to other power-sector stakeholders as they make decisions that will influence this constantly changing electricity sector. 


\section{References}

ABB. 2019. “ABB Velocity Suite.” 2019. https://new.abb.com/enterprise-software/energyportfolio-management/market-intelligence-services/velocity-suite.

Barbose, Galen. 2019. "U.S. Renewables Portfolio Standards: 2019 Annual Status Update." Lawrence Berkeley National Laboratory. https://emp.lbl.gov/sites/default/files/2019annual-rps-summary-report.pdf.

Bolinger, Mark. 2014. "An Analysis of the Costs, Benefits, and Implications of Different Approaches to Capturing the Value of Renewable Energy Tax Incentives." LBNL-6610E. Berkeley, CA: Lawrence Berkeley National Laboratory. https://emp.lbl.gov/publications/analysis-costs-benefits-and.

CAISO. 2018. "2018 Interconnection Process Enhancements." California ISO. https://www.caiso.com/Documents/IssuePaper2018InterconnectionProcessEnhancements.pdf.

Cohen, Stuart M., Jonathon Becker, David A. Bielen, Maxwell Brown, Wesley J. Cole, Kelly P. Eurek, Allister Frazier, et al. 2019. "Regional Energy Deployment System (ReEDS) Model Documentation: Version 2018." NREL/TP-6A20-72023. Golden, CO: National Renewable Energy Laboratory. https://doi.org/10.2172/1505935.

Cole, Wesley, Kelly P. Eurek, Nina M. Vincent, Trieu T. Mai, Gregory L. Brinkman, and Matthew Mowers. 2018. "Operating Reserves in Long-Term Planning Models." NREL/PR-6A20-71148. Golden, CO: National Renewable Energy Laboratory. https://doi.org/10.2172/1455165.

Cole, Wesley, and Frazier, A. Will. 2019. "Cost Projections for Utility-Scale Battery Storage." NREL/TP-6A20-73222. Golden, CO: National Renewable Energy Laboratory. https://www.nrel.gov/docs/fy19osti/73222.pdf.

Cole, Wesley, A. Will Frazier, Paritosh Das, Trieu Mai, and Paul Donohoo-Vallett. 2018. "2018 Standard Scenarios Report: A U.S. Electricity Sector Outlook." NREL/TP-6A20-71913. Golden, CO: National Renewable Energy Laboratory. https://doi.org/10.2172/1481848.

Cole, Wesley, Kenneth B. Medlock III, and Aditya Jani. 2016. "A View to the Future of Natural Gas and Electricity: An Integrated Modeling Approach.” Energy Economics 60 (November): 486-96. https://doi.org/10.1016/j.eneco.2016.03.005.

CPUC. 2018. Decision Setting Requirements for Load Serving Entities Filing Integrated Resource Plans. Vol. 16-02-007. http://docs.cpuc.ca.gov/PublishedDocs/Published/G000/M209/K771/209771632.PDF.

Denholm, Paul L., Yinong Sun, and Trieu T. Mai. 2019. “An Introduction to Grid Services: Concepts, Technical Requirements, and Provision from Wind.” NREL/TP-6A20-72578. Golden, CO: National Renewable Energy Laboratory. https://doi.org/10.2172/1493402.

Denholm, Paul, and Robert M. Margolis. 2007. "Evaluating the Limits of Solar Photovoltaics (PV) in Traditional Electric Power Systems." Energy Policy 35 (5): 2852-61. https://doi.org/10.1016/j.enpol.2006.10.014.

Denholm, Paul, Jacob Nunemaker, Pieter Gagnon, and Wesley Cole. 2019. "The Potential for Battery Energy Storage to Provide Peaking Capacity in the United States." NREL/TP6A20-74184. Golden, CO: National Renewable Energy Laboratory. https://www.nrel.gov/docs/fy19osti/74184.pdf.

DOE. 2012. "SunShot Vision Study." DOE/GO-102012-3037. Washington, D.C.: U.S. Department of Energy. http://www.nrel.gov/docs/fy12osti/47927.pdfDOE/GO-1020123037. 
. 2015. "Wind Vision: A New Era for Wind Power in the United States." DOE/GO102015-4557. Washington, D.C.: U.S. Department of Energy. http://www.energy.gov/sites/prod/files/WindVision_Report_final.pdf.

- 2016. "Hydropower Vision: A New Chapter for America's 1st Renewable Electricity Source.” Technical Report DOE/GO-102016-4869. Washington, D.C.: U. S. Department of Energy. http://energy.gov/eere/water/articles/hydropower-vision-new-chapter-americas-1st-renewable-electricity-source.

DOER. 2018. "Electricity Sector Regulations: Fact Sheet.” Boston, MA: Massachusetts Department of Environmental Protection. https://www.mass.gov/files/documents/2018/09/26/3dfs-electricity.pdf.

EIA. 2019a. “Annual Energy Outlook 2019.” Washington, D.C.: U.S. Energy Information Administration. https://www.eia.gov/outlooks/aeo/pdf/aeo2019.pdf. . 2019b. "Commercial Buildings Energy Consumption Survey (CBECS) - U.S. Energy Information Administration (EIA)." 2019. https://www.eia.gov/consumption/commercial/maps.php\#census.

—. 2019c. "Electric Power Monthly." Washington, D.C.: U.S. Energy Information Agency. https://www.eia.gov/electricity/monthly/.

EIPC. 2012. "Phase 2 Report: DOE Draft - Parts 2-7 Interregional Transmission Development and Analysis for Three Stakeholder Selected Scenarios.” Eastern Interconnect Planning Collaborative. http://nebula.wsimg.com/2964d965b867c8786028b950057c7e52?AccessKeyId=E28DF A42F06A3AC21303\&disposition=0\&alloworigin=1.

ERCOT. 2019. "Report on the Capacity, Demand and Reserves (CDR) in the ERCOT Region, 2020-2029." ERCOT. http://www.ercot.com/content/wcm/lists/167023/CapacityDemandandReserveReportMay2019.pdf.

Frew, Bethany A. 2018. "Impact of Dynamic Storage Capacity Valuation in Capacity Expansion Models.” NREL/PR-6A20-71858. Golden, CO: National Renewable Energy Laboratory. https://www.nrel.gov/docs/fy18osti/71858.pdf.

Frew, Bethany, Wesley Cole, Yinong Sun, James Richards, and Trieu Mai. 2017. "8760-Based Method for Representing Variable Generation Capacity Value in Capacity Expansion Models." In . College Park, MD: International Energy Workshop. https://www.nrel.gov/docs/fy17osti/68869.pdf.

Gagnon, Pieter, Robert Margolis, Jennifer Melius, Caleb Phillips, and Ryan Elmore. 2016. "Rooftop Solar Photovoltaic Technical Potential in the United States: A Detailed Assessment." NREL/TP-6A20-65298. Golden, CO: National Renewable Energy Laboratory. https://www.nrel.gov/docs/fy16osti/65298.pdf.

Haratyk, Geoffrey. 2017. "Early Nuclear Retirements in Deregulated US Markets: Causes, Implications and Policy Options." https://assets.documentcloud.org/documents/3723775/MIT-Early-Nuclear-Retirement-32017.pdf.

Holt, Ed. 2016. "Potential RPS Markets for Renewable Energy Generators." Ed Holt \& Associates, Inc. http://www.cesa.org/assets/2016-Files/Potential-RPS-Markets-ReportHolt.pdf. 
Hostick, D., D.B. Belzer, S.W. Hadley, T. Markel, C. Marnay, and M. Kintner-Meyer. 2012. "Renewable Electricity Futures Study Volume 3: End-Use Electricity Demand." NREL/TP-6A20-52409-3. National Renewable Energy Laboratory.

IRENA. 2019. "Renewable Power Generation Costs in 2018." Abu Dhabi: International Renewable Energy Agency. https://www.irena.org/publications/2019/May/Renewablepower-generation-costs-in-2018.

ISO-NE. 2019. https://www.iso-ne.com/staticassets/documents/regulatory/tariff/sect_3/mr1_sec_13_14.pdf.

Kavlak, Goksin, James McNerney, and Jessika E. Trancik. 2018. "Evaluating the Causes of Cost Reduction in Photovoltaic Modules.” Energy Policy 123 (December): 700-710. https://doi.org/10.1016/j.enpol.2018.08.015.

Lew, Debbie, Greg Brinkman, Eduardo Ibanez, Anthony Florita, M. Heaney, Bri-Matthias Hodge, Marissa Hummon, et al. 2013. "The Western Wind and Solar Integration Study Phase 2.” NREL/TP-5500-55588. Golden, CO: National Renewable Energy Laboratory. https://doi.org/10.2172/1095399.

Mai, Trieu, Wesley Cole, Venkat Krishnana, and Mark Bolinger. 2015. "Impact of Federal Tax Policy on Utility-Scale Solar Deployment Given Financing Interactions." NREL/PR6A20-65014. Golden, CO: National Renewable Energy Laboratory.

Mai, Trieu, Jeffrey Logan, Nate Blair, Patrick Sullivan, and Morgan Bazilian. 2013. "REASSUME: A Decision Maker's Guide to Evaluating Energy Scenarios, Modeling, and Assumptions.” http://iea-retd.org/wp-content/uploads/2013/07/RE-ASSUME_IEARETD_2013.pdf.

Mai, Trieu, R. Wiser, D. Sandor, G. Brinkman, G. Heath, P. Denholm, D. J. Hostick, N. Darghouth, A. Schlosser, and K. Strzepek. 2012. "Exploration of High-Penetration Renewable Electricity Futures. Vol. 1 of Renewable Electricity Futures Study." NREL/TP-6A20-52409-1. Golden, CO: National Renewable Energy Laboratory.

Milligan, Michael, Bethany Frew, Eduardo Ibanez, Juha Kiviluoma, Hannele Holttinen, and Lennart Söder. 2017. "Capacity Value Assessments of Wind Power.” Wiley Interdisciplinary Reviews: Energy and Environment 6 (1): e226. https://doi.org/10.1002/wene.226.

Mills, Andrew, and Ryan Wiser. 2012. "Changes in the Economic Value of Variable Generation at High Penetration Levels: A Pilot Case Study of California.” LBNL-5445E. Berkeley, CA: Lawrence Berkeley National Laboratory. http://emp.lbl.gov/sites/all/files/lbnl5445e.pdf.

MISO. 2017. "Planning Year 2018-2019: Wind Capacity Credit." https://cdn.misoenergy.org/2018\%20Wind\%20Capacity\%20Report89288.pdf.

Musial, Walter, Philipp Beiter, Paul Spitsen, Jacob Nunemaker, and Vahan Gevorgian. 2019. “2018 Offshore Wind Technologies Market Report.” 2019. Washington, D.C.: U. S. Department of Energy. https://doi.org/10.2172/1375395.

NEB. 2016. "Canada's Energy Futures 2016: Energy Supply and Demand Projections through 2040.” NE2-12/2015E-PDF. National Energy Board. http://www.nebone.gc.ca/nrg/ntgrtd/ftr/2016/2016nrgftr-eng.pdf. . 2018. "Canada's Energy Futures 2018: Energy Supply and Demand Projections through 2040.” NE2-12/2015E-PDF. National Energy Board. https://www.nebone.gc.ca/nrg/ntgrtd/ftr/2018/index-eng.html. 
NERC. 2017. “2017 Long-Term Reliability Assessment.” North American Electric Reliability Corporation.

https://www.nerc.com/pa/RAPA/ra/Reliability\%20Assessments\%20DL/NERC_LTRA_1 2132017_Final.pdf.

. 2018. “'2018 Long-Term Reliability Assessment." North American Electric Reliability Corporation.

https://www.nerc.com/pa/RAPA/ra/Reliability\%20Assessments\%20DL/NERC_LTRA_2 018_12202018.pdf.

NREL. 2018. “2018 Annual Technology Baseline.” Golden, CO: National Renewable Energy Laboratory. https://atb.nrel.gov/.

—. 2019. "2019 Annual Technology Baseline." Golden, CO: National Renewable Energy Laboratory. https://atb.nrel.gov/.

NYISO. 2019. “Installed Capacity Manual.” New York Independent System Operator. https://www.nyiso.com/documents/20142/2923301/icap_mnl.pdf/234db95c-9a91-66fe7306-2900ef905338.

Pfeifenberger, Johannes P, Kathleen Spees, Kevin Carden, and Nick Wintermantel. 2013. "Resource Adequacy Requirements: Reliability and Economic Implications." The Brattle Group \& Astrape Consulting. https:/www.ferc.gov/legal/staff-reports/2014/02-07-14consultant-report.pdf.

Previsic, Mirko, Jeff Epler, Maureen Hand, Donna Heimiller, Walter Short, and Kelly Eurek. 2012. "The Future Potential of Wave Power in the United States." RE Vision Consulting. http://www.revision.net/documents/The\%20Future $\% 20$ of $\% 20$ Wave $\% 20$ Power\%20MP\%209-20$12 \% 20 \mathrm{~V} 2 . \mathrm{pdf}$.

Reimers, Andrew, Wesley Cole, and Bethany Frew. 2019. "The Impact of Planning Reserve Margins in Long-Term Planning Models of the Electricity Sector." Energy Policy 125 (February): 1-8. https://doi.org/10.1016/j.enpol.2018.10.025.

Rocha-Garrido, Patricio. 2019. "Proposed Changes to PJM Manual 21: Calculation of Capacity Values for Wind and Solar Capacity Resources." PJM. https:/wired.pjm.com//media/committees-groups/subcommittees/irs/20190313/20190313-item-05-calculationof-capacity-values-for-wind-and-solar-capacity-resources.ashx.

Sigrin, Benjamin, Michael Gleason, Robert Preus, Ian Baring-Gould, and Robert Margolis. 2016. "The Distributed Generation Market Demand Model (DGen): Documentation." NREL/TP-6A20-65231. Golden, CO: National Renewable Energy Laboratory. http://www.nrel.gov/docs/fy16osti/65231.pdf.

Sigrin, Benjamin, and Meghan Mooney. 2018. "Rooftop Solar Technical Potential for Low-toModerate Income Households in the United States.” NREL/TP-6A20-70901. Golden, CO: National Renewable Energy Laboratory. https://www.nrel.gov/docs/fy18osti/70901.pdf.

SPP. 2017a. "2019 Integrated Transmission Planning Assessment Scope." Southwest Power Pool. o https://www.spp.org/documents/56206/2019\%20itp\%20scope\%20final.docx.

- 2017b. "Wind and Solar Report." Southwest Power Pool. https://www.spp.org/documents/53721/sawg\%20approved_wind\%20and\%20solar\%20re port.pdf.

Steckler, Nicholas. 2017. "Half of U.S. Nuclear Power Plants Are Underwater.” Bloomberg New Energy Finance. 
Stehly, Tyler J., Philipp C. Beiter, Donna M. Heimiller, and George N. Scott. Forthcoming. "2018 Cost of Wind Energy Review." NREL/TP-5000-74598. Golden, CO: National Renewable Energy Laboratory. https://doi.org/10.2172/1475534.

Tidball, Rick, Joel Bluestein, Nick Rodriguez, and Stu Knoke. 2010. "Cost and Performance Assumptions for Modeling Electricity Generation Technologies." NREL/SR-6A2048595. Golden, CO: National Renewable Energy Laboratory. http://www.nrel.gov/docs/fy11osti/48595.pdf.

Vajjhala, Shalini P, and Paul S Fischbeck. 2007. "Quantifying Siting Difficulty: A Case Study of US Transmission Line Siting.” Energy Policy 35 (1): 650-71.

Wiser, Ryan, and Mark Bolinger. 2018. "2017 Wind Technologies Market Report." Berkeley, CA: Lawrence Berkeley National Laboratory. https://doi.org/10.2172/1471044.

Wiser, Ryan, Andrew Mills, Joachim See, Todd Levin, and Audun Botterud. 2017. "Impacts of Variable Renewable Energy on Bulk Power System Assets, Pricing, and Costs." LBNL2001082. Berkeley, CA: Lawrence Berkeley National Laboratory.

https://emp.lbl.gov/sites/default/files/lbnl_anl_impacts_of_variable_renewable_energy_fi nal.pdf.

Wood Mackenzie. 2018. "Global Wind Turbine Technology Market Report 2018.” Wood Mackenzie. https://www.woodmac.com/reports/power-markets-global-wind-turbinetechnology-market-report-2018-37070.

Zhou, Ella, Wesley Cole, and Bethany Frew. 2018. "Valuing Variable Renewable Energy for Peak Demand Requirements.” Energy 165 (December): 499-511. https://doi.org/10.1016/j.energy.2018.09.009. 


\section{Appendix}

\section{A.1 Standard Scenarios Input Assumptions}

This section describes the input assumptions used in the scenarios listed in Table A-1. For details about model assumptions, see the documentation for ReEDS (Cohen et al. 2019) and dGen (Sigrin et al. 2016).

Table A-1. Summary of the 2019 Standard Scenarios. The scenario settings listed in blue italics correspond to the settings used in the Mid-case scenario, which is used in this analysis to reflect "business-as-usual" conditions.

\begin{tabular}{|c|c|c|}
\hline Group & Scenario Setting & Notes \\
\hline \multirow{4}{*}{$\begin{array}{l}\text { Electricity Demand } \\
\text { Growth }\end{array}$} & Reference Demand Growth & $\begin{array}{l}\text { AEO } 2019 \text { reference scenario growth } \\
\text { rate }\end{array}$ \\
\hline & Low Demand Growth & $\begin{array}{l}\text { AEO } 2019 \text { low economic growth scenario } \\
\text { growth rate }\end{array}$ \\
\hline & High Demand Growth & $\begin{array}{l}\text { AEO } 2019 \text { high economic growth } \\
\text { scenario growth rate }\end{array}$ \\
\hline & Vehicle Electrification & $\begin{array}{l}\text { Adoption of plug-in electric vehicles and } \\
\text { plug-in hybrid electric vehicles reaches } \\
40 \% \text { of sales by } 2050 ; 45 \% \text { of charging } \\
\text { utility-controlled, } 55 \% \text { opportunistic }\end{array}$ \\
\hline \multirow{3}{*}{ Fuel Prices } & Reference Natural Gas Prices & AEO 2019 reference ${ }^{a}$ \\
\hline & Low Natural Gas Prices & $\begin{array}{l}\text { AEO } 2019 \text { high oil and gas resource } \\
\text { and technology }\end{array}$ \\
\hline & High Natural Gas Prices & $\begin{array}{l}\text { AEO } 2019 \text { low oil and gas resource } \\
\text { and technology }\end{array}$ \\
\hline \multirow{5}{*}{$\begin{array}{l}\text { Electricity } \\
\text { Generation } \\
\text { Technology Costs }\end{array}$} & Mid Technology Cost & $\begin{array}{l}2019 \text { Annual Technology Baseline (ATB) } \\
\text { mid-case projections }\end{array}$ \\
\hline & Low RE ${ }^{b}$ Cost & $\begin{array}{l}2019 \text { ATB renewable energy low- } \\
\text { case projections }\end{array}$ \\
\hline & High RE Cost & $\begin{array}{l}2019 \text { ATB renewable energy constant- } \\
\text { case projections }\end{array}$ \\
\hline & Low Wind Cost & $\begin{array}{l}2019 \text { ATB low-case projection for land- } \\
\text { based and offshore wind }\end{array}$ \\
\hline & High Wind Cost & $\begin{array}{l}2019 \text { ATB constant-case projection for } \\
\text { land-based and offshore wind }\end{array}$ \\
\hline
\end{tabular}




\begin{tabular}{|c|c|c|}
\hline Group & Scenario Setting & Notes \\
\hline & Low PV Cost & 2019 ATB low-case projection for PV \\
\hline & High PV Cost & 2019 ATB constant-case projection for PV \\
\hline & Low Geothermal Cost & $\begin{array}{l}2019 \text { ATB low-case projection for } \\
\text { geothermal }\end{array}$ \\
\hline & High Geothermal Cost & $\begin{array}{l}2019 \text { ATB constant-case projection for } \\
\text { geothermal }\end{array}$ \\
\hline & Low CSPc Cost & 2019 ATB low-case projection for CSP \\
\hline & High CSP Cost & 2019 ATB constant-case projection for CSP \\
\hline & Low Hydro Cost & 2019 ATB low-case projection for hydro \\
\hline & High Hydro Cost & $\begin{array}{l}2019 \text { ATB constant-case projection for } \\
\text { hydro }\end{array}$ \\
\hline & Low Offshore Wind Cost & $\begin{array}{l}2019 \text { ATB low-case projection for } \\
\text { offshore wind }\end{array}$ \\
\hline & High Offshore Wind Cost & $\begin{array}{l}2019 \text { ATB constant-case projection for } \\
\text { offshore wind }\end{array}$ \\
\hline & $\begin{array}{l}\text { Nuclear Technology } \\
\text { Breakthrough }\end{array}$ & $\begin{array}{l}50 \% \text { reduction in nuclear capital costs } \\
\text { over all years }\end{array}$ \\
\hline \multirow{3}{*}{$\begin{array}{l}\text { Battery Storage } \\
\text { Costs }\end{array}$} & Mid Battery Storage Cost & Mid-case projection from 2019 ATB \\
\hline & Low Battery Storage Cost & Low-case projection from 2019 ATB \\
\hline & High Battery Storage Cost & High-case projection from 2019 ATB \\
\hline \multirow{3}{*}{$\begin{array}{l}\text { Financing } \\
\text { Assumptions }\end{array}$} & Mid Finance Projections & $\begin{array}{l}\text { Financing values from } 2019 \text { ATB with the } \\
\text { 20-year capital recovery period }\end{array}$ \\
\hline & Shortened Cost Recovery & Capital recovery period of 10 years \\
\hline & Extended Cost Recovery & Capital recovery period of 30 years \\
\hline $\begin{array}{l}\text { Existing Fleet } \\
\text { Retirements }\end{array}$ & Reference Retirement & $\begin{array}{l}\text { Lifetime retirements for non-nuclear } \\
\text { based on plant age; at-risk nuclear } \\
\text { retired at } 60 \text { years, all other nuclear at } 80 \\
\text { years }\end{array}$ \\
\hline
\end{tabular}




\begin{tabular}{|c|c|c|}
\hline Group & Scenario Setting & Notes \\
\hline & Accelerated Retirements & $\begin{array}{l}\text { Coal plant lifetimes reduced by } 10 \text { years; } \\
\text { at-risk nuclear plants retired at } 50 \text { years, all } \\
\text { nuclear plants at } 60 \text { years }\end{array}$ \\
\hline & Extended Lifetimes & $\begin{array}{l}\text { Coal plant lifetimes increased by } 10 \text { years; } \\
\text { no retirement of underutilized coal plants; } \\
\text { all nuclear plants have } 80 \text {-year life }\end{array}$ \\
\hline & Endogenous Retirements & $\begin{array}{l}\text { Plant retirements are determined by the } \\
\text { model; plants with negative revenues will } \\
\text { be retired }\end{array}$ \\
\hline \multirow{2}{*}{ Foresight } & No Foresight & $\begin{array}{l}\text { Model solves each two-year period } \\
\text { without any look-ahead }\end{array}$ \\
\hline & Perfect Foresight & Model solves for all years simultaneously \\
\hline \multirow{3}{*}{$\begin{array}{l}\text { Resource and } \\
\text { System } \\
\text { Constraints }\end{array}$} & Default Resource Constraints & See ReEDS documentation for details \\
\hline & Reduced RE Resource & $\begin{array}{l}25 \% \text { reduction to all resource classes in } \\
\text { input supply curves }\end{array}$ \\
\hline & $\begin{array}{l}\text { Barriers to Transmission } \\
\text { System Expansion }\end{array}$ & $\begin{array}{l}3 x \text { transmission capital cost } \\
2 x \text { transmission loss factors }\end{array}$ \\
\hline $\begin{array}{l}\text { Policy/Regulatory } \\
\text { Environment }\end{array}$ & Current Law & $\begin{array}{l}\text { Includes state, regional, and federal } \\
\text { policies as of July 31, } 2019\end{array}$ \\
\hline \multirow{4}{*}{$\begin{array}{l}\text { Combination } \\
\text { Scenarios }\end{array}$} & $\begin{array}{l}\text { Low Natural Gas Prices \& Low } \\
\text { RE Cost }\end{array}$ & $\begin{array}{l}\text { AEO } 2019 \text { High Oil and Gas Resource } \\
\text { and Technology and } 2019 \text { ATB } \\
\text { Renewable Low-Case Projections }\end{array}$ \\
\hline & $\begin{array}{l}\text { High Natural Gas Prices \& Low } \\
\text { RE Cost }\end{array}$ & $\begin{array}{l}\text { AEO } 2019 \text { Low Oil and Gas Resource } \\
\text { and Technology and } 2019 \text { ATB } \\
\text { Renewable Low-Case Projections }\end{array}$ \\
\hline & $\begin{array}{l}\text { Low Natural Gas Prices \& High } \\
\text { RE Cost }\end{array}$ & $\begin{array}{l}\text { AEO } 2019 \text { High Oil and Gas Resource } \\
\text { and Technology and } 2019 \text { ATB } \\
\text { Renewable High-Case Projections }\end{array}$ \\
\hline & $\begin{array}{l}\text { High Natural Gas Prices \& High } \\
\text { RE Cost }\end{array}$ & $\begin{array}{l}\text { AEO } 2019 \text { Low Oil and Gas Resource } \\
\text { and Technology and } 2019 \text { ATB } \\
\text { Renewable High-Case Projections }\end{array}$ \\
\hline
\end{tabular}

a Natural gas prices are based on Annual Energy Outlook (AEO) 2019 electricity sector natural gas prices but are not identical due to natural gas price elasticities. See Appendix A.1.1.

${ }^{\mathrm{b}} \mathrm{RE}=$ renewable energy

${ }^{c} \mathrm{CSP}=$ concentrating solar power 


\section{A.1.1 Fuel Prices}

The natural gas input price points are based on the trajectories from AEO 2019 (EIA 2019a). The prices are shown in Figure A-1 (left) and are from the AEO 2019 Reference scenario, the Low Oil and Gas Resource and Technology scenario, and the High Oil and Gas Resource and Technology scenarios (EIA 2019a). Actual natural gas prices in ReEDS are based on the AEO scenarios, but they are not exactly the same; instead, they are price-responsive to ReEDS natural gas demand. Each census region includes a natural gas supply curve that adjusts the natural gas input price based on both regional and national demand (Cole, Medlock III, and Jani 2016). The reference coal and uranium price trajectories are from the AEO 2019 Reference scenario and are shown in Figure A-1 (right). Both coal and uranium prices are assumed to be fully inelastic. Figure A-1 shows the national prices for the resources, but input prices for ReEDS are taken from the AEO 2019 census region projections.
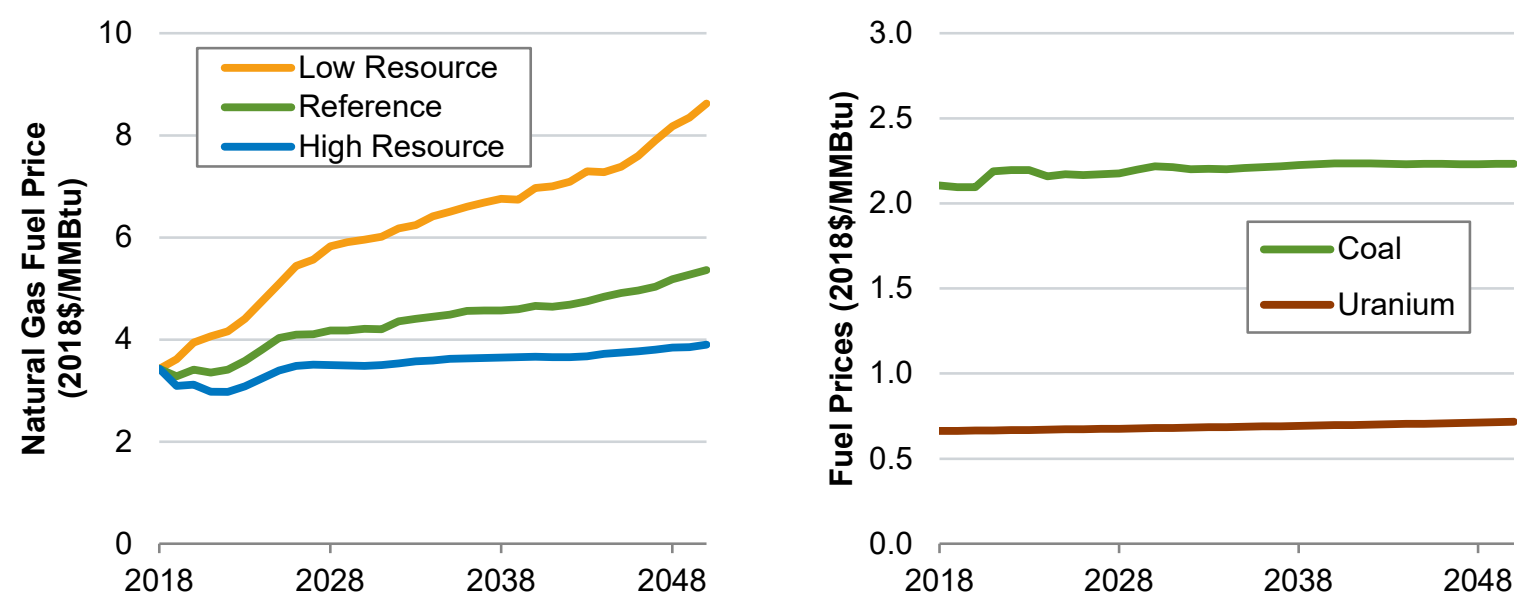

Figure A-1. Fuel price trajectories used in the Standard Scenarios

\section{A.1.2 Demand Growth}

The Mid-case scenario is based on the AEO 2019 Reference scenario load growth (EIA 2019a). The high- and low-load growth scenarios are also from AEO 2019, based on the Low and High Economic Growth scenarios, which use lower/higher rates of population growth, productivity, and lower/higher inflation than the Reference scenario (see Figure A-2). We assume inelastic electricity demand in all scenarios presented. 


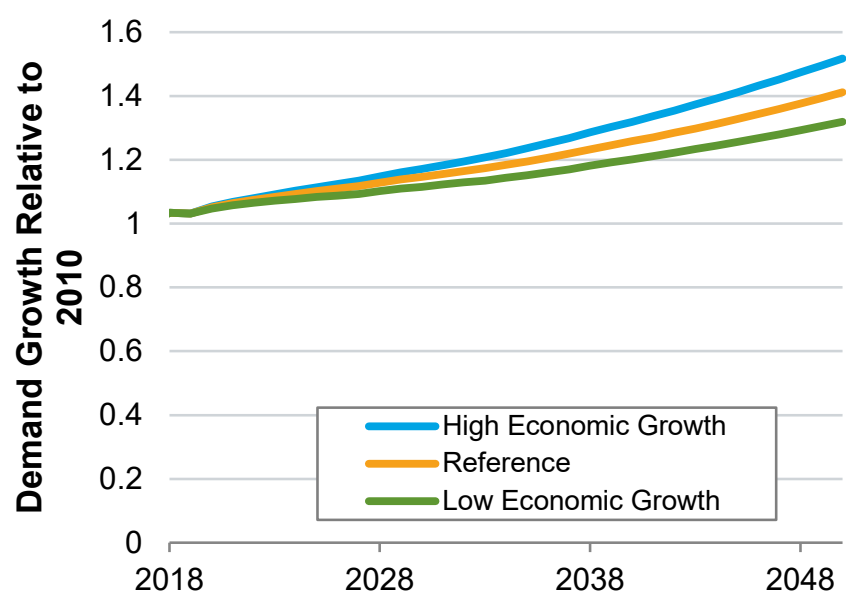

Figure A-2. Demand growth trajectories used in the Standard Scenarios

\section{A.1.3 Technology Cost and Performance}

Except for the 2018 ATB scenario, technology cost and performance assumptions are taken from the 2019 ATB (NREL 2019). The ATB includes low, mid, and high (constant) cost and performance projections through 2050 for the generating and storage technologies used in the ReEDS and dGen models. The Low RE Cost scenario uses the low cost projections for all RE technologies, and the High RE Cost scenario uses the high cost projection. The high cost projection uses constant costs at or near the 2019 cost for the full projection period. The Low and High PV Cost scenarios use the low cost projections for both utility and distributed PV technologies, and the Low and High Wind Cost scenario uses the low and high cost projections for both land-based and offshore wind technologies. The Low and High Geo Cost, Hydro Cost, CSP cost, and Offshore Wind Cost scenarios use the low and high cost projections for the technology defined in the scenario name. The Low and High Battery Cost scenarios use the low and high battery cost projections. Batteries are assumed to be 4 -hour batteries with $85 \%$ roundtrip efficiency and a 15-year lifetime.

The 2018 ATB scenario uses the mid cost and performance assumptions from the 2018 ATB (NREL 2018). All other inputs, including fuel prices, are unchanged.

\section{A.1.4 Existing Fleet Retirements}

Retirements for conventional power plants are made based on age (unless an official retirement date has been announced), with plant online dates taken from the National Energy Modeling System (NEMS) plant database for the AEO 2019 (EIA 2019a). Tables A-2 and A-3 show the plant lifetime assumptions used in ReEDS. For the Endogenous Retirements scenario, conventional power plants are still required to retire at their age-based retirement date but are allowed to be retired before their age-based retirement date if the model deems it cost-optimal to do so. 
Table A-2. Lifetimes of Renewable Energy Generators and Batteries (Cohen et al. 2019)

\begin{tabular}{lcl}
\hline Technology & $\begin{array}{c}\text { Lifetime } \\
\text { (Years) }\end{array}$ & Source \\
\hline Land-based Wind & 24 & Wind Vision (DOE 2015) \\
Offshore Wind & 24 & Wind Vision (DOE 2015) \\
Solar Photovoltaic & 30 & SunShot Vision (DOE 2012) \\
Concentrating Solar Power & 30 & SunShot Vision (DOE 2012) \\
Geothermal & 30 & Renewable Electricity Futures Study, Vol. 1 (Mai et \\
& & al. 2012) \\
Hydropower & 100 & Hydropower Vision (DOE 2016) \\
Biopower & 50 & ABB (2010) \\
Marine Hydrokinetic & 20 & Previsic et al. (2012) \\
Battery & 15 & (Cole, Wesley and Frazier, A. Will 2019) \\
\hline
\end{tabular}

Table A-3. Lifetimes of Conventional Energy Generators (Cohen et al. 2019)

\begin{tabular}{lcc}
\hline Technology & $\begin{array}{c}\text { Lifetime less than } \\
\text { (Years) }\end{array}$ & $\begin{array}{c}\text { Lifetime greater or equal } \\
\text { to 100 MW (Years) }\end{array}$ \\
\hline Gas Combustion Turbine & 50 & 50 \\
Gas Combined Cycle and CCS & 60 & 60 \\
Coal, all techs, including cofired & 65 & 75 \\
Oil-Gas-Steam & 50 & 75 \\
Compressed-Air Energy Storage & 100 & 100 \\
\hline
\end{tabular}

The nuclear retirement lifetimes were defined by dividing the currently operating reactors into one of two bins. Any plants participating in a restructured market and all single-reactor plants were assigned to Bin 1 . The remaining plants, which were all multi-reactor plants in a traditional regulated environment, were assigned to Bin 2 . The only exception to this categorization was that the two plants that have announced their intent to seek a second operating license renewal from the Nuclear Regulatory Commission are included in Bin 2. Table A-4 breaks down the bins and shows total capacity in each case. These bins are not meant to be predictions of which plants are more "at-risk" or more likely to retire. Rather, they represent a simple categorization that reflects the current discussion, which points to more economic pressure for restructured and single-reactor units (Haratyk 2017; Steckler 2017). Current under-construction nuclear power plants are assumed to come online according to the online dates in the AEO 2019 NEMS database (EIA 2019a).

The Mid-case scenario uses a mix of 60- and 80-year plant lifetimes for nuclear power plants (see Table A-5). The Accelerated Retirements scenario shortens the nuclear lifetimes, as shown in Table A-5, and decreases coal plant lifetimes by 10 years. The Extended Lifetimes scenario sets all nuclear power plant lifetimes to 80 years and increases coal plant lifetimes by 10 years. 
Table A-4. Amount of Nuclear Power Plant Capacity (in GW) in Each Bin

\begin{tabular}{|l|c|c|}
\hline Reactor Type & Bin 1 & Bin 2 \\
\hline Restructured, single reactor & 8.7 & - \\
\hline Restructured, multi reactor & 27.5 & $2.0^{\mathrm{a}}$ \\
\hline Regulated, single reactor & 15.7 & - \\
\hline Regulated, multi reactor & - & 42.1 \\
\hline Total & $\mathbf{5 1 . 9}$ & $\mathbf{4 4 . 1}$ \\
\hline
\end{tabular}

a Because the Peach Bottom plant $(2.0 \mathrm{GW})$ has announced its intent to seek a second license renewal, it is assigned to Bin 2 even though it is in a restructured market.

Table A-5. Nuclear Power Plant Lifetime (in Years) for Each Scenario by Bin

\begin{tabular}{|l|r|r|}
\hline Scenario Name & Bin 1 & Bin 2 \\
\hline Accelerated Retirements & 50 & 60 \\
\hline Mid-case & 60 & 80 \\
\hline Extended Lifetimes & 80 & 80 \\
\hline
\end{tabular}

\section{A.1.5 Vehicle Electrification}

The Vehicle Electrification scenario assumes $40 \%$ of passenger vehicle sales are electric vehicles in 2050. The charging profile defined for this scenario assumes that 55\% (energy-basis) was owner-controlled (static, evening-weighted), and the utility/model could control timing of the remaining $45 \%$. The dynamic-charging portion is a model decision, and ReEDS can choose how to distribute the charging across the day. For details about how the charging demand and profiles were developed, see Appendix K of the Renewable Electricity Futures Study, Volume 3 (Hostick et al. 2012). ${ }^{16}$

\section{A.1.6 Reduced Renewable Energy Resource}

This scenario reduces the amount of RE resource available in the model for building new RE generators. Specifically, the scenario reduces modeled wind, PV, CSP, geothermal, hydropower, ${ }^{17}$ and biopower technical potential by $25 \%$. The reduction is applied uniformly across geography and resource classes (i.e., all regions and classes experience the same $25 \%$ reduction). This scenario provides a sensitivity to estimates of technical potential for RE resources.

\section{A.1.7 Barriers to Transmission System Expansion}

The ReEDS model assumes new transmission lines can be constructed as needed, at costs taken from the Eastern Interconnection Planning Collaborative (EIPC 2012) on regional transmission development and extrapolated to the contiguous United States (DOE 2015). Those cost assumptions include regional multipliers that imply higher siting and construction costs in certain areas, notably California and the Northeast. Only existing transmission connections can be

\footnotetext{
${ }^{16}$ The National Economic Value Assessment of Plug-In Electric Vehicles (Melaina et al. 2016) uses ReEDS and other models to provide another assessment of electric vehicles and their impacts to the electricity system under different charging regimes.

17 This reduction does not apply to pumped-storage hydropower.
} 
expanded except for AC-DC-AC interties, where expansion is not allowed. This scenario takes the EIPC-sourced siting difficulties a step further, reflecting a concern that transmission-line siting is and will continue to be difficult and expensive (Vajjhala and Fischbeck 2007). As a proxy for explicit barriers to transmission expansion, this scenario bars any new interconnection interties, triples the capital cost of any new inter-balancing authority transmission capacity, and doubles the transmission loss rate from $1 \%$ to $2 \%$ per 100 miles. Renewable generator spur line costs are unaffected. The higher rate of transmission losses generally discourages relying on the transmission system to transmit power long distances.

\section{A.1.8 Nuclear Technology Breakthrough}

This scenario explores a future in which nuclear fission-generating technologies have growing public support and see increased technological advancement. The Nuclear Breakthrough scenario implements a 50\% reduction in the overnight capital costs for new nuclear power plants. Other cost and performance assumptions for nuclear power plants remain unchanged.

\section{A.1.9 Financing Costs}

The Mid-case scenario uses the financing assumptions from the 2019 ATB (NREL 2019) market factors, except that the Mid-case uses a 20-year cost recovery period rather than a 30-year period. The interest and equity rates in the ATB change over time. Other financial assumptions, such as debt fractions and Modified Accelerated Cost Recovery System schedules are technology specific and vary over time. The Extended Cost Recovery scenario uses these same technologyspecific financing assumptions, but it uses a 30-year cost recovery period for all technologies in place of the 20 -year recovery period. The Shortened Cost Recovery scenario uses a 10 -year cost recovery period.

\section{A.1.10 Perfect Foresight}

All scenarios except for the Perfect Foresight scenario use a sequential, myopic approach. For example, the model will solve for the year 2020, update relevant parameters, then solve 2022, update parameters, solve 2024, etc., through 2050. In the Perfect Foresight scenario, the model is solved intertemporally such that all years are solved at the same time. This framework enables the model to have perfect foresight (e.g., the model has perfect information about costs in 2040 while it makes build decisions in 2020).

The intertemporal solution results in a much larger model size and is more difficult to solve. Because of this added difficulty, the Perfect Foresight scenario only solves for even years through 2030. After 2030, the model only considers 2035, 2040, 2045, and 2050. ${ }^{18}$

\section{A.2 Changes from the 2019 Edition}

Since last year's Standard Scenarios report (Cole, Frazier, et al. 2018), a variety of key modeling changes have been made in the ReEDS and dGen models. Most notably, the ReEDS model was rewritten, with the new version called ReEDS 2.0. ReEDS 2.0 includes many additional model features, such as the ability to solve sequentially, using a window solve, or intertemporally (as is done in the Perfect Foresight scenario); endogenous retirements (used in the Endogenous

\footnotetext{
${ }^{18}$ Because the online scenario viewer (https://openei.org/apps/reeds/) only shows data even years, the 2035 and 2045 solutions will not show up in the viewer.
} 
Retirements scenario); flexible solve year definitions; and simplified model structure. In addition to the change in model version, other model changes are summarized in Tables A-6 and A-7.

New scenarios in this year's report include Endogenous Retirements, Shortened Cost Recovery, and Perfect Foresight, as well as the High Wind, PV, Hydro, Geo, CSP, and Offshore Wind scenarios. The combination scenarios that included low or high NG prices coupled with an individual low RE cost are no longer included. The Early Nuclear Retirements, 60-year Nuclear Lifetime, and 80-year Nuclear Lifetime have also been dropped in this year's edition. The Impacts of Climate Change and Restricted Cooling Water Use scenarios were not included in the 2019 edition because the model features needed for those scenarios have not yet been included in ReEDS 2.0. We anticipate that they will be included in the 2020 edition. The three policy scenarios (Carbon Cap, National 80\% RPS, and Tax Credit Extension) have also been removed.

Table A-6. Key Differences in Model Inputs and Treatments for ReEDS Model Versions. The 2018 version was used in the 2018 Standard Scenarios report (Cole, Frazier, et al. 2018), and the 2019 version is used for this report.

\begin{tabular}{|c|c|c|}
\hline $\begin{array}{l}\text { Inputs and } \\
\text { Treatments }\end{array}$ & 2018 Version (June 2018) & 2019 Version (July 2019) \\
\hline Base ReEDS model & Heritage ReEDS version & ReEDS 2.0 \\
\hline Fuel prices & AEO 2018 & AEO 2019 \\
\hline Demand growth & AEO 2018 & AEO 2019 \\
\hline $\begin{array}{l}\text { Generator } \\
\text { technology cost, } \\
\text { performance, and } \\
\text { financing }\end{array}$ & ATB $2018^{a}$ & ATB 2019a \\
\hline Tax credit penalty & $\begin{array}{l}\text { Estimated using a change in equity } \\
\text { fraction that was proportional to the } \\
\text { tax credit (Mai et al. 2015) }\end{array}$ & $\begin{array}{l}\text { Set at } 1 / 3 \text { of the value of the tax } \\
\text { credit (Bolinger 2014) }\end{array}$ \\
\hline $\begin{array}{l}\text { Wind supply curves } \\
\text { and profiles }\end{array}$ & Based on a 2016 vintage wind turbine & $\begin{array}{l}\text { Based on an estimated } 2030 \\
\text { vintage wind turbine (Wood } \\
\text { Mackenzie 2018; Stehly et al. } \\
\text { Forthcoming) }\end{array}$ \\
\hline $\begin{array}{l}\text { Existing fleet, } \\
\text { retirements, and } \\
\text { prescribed builds }\end{array}$ & ABB Velocity Suite from May 2018 & $\begin{array}{l}\text { NEMS plant database from AEO } \\
2019\end{array}$ \\
\hline $\begin{array}{l}\text { Storage capacity } \\
\text { credit }\end{array}$ & $\begin{array}{l}\text { Varies based on storage and PV } \\
\text { penetration (Frew 2018) }\end{array}$ & $\begin{array}{l}\text { Varies based on load shape, wind, } \\
\text { PV, and storage penetration }\end{array}$ \\
\hline $\begin{array}{l}\text { Storage curtailment } \\
\text { recovery }\end{array}$ & $\begin{array}{l}\text { If storage charges during a timeslice } \\
\text { with curtailment, it reduces } \\
\text { curtailment by } 1 \mathrm{MWh} \text { for every } \\
1 \mathrm{MWh} \text { it charges }\end{array}$ & $\begin{array}{l}\text { If storage charges during a } \\
\text { timeslice with curtailment, it } \\
\text { reduces curtailment by } 0.5 \mathrm{MWh} \\
\text { for every } 1 \mathrm{MWh} \text { it charges }{ }^{\mathrm{b}}\end{array}$ \\
\hline $\begin{array}{l}\text { Transmission } \\
\text { distances }\end{array}$ & $\begin{array}{l}\text { Calculated using the straight-line } \\
\text { distance between the geographic } \\
\text { centroids of balancing areas (BA) }\end{array}$ & $\begin{array}{l}\text { BA centroids were moved to the } \\
\text { highest population area within the } \\
\text { BA; distances between these new } \\
\text { centroids were calculated by } \\
\text { tracing actual transmission }\end{array}$ \\
\hline
\end{tabular}




\begin{tabular}{|c|c|c|}
\hline $\begin{array}{l}\text { Inputs and } \\
\text { Treatments }\end{array}$ & 2018 Version (June 2018) & 2019 Version (July 2019) \\
\hline & & $\begin{array}{l}\text { pathways that connected the } \\
\text { centroids }\end{array}$ \\
\hline AC-DC-AC interties & $\begin{array}{l}\text { Existing interties represented and } \\
\text { allowed to be expanded }\end{array}$ & $\begin{array}{l}\text { Existing interties represented, but } \\
\text { expansion of interties is not } \\
\text { allowed }\end{array}$ \\
\hline $\begin{array}{l}\text { Clean energy } \\
\text { policies }\end{array}$ & Not included & $\begin{array}{l}\text { Included for California, } \\
\text { Massachusetts, New Mexico, } \\
\text { Washington state, and the Xcel } \\
\text { portion of Colorado }\end{array}$ \\
\hline $\begin{array}{l}\text { Renewable portfolio } \\
\text { standards and } \\
\text { carveouts }\end{array}$ & Updated as of May 2018 & Updated as of July 31, 2019 \\
\hline $\begin{array}{l}\text { State storage } \\
\text { mandates }\end{array}$ & Updated as of May 2018 & Updated as of July 31, 2019 \\
\hline Canadian imports & $\begin{array}{l}\text { Set exogenously based on Canada's } \\
\text { Energy Future } 2016 \text { (NEB 2016) }\end{array}$ & $\begin{array}{l}\text { Set exogenously based on } \\
\text { Canada's Energy Future } 2018 \\
\text { (NEB 2018) }\end{array}$ \\
\hline $\begin{array}{l}\text { Thermal unit } \\
\text { representation }\end{array}$ & $\begin{array}{l}\text { Coal units grouped into four bins per } \\
\text { BA, all other units grouped into a } \\
\text { single bin per BA, with representative } \\
\text { costs and heat rates per bin }\end{array}$ & $\begin{array}{l}\text { All unit types grouped into four bins } \\
\text { per BA, with representative costs } \\
\text { and heat rates per bin }\end{array}$ \\
\hline $\begin{array}{l}\text { Planning reserve } \\
\text { margin }\end{array}$ & $\begin{array}{l}\text { Planning reserve margin ramped } \\
\text { down from current levels to NERC } \\
\text { reference levels by } 2025 \text { (Reimers, } \\
\text { Cole, and Frew 2019) }\end{array}$ & $\begin{array}{l}\text { Planning reserve margin set at } \\
\text { NERC reference levels for all } \\
\text { years, except ERCOT in } 2018 \text { and } \\
2019 \text { is set to actual values } \\
\text { because the actuals were lower } \\
\text { than the NERC reference levels }\end{array}$ \\
\hline $\begin{array}{l}\text { NOx ozone season } \\
\text { limits }\end{array}$ & Not represented & Included \\
\hline
\end{tabular}

${ }^{a}$ As noted in the scenario descriptions, the default cost recovery period in ReEDS is 20 years, while it is 30 years in the ATB.

${ }^{\mathrm{b}}$ This change was made based on tests performed in PLEXOS to examine the potential of storage to recover curtailed RE. 
Table A-7. Key Differences in dGen Model Versions. The 2018 version was used in the 2018 Standard Scenarios report, and the 2019 version is used for this report.

\begin{tabular}{|c|c|c|}
\hline $\begin{array}{l}\text { Inputs and } \\
\text { Treatments }\end{array}$ & 2018 Version & 2019 Version \\
\hline Demand growth & AEO 2018 & AEO 2019 \\
\hline Technology cost & ATB 2018 & ATB 2019 \\
\hline Tariff set & Curated in January 2018 & Curated in January 2019 \\
\hline Tariff selection & $\begin{array}{l}\text { Residential agents are assigned a } \\
\text { curated default (most applicable) tariff } \\
\text { from among those available in their } \\
\text { class. }\end{array}$ & $\begin{array}{l}\text { Residential agents are assigned a } \\
\text { curated default (most applicable) tariff } \\
\text { from among those available in their } \\
\text { class }\end{array}$ \\
\hline Agent rooftop area & $\begin{array}{l}\text { Set to equal observed county values } \\
\text { and estimated residential/non- } \\
\text { residential breakdown (Gagnon et al. } \\
\text { 2016; Sigrin and Mooney 2018) }\end{array}$ & $\begin{array}{l}\text { Set to equal observed county values } \\
\text { and estimated residential/non- } \\
\text { residential breakdown (Gagnon et al. } \\
\text { 2016; Sigrin and Mooney 2018) }\end{array}$ \\
\hline $\begin{array}{l}\text { Solar economics } \\
\text { metric }\end{array}$ & Simple payback period & Simple payback period \\
\hline System sizing & $\begin{array}{l}\text { Systems are optimally sized based on } \\
\text { the tariff, roof size, and consumption }\end{array}$ & $\begin{array}{l}\text { Systems are optimally sized based on } \\
\text { the tariff, roof size, and consumption }\end{array}$ \\
\hline Sampling rate & $\begin{array}{l}\text { Ten statistically representative } \\
\text { consumers per sector per county were } \\
\text { sampled }\end{array}$ & $\begin{array}{l}\text { Ten statistically representative } \\
\text { consumers per sector per county were } \\
\text { sampled }\end{array}$ \\
\hline $\begin{array}{l}\text { State net energy } \\
\text { metering, policies }\end{array}$ & Updated in March 2018 & Updated in March 2019a \\
\hline
\end{tabular}

Figure A-3 shows how the Mid-case projection has changed over the course of the five editions of the Standard Scenarios. Of the changes in RE generation, most of the changes between the 2018 and 2019 versions is driven by increased wind penetration. 

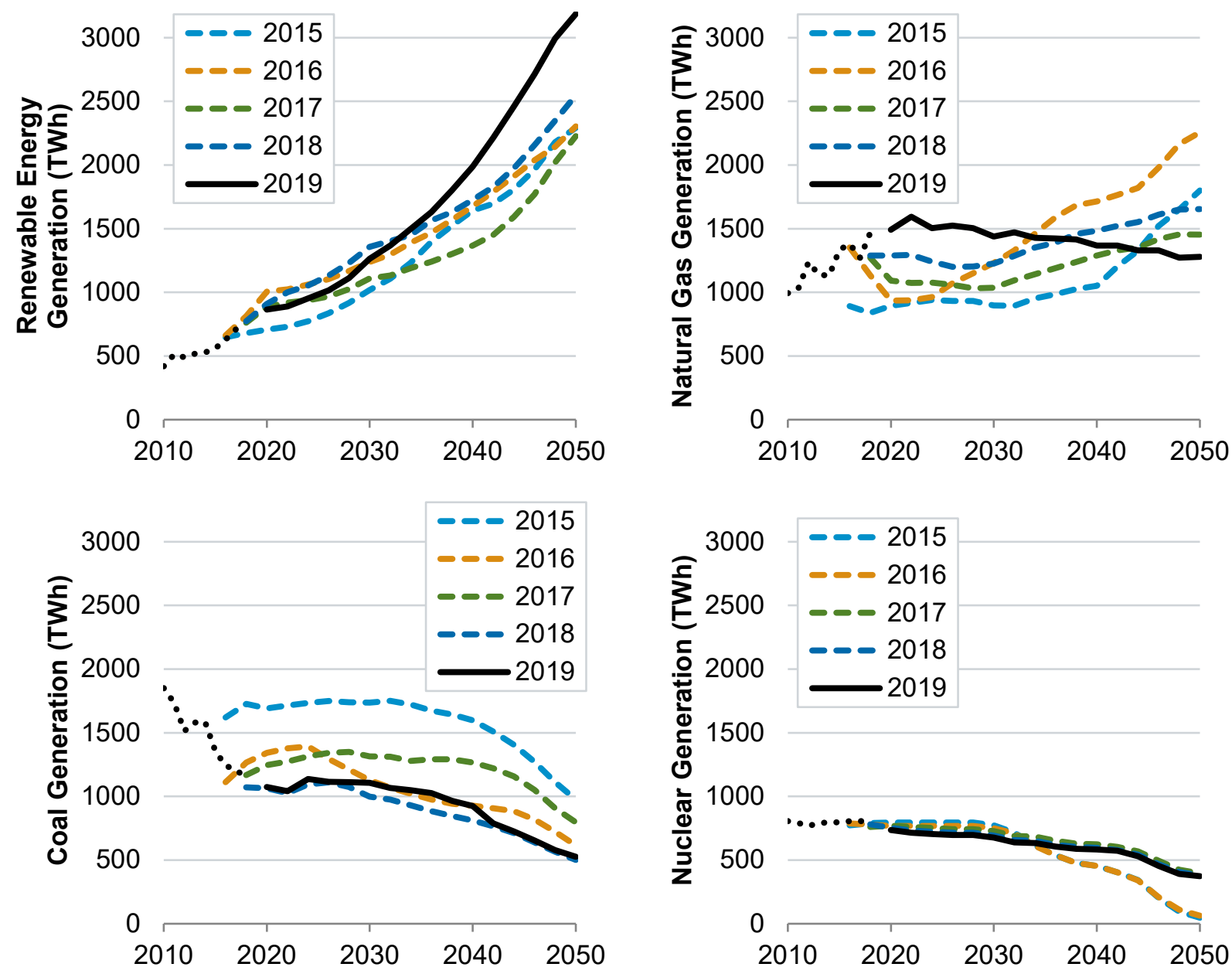

Figure A-3. Mid-case projections from the 2015, 2016, 2017, 2018, and 2019 editions of the Standard Scenarios. Historical values are shown as the black dotted line.

\section{A.3 Capacity Credit of Wind and PV}

The capacity credit of wind and PV is estimated by a regional transmission organization (RTO) using a variety of techniques. Those techniques are summarized in Table A-8. Those techniques and associated values are separate from those used in the model. The model's capacity credit method is summarized in the ReEDS documentation (Cohen et al. 2019). It is generally based on considering the contribution of wind, PV, and storage to the top 10 net load hours using wind, PV, and load profiles from 2012. 
Table A-8. Capacity Credit Approaches and Values for Wind and PV by RTO. Note that these values are not the values used within the ReEDS model.

\begin{tabular}{|c|c|c|}
\hline RTO & Approach & Values $^{a}$ \\
\hline \multirow[t]{2}{*}{ PJM } & \multirow{2}{*}{$\begin{array}{l}\text { PJM proposes to use an effective load carrying } \\
\text { capability (ELCC) approach to calculating capacity } \\
\text { credit for wind and solar (Rocha-Garrido 2019). }\end{array}$} & Wind: $12.3 \%$ \\
\hline & & PV: $45.1 \%$ \\
\hline \multirow[t]{3}{*}{ ERCOT } & \multirow{3}{*}{$\begin{array}{l}\text { ERCOT assigns values based on average historical } \\
\text { availability during the highest } 20 \text { seasonal peak } \\
\text { load hours for each season ( } 2009-2016) \text {. Values } \\
\text { recalculated after each season with new historical } \\
\text { data (NERC 2017; ERCOT 2019). }\end{array}$} & $\begin{array}{l}\text { Summer Wind: } 15 \% \text { Non- } \\
\text { Coastal/58\% Coastal }\end{array}$ \\
\hline & & $\begin{array}{l}\text { Winter Wind: } 20 \% \text { Non- } \\
\text { Coastal/ } 43 \% \text { Coastal }\end{array}$ \\
\hline & & $\begin{array}{l}\text { Summer PV: } 74 \% \\
\text { Winter PV: } 12 \%\end{array}$ \\
\hline \multirow[t]{2}{*}{ CAISO } & \multirow{2}{*}{$\begin{array}{l}\text { CAISO uses an ELCC approach to assign capacity } \\
\text { credit for wind and solar by month. These are the } \\
\text { average values of the summer and winter months } \\
\text { for each technology (CAISO 2018). }\end{array}$} & $\begin{array}{l}\text { Summer Wind: } 35 \% \\
\text { Winter Wind: } 15 \%\end{array}$ \\
\hline & & $\begin{array}{l}\text { Summer PV: } \mathbf{4 3} \% \\
\text { Winter PV: } \mathbf{0 . 8 \%}\end{array}$ \\
\hline \multirow[t]{2}{*}{ ISO-NE } & \multirow{2}{*}{$\begin{array}{l}\text { Based on the seasonal claimed capability and } \\
\text { equal to the median of the resource's summer net } \\
\text { output during reliability hours (14:00-18:00; June- } \\
\text { September) of the previous year (NERC 2017; ISO- } \\
\text { NE 2019). }\end{array}$} & Summer Wind: $13 \%$ \\
\hline & & \\
\hline \multirow[t]{2}{*}{ NYISO } & \multirow[t]{2}{*}{$\begin{array}{l}\text { Summer and winter unforced capacity based on } \\
\text { average 4-hour production beginning at 14:00 } \\
\text { during the summer or 16:00 during the winter. } \\
\text { These values for solar are based on the average of } \\
\text { multiple technology variations (NYISO 2019). }\end{array}$} & $\begin{array}{l}\text { Summer Wind: } \mathbf{1 0 \%} \\
\text { Winter Wind: } \mathbf{3 0 \%} \\
\text { Offshore: } \mathbf{3 8 \%} \text { (Winter and } \\
\text { Summer) }\end{array}$ \\
\hline & & $\begin{array}{l}\text { Summer PV: } 39 \% \\
\text { Winter PV: } 1 \%\end{array}$ \\
\hline \multirow[t]{2}{*}{ MISO } & \multirow{2}{*}{$\begin{array}{l}\text { New wind resources receive } 15.2 \% \text { capacity credit, } \\
\text { as operational data are available; MISO employs a } \\
\text { deterministic approach with ELCC using the } \\
\text { historical output (MISO } 2017 \text { ). } \\
\text { New solar resources receive } 50 \% \text {, after which the } \\
\text { summer on-peak value is applied once actual } \\
\text { operation data are available. MISO is considering } \\
\text { using ELCC in the future (NERC } 2017 \text { ). }\end{array}$} & Wind: $15.2 \%$ \\
\hline & & PV: $\mathbf{5 0 \%}$ \\
\hline \multirow[t]{2}{*}{ SPP } & \multirow[t]{2}{*}{$\begin{array}{l}\text { SPP accredits value for wind and solar resources } \\
\text { based on load (SPP 2017a, 2017b). }\end{array}$} & $\begin{array}{l}\text { Summer Wind: } 24 \% \\
\text { Winter Wind: } 16 \%\end{array}$ \\
\hline & & PV: $\mathbf{7 0 \%}$ \\
\hline
\end{tabular}

a Values are frequently updated by the RTO and can vary from one location within an RTO to another. Therefore, consider these values shown here as representative. 


\section{A.4 State Policy Model Representation}

The high spatial resolution of ReEDS makes it well-suited for modeling state policies, especially given the significant variations that exist between the policies. State RPS policies are represented as model constraints that require a minimum fraction of a state's annual load to come from eligible sources. This minimum RPS fraction takes into account different requirements for the various LSEs in a state. Technology eligibility also accounts for vintage requirements and technology type within a broad ReEDS technology category (e.g., different hydropower and biomass technologies). The data and underlying assumptions for the RPS and carveout requirements, different LSE requirements, and technology eligibility are based primarily on data from Barbose (2019). ${ }^{19}$

Other factors that are represented in ReEDS include the effects of distributed RE generation, which can affect RPS compliance in two ways simultaneously. Unless otherwise clarified by the state policies (such as for the California RPS), credits from distributed generation can be used to comply with RPS mandates, and distributed generation reduces the amount of retail sales, thereby reducing RPS demand (in MWh terms). ACPs, which enable LSEs to meet RPS requirements without additional RE generation, are also represented. ${ }^{20}$ The ReEDS model represents state-specific geographic eligibility rules that limit where a state can procure credits to meet RPS requirements. The model representation accounts for separate "bundled" and "unbundled" requirements in approximate form. ${ }^{21}$ Credit trading is modeled based on estimates from Holt (2016).

In addition to the primary RE generation requirements, separate constraints are used to model individual technology carveouts specified by the state RPS policies. Carveouts are modeled for solar, wind, and offshore wind. All carveout requirements are based on data from Barbose (2019) except for offshore wind, where we model capacity requirements based on data from the 2018 Offshore Wind Technologies Market Report (Musial et al. 2019). ${ }^{22}$ These requirements are implemented with the assumed capacity levels, commercial operation dates, and locations as specified in Musial et al. (2019). All prescribed capacity is located in six Northeast states (Connecticut, Massachusetts, Maryland, New Jersey, New York, and Rhode Island) and is, in aggregate, a total of $20 \mathrm{GW}$ by 2035 . Given the nascent U.S. offshore wind industry and the evolving policies for offshore wind, we recognize that there are significant uncertainties with respect to this future deployment and its timeline. Nonetheless, the existing and recent RPS policies suggest a growing interest in offshore wind that could spur development. We also include state storage mandates, which are estimated to require $6.5 \mathrm{GW}$ of new energy storage.

As CESs are generalized versions of RPSs, their model representations are very similar with the only differences in technology eligibility. For all but one of the CES policies (Massachusetts),

\footnotetext{
${ }^{19}$ Minor adjustments to the data from Barbose (2019) were made for the model implementation. These adjustments and other differences in end-use demand, load growth, and distributed generation assumptions can lead to slightly different projections of future RPS demand between our modeling analysis and that presented in Barbose (2019).

${ }^{20}$ Cost caps are not modeled in ReEDS.

${ }^{21}$ Bundling refers to whether the physical electricity needs to be delivered to the LSE together with the financial credit.

${ }^{22}$ The generation from the prescribed offshore wind capacity counts toward the general RE generation requirements; therefore, the offshore carveouts would not incentivize incrementally greater RE generation beyond that from the main RPS targets.
} 
we assume that all zero-carbon-emitting sources (on a direct emissions basis) can contribute to the CES requirement. This includes all RE (including hydropower and distributed PV) technologies, nuclear power, and imports from Canada. ${ }^{23}$ The modeled CES policies require a floor on electricity generated from clean energy technologies but does not cap generation from non-clean sources. As a result, in our model representation, a state can continue to generate from existing fossil plants as long as the amount of clean energy generation exceeds the requirement (even if the requirement approaches $100 \%$ of sales). Most of the CES policies are assumed to start in 2030 and ramp to their final targets by 2040 or $2050 .{ }^{24}$ For other aspects of the CES model representation, we use the same assumptions as the corresponding state RPS. These include assumptions around credit trading and variations in LSE requirements. Improvements to the simple CES model representations require additional CES policy details and model improvements.

$\mathrm{CO}_{2}$ emissions cap policies are represented using constraints that limit the direct emissions from in-state generators as well as estimated emissions from electricity imports. For California, an effective emissions limit, which approximates the California electricity system share for total economy-wide emissions reductions, from the California Public Utilities Commission (CPUC 2018 ), is used. This effective annual emissions limit is assumed to be $42 \mathrm{MT} \mathrm{CO}_{2}$ annually from 2030 to 2050 . We also represent an emissions cap for the RGGI states. The ReEDS documentation (Cohen et al. 2019) describes the model representation of the California policy and RGGI. To account for New Jersey rejoining RGGI, we adjust the RGGI cap by 18 million tons, leading to a total $\mathrm{CO}_{2}$ cap of 61 million metric tons of $\mathrm{CO}_{2}$ in 2030 and remaining at that annual level through 2050.

Tables A-9 to A-12 present the numerical assumptions for the state-level policies represented in ReEDS in the scenarios modeled.

Table A-9. Effective State RPS Requirements in ReEDS

\begin{tabular}{|c|c|c|c|c|c|}
\hline \multirow[b]{2}{*}{ State } & \multicolumn{3}{|c|}{$\begin{array}{l}\text { RPS target / Solar / Wind set-asides } \\
(\%)\end{array}$} & \multirow{2}{*}{$\begin{array}{l}\text { Allowable states for REC import, } \\
\text { includes Canadian provinces } \\
\text { (*bundling requirement) }\end{array}$} & \multirow{2}{*}{$\begin{array}{l}\text { REC import } \\
\text { limit (\% of } \\
\text { RPS target) }\end{array}$} \\
\hline & 2020 & 2030 & 2050 & & \\
\hline$A Z$ & $5.8 /-/-$ & 8.7/-/- & 8.7/-/- & $\mathrm{CA}^{*}, \mathrm{CO}^{*}, \mathrm{NM}^{*}$ & 100 \\
\hline CA & $30.4 /-/-$ & $55.4 /-/-$ & $55.4 /-/-$ & $\begin{array}{l}A Z^{*}, I D, M T, N M, N V^{*}, O^{*}, U^{*} \\
W A, W Y^{*}, M E X^{*}\end{array}$ & $\begin{array}{l}10 \text { (after } \\
2017 \text {-only } \\
\text { unbundled, } \\
100 \% \text { for } \\
\text { bundled) }\end{array}$ \\
\hline $\mathrm{CO}^{\mathrm{a}}$ & $19.2 /-/-$ & 19.8/-/- & 20.1/-/- & WY & 8 \\
\hline CT & 24.9/-/- & $43.8 /-/-$ & $43.8 /-/-$ & $\begin{array}{l}\mathrm{MA}, \mathrm{ME}, \mathrm{NH}, \mathrm{NY}^{*}, \mathrm{RI}, \mathrm{VT}, \mathrm{NB}^{*}, \mathrm{NL}^{*} \\
\mathrm{NS}^{*}, \mathrm{QC}^{*}, \mathrm{NFI}^{*}, \mathrm{PEI}^{*}\end{array}$ & 59 \\
\hline $\mathrm{DE}^{\mathrm{b}}$ & 13/1.7/- & $18.7 / 3 /-$ & 18.7/2.9/- & $\mathrm{IL}^{*}, \mathrm{IN}^{*}, \mathrm{MD}, \mathrm{PA}^{*}, \mathrm{VA}{ }^{*}, \mathrm{WV}^{*}$ & 94 \\
\hline
\end{tabular}

${ }^{23}$ For Massachusetts, we assume CCS technologies are also eligible but disallow hydropower due to the post-2010 commercial operation date requirement in the state policy (DOER 2018).

${ }^{24}$ The modeled CES for $\mathrm{CO}_{2}$ is assumed to start in 2020 and includes the clean energy commitments from the largest electric utility in the state (Xcel Energy), which were codified into law in 2019. The modeled CES for Massachusetts begins at $16 \%$ in 2018 and increases to $80 \%$ by 2050 . 


\begin{tabular}{|c|c|c|c|c|c|}
\hline \multirow[b]{2}{*}{ State } & \multicolumn{3}{|c|}{$\begin{array}{l}\text { RPS target / Solar / Wind set-asides } \\
\text { (\%) }\end{array}$} & \multirow{2}{*}{$\begin{array}{l}\text { Allowable states for REC import, } \\
\text { includes Canadian provinces } \\
\text { ('bundling requirement) }\end{array}$} & \multirow{2}{*}{$\begin{array}{l}\text { REC import } \\
\text { limit (\% of } \\
\text { RPS target) }\end{array}$} \\
\hline & 2020 & 2030 & 2050 & & \\
\hline$I L^{b, c}$ & $\begin{array}{l}14.4 / 1.4 / 1 \\
4\end{array}$ & $24.4 / 2.9 / 2.9$ & $25.6 / 2.9 / 2.9$ & $\begin{array}{l}\text { IA, IN, MD, MN, MO, ND, NY, OH, } \\
\text { PA, SD, VA, WI, WV }\end{array}$ & 60 \\
\hline$M A^{b}$ & $16.6 / 7.2 /-$ & $33 / 10 /-$ & $50.3 / 9.6 /-$ & $\begin{array}{l}\text { CT, ME, NH, NY*, RI, VT, NB* }{ }^{*} \mathrm{NL}^{*} \\
\mathrm{NS}^{*}, \mathrm{QC}^{*}, \mathrm{NFI}^{*}, \mathrm{PEI}^{*}\end{array}$ & 62 \\
\hline$M D^{b, d}$ & $26.1 / 5.3 /-$ & $54.6 / 12.7 /-$ & $56.7 / 13.4 /-$ & $\begin{array}{l}\mathrm{DE}, \mathrm{IA}, \mathrm{IL}, \mathrm{IN}^{*}, \mathrm{NC}^{*}, \mathrm{NY}^{*}, \mathrm{OH}^{*}, \mathrm{PA}^{*} \\
\mathrm{TN}^{*}, \mathrm{VA}^{*}, \mathrm{WI}^{*}, \mathrm{WV}^{*}\end{array}$ & 70 \\
\hline ME & $36 /-/-$ & $72.4 /-/-$ & $72.4 /-/-$ & $\begin{array}{l}\mathrm{CT}, \mathrm{MA}, \mathrm{NH}, \mathrm{RI}, \mathrm{VT}, \mathrm{NB}^{*}, \mathrm{NL}^{*}, \mathrm{NS}^{*} \text {, } \\
\mathrm{QC}^{*}, \mathrm{NFI}^{*}, \mathrm{PEI}^{*}\end{array}$ & 18 \\
\hline MI & 10.8/-/- & $12.5 /-/-$ & $11.9 /-/-$ & IA, IN, MN, WI & 0 \\
\hline MN & $\begin{array}{l}25.2 / 0.8 / 11 \\
.1\end{array}$ & $28 / 0.8 / 11.1$ & $28 / 0.8 / 11.1$ & IA, MI, ND, SD, WI, MB, ON, SK & 24 \\
\hline $\mathrm{MO}^{\mathrm{b}}$ & $6.7 / 0.1 /-$ & $10 / 0.2 /-$ & $10 / 0.2 /-$ & $\mathrm{IA}, \mathrm{KS}$, & 94 \\
\hline MT & $10.8 /-/-$ & 10.8/-/- & $10.8 /-/-$ & $\mathrm{ND}^{*}, \mathrm{OR}^{*}, \mathrm{WA}^{*}, \mathrm{BC}^{*}$ & 6 \\
\hline NC & $5 / 0.2 /-$ & $4.7 / 0.2 /-$ & $4.3 / 0.2 /-$ & $\begin{array}{l}\mathrm{AL}^{*}, \mathrm{FL}^{*}, \mathrm{GA}^{*}, \mathrm{LA}^{*}, \mathrm{MS}^{*}, \mathrm{OH}^{*}, \mathrm{PA}^{*} \\
\mathrm{SC}^{*}, \mathrm{TN}^{*}, \mathrm{VA}^{*}, \mathrm{WV}^{*}\end{array}$ & 43 \\
\hline $\mathrm{NH}^{\mathrm{b}}$ & $17.4 / 0.7 /-$ & $20.6 / 0.7 /-$ & $20.6 / 0.7 /-$ & $\begin{array}{l}\text { CT, MA, ME, NY*, RI, VT, NB* }{ }^{*} \mathrm{NL}^{*} \\
\mathrm{NS}^{*}, \mathrm{QC}^{*}, \mathrm{NFI}^{*}, \mathrm{PEI}^{*}\end{array}$ & 35 \\
\hline$N J^{b}$ & $27.5 / 4.7 /-$ & $53.5 / 2.2 /-$ & $51.2 /-/-$ & $\begin{array}{l}\mathrm{DE}, \mathrm{IL}^{*}, \mathrm{IN}^{*}, \mathrm{MD}, \mathrm{OH}^{*}, \mathrm{PA}^{*} \mathrm{VA}^{*} \\
\mathrm{WV}^{*}\end{array}$ & 76 \\
\hline NM & $15.8 /-/-$ & $44.8 /-/-$ & $65.3 /-/-$ & - & 0 \\
\hline NV & 16.6/-/- & $44.2 /-/-$ & $44.3 /-/-$ & - & 100 \\
\hline NY & $32.4 /-/-$ & $74.5 /-/-$ & $74.5 /-/-$ & $\mathrm{RI}^{*}, \mathrm{ON}^{*}, \mathrm{QC}^{*}$ & 4 \\
\hline $\mathrm{OH}^{\mathrm{b}}$ & $4.8 /-/-$ & $-/-/-$ & $-/-/-$ & $\mathrm{IN}^{*}, \mathrm{KY}^{*}, \mathrm{MI}^{*}, \mathrm{PA}^{*}, \mathrm{WV}^{*}$ & 57 \\
\hline $\mathrm{OR}^{\mathrm{b}}$ & $13.7 /-/-$ & 25.1/-/- & $34.8 /-/-$ & $\mathrm{CA}^{*}, \mathrm{ID}^{*}, \mathrm{MT}^{*}, \mathrm{UT}^{*}, \mathrm{WA}^{*}, \mathrm{WY}^{*}, \mathrm{BC}^{*}$ & 42 \\
\hline$P A^{b}$ & $7.2 / 0.4 /-$ & $7.8 / 0.5 /-$ & $7.8 / 0.5 /-$ & $\begin{array}{l}\text { DE, IL, IN, MD, NC, NJ, OH, VA, } \\
\text { WV }\end{array}$ & 47 \\
\hline RI & 15.9/-/- & $30.8 /-/-$ & $38.2 /-/-$ & $\begin{array}{l}\mathrm{CT}, \mathrm{MA}, \mathrm{ME}, \mathrm{NH}, \mathrm{NY}^{*}, \mathrm{VT}, \mathrm{NB}^{*} \\
\mathrm{NL}^{*}, \mathrm{NS}^{*}, \mathrm{QC}^{*}, \mathrm{NFI}^{*}, \mathrm{PEI}^{*}\end{array}$ & 77 \\
\hline TX & $4.2 /-/-$ & $3.8 /-/-$ & $3.5 /-/-$ & - & 0 \\
\hline VT & $59 /-/-$ & 71/-/- & $75 /-/-$ & $\mathrm{CT}, \mathrm{MA}, \mathrm{ME}^{*}, \mathrm{NH}, \mathrm{RI}$ & 100 \\
\hline WA & $12.1 /-/-$ & $12.4 /-/-$ & $12.3 /-/-$ & ID, MT, OR, BC* & 43 \\
\hline WI & 9.9/-/- & 9.9/-/- & 9.9/-/- & $\mathrm{IA}^{*}, \mathrm{MI}^{*}, \mathrm{MN}^{*}, \mathrm{ND}^{*}, \mathrm{SD}^{*}, \mathrm{MB}^{*}, \mathrm{SK}^{*}$ & 41 \\
\hline
\end{tabular}

*Interstate REC transactions that are required to be bundled with energy are marked with an asterisk.

a Based on historical observation, only $50 \%$ of the actual DG carve out for Colorado is assumed to be met using distributed solar technologies (DUPV and distributed PV).

${ }^{\mathrm{b}}$ Based on historical observation, the solar carve out in these states are seen to be met primarily using distribution side solar technologies. 
c Illinois allows for $50 \%$ of its RPS target to be met using alternative compliance payments, and hence ReEDS targets are adjusted to reflect this.

d Washington, D.C. RPS targets are rolled into Maryland (Washington D.C. load also rolled into Maryland).

Table A-10. Cumulative offshore wind capacity (MW) that is mandated in ReEDS.

For example, there has been a total of 19,698 MW of offshore wind capacity mandated through 2050. This mandate represents a lower bound on offshore wind capacity.

\begin{tabular}{|c|c|c|c|c|}
\hline State & $\mathbf{2 0 2 0}$ & $\mathbf{2 0 3 0}$ & $\mathbf{2 0 4 0}$ & $\mathbf{2 0 5 0}$ \\
\hline CT & - & 2,000 & 2,000 & 2,000 \\
\hline MA & - & 3,200 & 3,200 & 3,200 \\
\hline MD & - & 1,568 & 1,568 & 1,568 \\
\hline NJ & - & 3,500 & 3,500 & 3,500 \\
\hline NY & - & 4,000 & 9,000 & 9,000 \\
\hline RI & 30 & 430 & 430 & 430 \\
\hline
\end{tabular}

Table A-11. Clean energy requirement as a percentage of in-state sales.

\begin{tabular}{|c|c|c|c|c|}
\hline State & $\mathbf{2 0 2 0}$ & $\mathbf{2 0 3 0}$ & $\mathbf{2 0 4 0}$ & $\mathbf{2 0 5 0}$ \\
\hline CA & $0 \%$ & $55 \%$ & $85 \%$ & $100 \%$ \\
\hline CO & $19 \%$ & $44 \%$ & $50 \%$ & $55 \%$ \\
\hline MA & $20 \%$ & $37 \%$ & $54 \%$ & $71 \%$ \\
\hline NM & $0 \%$ & $45 \%$ & $75 \%$ & $100 \%$ \\
\hline NY & $0 \%$ & $75 \%$ & $100 \%$ & $100 \%$ \\
\hline WA & $0 \%$ & $80 \%$ & $93 \%$ & $100 \%$ \\
\hline
\end{tabular}

Table A-12. Power sector $\mathrm{CO}_{2}$ caps enforced in the model in RGGI states and in California (metric tons)

\begin{tabular}{|c|c|c|}
\hline & RGGI Cap & AB-32 Cap \\
\hline $\mathbf{2 0 2 0}$ & $87,248,792$ & $59,969,160$ \\
\hline $\mathbf{2 0 3 0}$ & $61,030,926$ & $42,000,000$ \\
\hline $\mathbf{2 0 4 0}$ & $61,030,926$ & $42,000,000$ \\
\hline $\mathbf{2 0 5 0}$ & $61,030,926$ & $42,000,000$ \\
\hline
\end{tabular}

